\title{
Natural Hazard Risk Assessment for an Insurance Program
}

\author{
by Don G. Friedman*
}

\section{Introduction}

An evaluation of the possible role of disaster insurance in reducing natural disaster impacts must include an analysis of risk information requirements needed in the development and operations of the insurance program and how these needs could be satisfied. The purpose of this paper is to outline the requirements including identification of the characteristics of insured physical elements (buildings, other property) that are exposed to large-scale geophysical events, such as storms, floods or earthquakes, and the vulnerability of these elements-at-risk to damage or loss when an event of given severity occurs.

Methods of risk assessment are outlined and a discussion is given on how statistics on physical elements and their damage vulnerability are utilized in an insurance program that currently covers many of the natural hazards in the United States.

In this paper, emphasis is on insured physical elements and their vulnerabilities to the wind hazard because other papers in this series discuss the national flood insurance program in the United States and risk assessment of the earthquake hazard. However, the information requirements and risk analysis procedures given here in connection with wind insurance also apply to insurance programs covering the other natural hazards including floods and earthquakes.

Information on the characteristics of insured elements-at-risk and vulnerability are major ingredients in natural hazard risk analysis. These assessments are either implicitly or explicitly made during development and operation of an insurance program and are needed to provide information in the actuarial, underwriting, reserving, reinsurance and claim functions.

* Director, Natural Hazard Research Program, Corporate Research Division, Travelers Insurance Company, Hartford, Connecticut, U.S.A. 


\section{Approach}

A six-step approach has been followed to define the risk information requirements for a natural disaster insurance program and the likely difficulties that would be encountered in attempting to satisfy the requirements :

1. Discussion of the use of conventional insurance procedures involving the use of past damage experience over a short period of preceding years as a basis for estimating present risk to the insured properties.

2. Definition of the risk assessment information needs in the development and operation of an insurance program to cover the natural hazards and methods of estimating risk. Two important measures of risk are average annual damage and catastrophe potential.

3. Description of four major factors that interact to produce natural disasters. These are the physical characteristics of the geophysical event (storm, flood, earthquake) ; local conditions that can modify the severity of the event; type, number and spatial distribution of the elements-at-risk ; and their vulnerabilities when an event of given severity occurs.

4. Mathematical simulation of the interaction of these factors to construct an approximation of the year-to-year damage producing characteristics of a natural hazard to a spatial array of property using observed storm occurrences over a long interval of time as basis for the calculation. This provides a means of specifying the "actual" long-term levels of risk as measured by the average annual damage and the catastrophe potential. The hurricane wind peril to the densely populated southeast coast of Florida is used to represent the natural hazard.

5. Application and operation of a hypothetical program to cover the hazard over the time interval including estimation of the two measures of risk using conventional actuarial procedures based upon past loss experience.

6. Comparison of the estimated values of the two risk factors obtained within the program on each of the years within the time interval with the "actual" long-term values of these risk measures based on the simulation analysis. Discussion of the utilization of supplementary information from other sources, including the physical and engineering sciences, in addition to the sole use of past damage experience as a means of more adequately satisfying the insurance programs needs for realistic risk estimates.

\section{Insurance coverage of natural hazards in the United States}

Natural hazards - storms, floods and earthquakes - cause considerable property damage in various parts of the world. Figure 1 graphically depicts some of these hazards that affect the United States where the average annual losses are rapidly increasing [29]. A large percentage of these damages occur as a result of infrequent, but severe, geophysical events (individual storms or earthquakes). If aggregate damage resulting from the event is exceptionally large, it is called a natural disaster. The number of natural disasters in the United States is becoming larger each year. Resultant property losses are growing even more rapidly. Increases in the density of properties susceptible to damage in hazard prone areas ; the value of these properties ; and the cost of repair have raised the probability of 


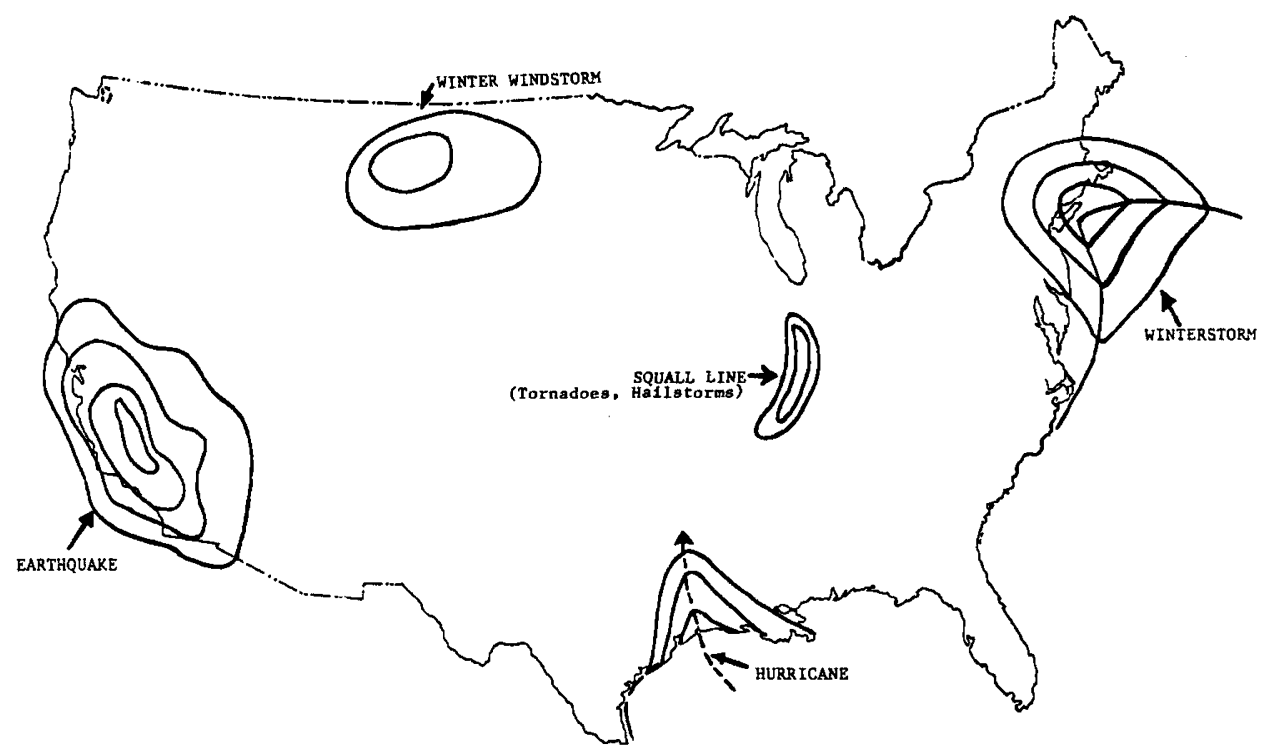

Figure 1: Graphical representation of typical large-scale natural hazards that affect the United States.

natural disaster occurrence in recent years even though the frequency and severity of the natural hazard events have not changed.

Insurance is one means of protection against the natural hazards for fixed property. To provide this protection, two components of risk must be evaluated, namely, risk per individual structure and risk of a large number of simultaneous losses - catastrophe potential. The latter component has attained added importance recently with the increased number and severity of natural disasters. In the United States, the wind and hail perils are grouped with a number of other perils such as fire in the "packaged" policies. Consequently, it is not possible to easily obtain an indication of total annual losses attributed solely to these weather perils. However, a " catastrophe coding" system of the Insurance Services Office is used which designates those wind or hail occurrences that cause insurance industry losses equal to/or greater than five million dollars.

Figure 2 a illustrates the annual number of these catastrophes caused by wind, hail or earthquakes since the system was begun in 1949 [29]. Figure $2 \mathrm{~b}$ shows the resulting annual loss expressed in 1983 dollars. Most of the damages caused by the flood hazard are covered by the National Flood Insurance Program and are not included. An adjustment was made to eliminate those events that did not exceed the five million (1983) dollar threshold. In past years, the minimum loss was one million dollars per event. The increase in the number of events in earlier years can be largely attributed to the still developing insurance program. However, there has been an increase in occurrences even in the most 


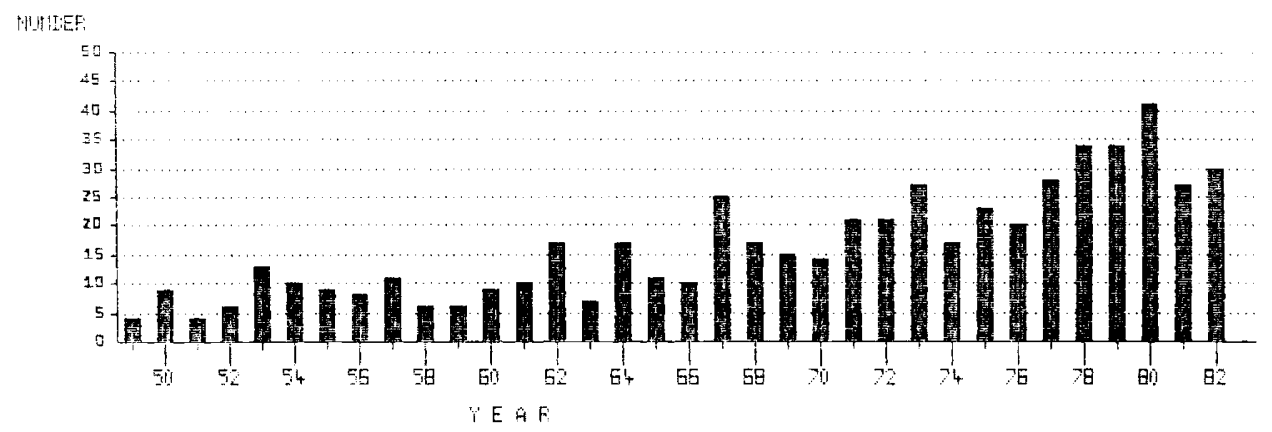

Figure $2 a$ : Number of catastrophes.

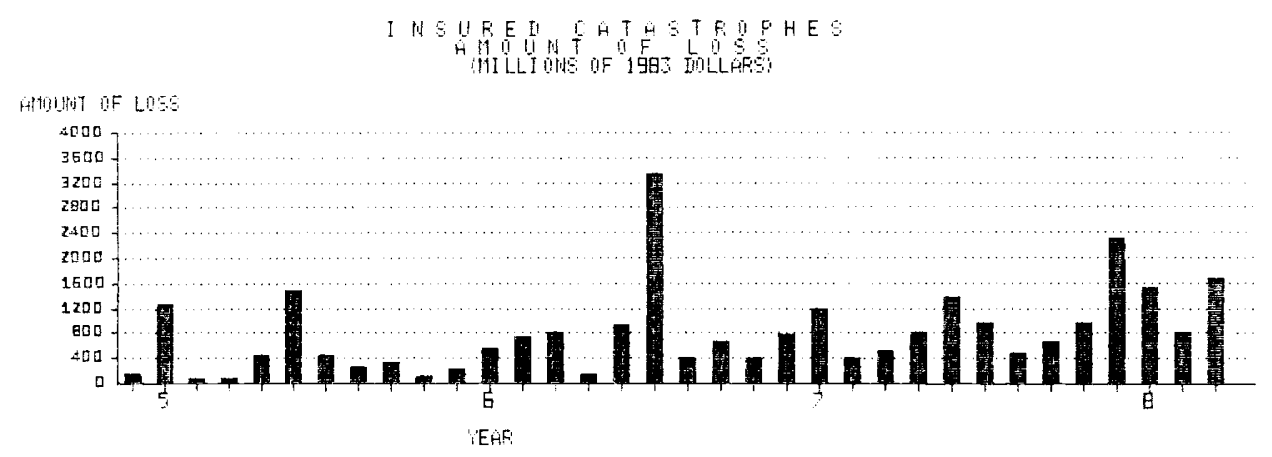

Figure $2 b$ : Amount of loss.

Figure 2ab: Number of catastrophe coded situations between 1949 and 1982 caused by insured natural hazards, such as storms, earthquakes, but excluding floods, in the United States (Figure 2 a). Only those events in which insurance industry losses exceeded $\$ 5$ million (1983 dollars) are included. Total amount of these losses is shown in Figure $2 b$.

recent ten year period when growth in the number of insured properties has stabilized. Note that the amount of loss attributed to these catastrophes varies greatly from year to year.

\section{Use of past experience as a measure of current risk}

The amount of year to year variation is even larger if only one hazard is considered. For convenience in this paper, " natural hazard " and " natural peril " are interchangeable. Figure 3 shows the individual contribution of the hurricane wind hazard to the number 


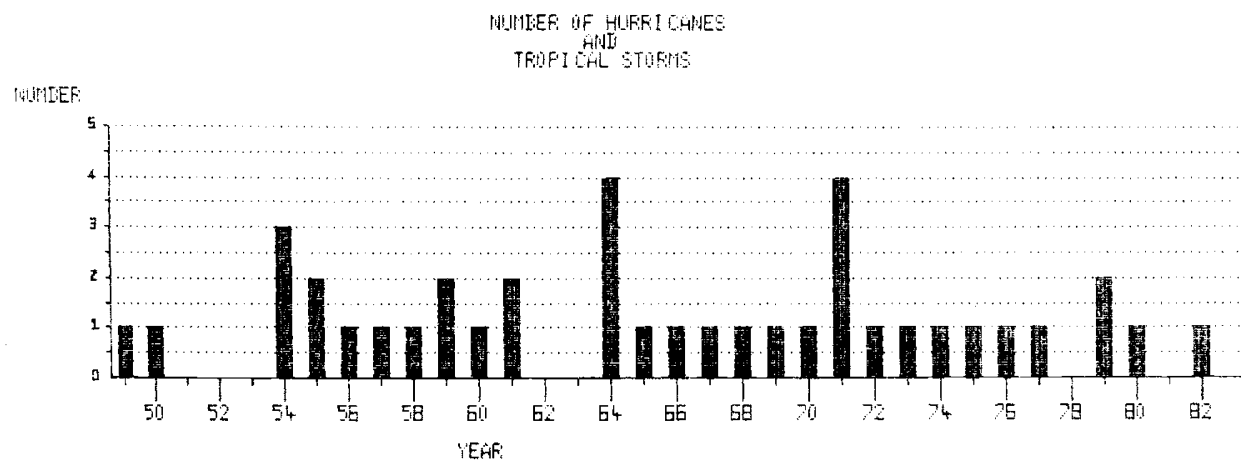

Figure $3 a$ : Number of catastrophes.

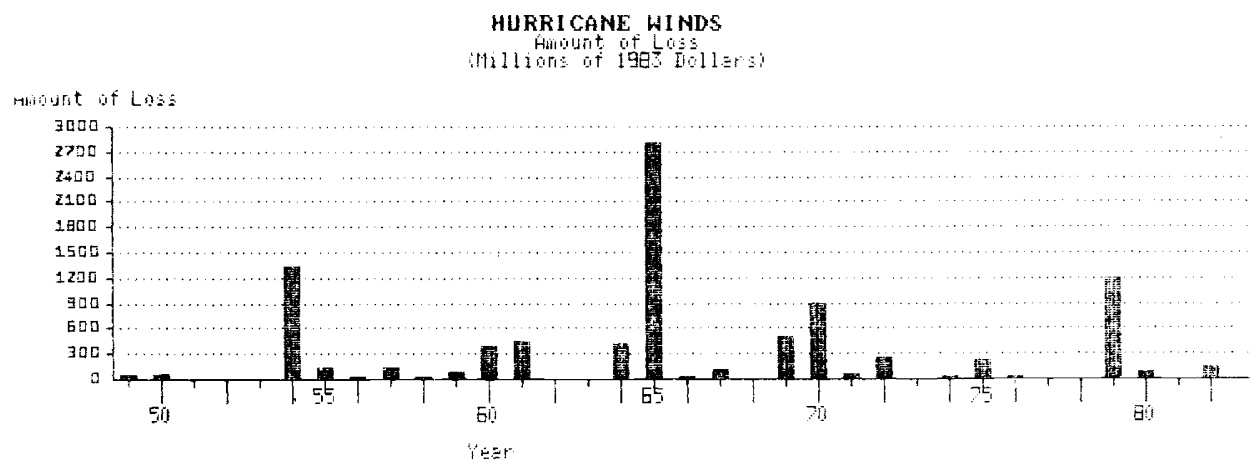

Figure $3 b:$ Amount of loss.

Figure $3 a b$ : Number of catastrophe coded situations between 1949 and 1982 caused by hurricanes and tropical storms in the United States (Figure 3 a). Only those events in which losses exceeded $\$ 5$ million (1983 dollars) are included. Total insured losses attributed to these events in 1983 dollars are shown in Figure 3 b.

of catastrophic events and amount of damage. If an insurance program were to be constructed to cover only this hazard, the classical type of information to use in the operation of the program would be past damage experience. It would result from the interaction of a hurricane (its intensity, track and wind speed severity pattern) with the number, type, vulnerability ${ }^{1}$ and geographical distribution of the elements-at-risk. hazard.

1 Refer to Appendix A for UNDRO definitions of vulnerability, risk, elements-at-risk and 


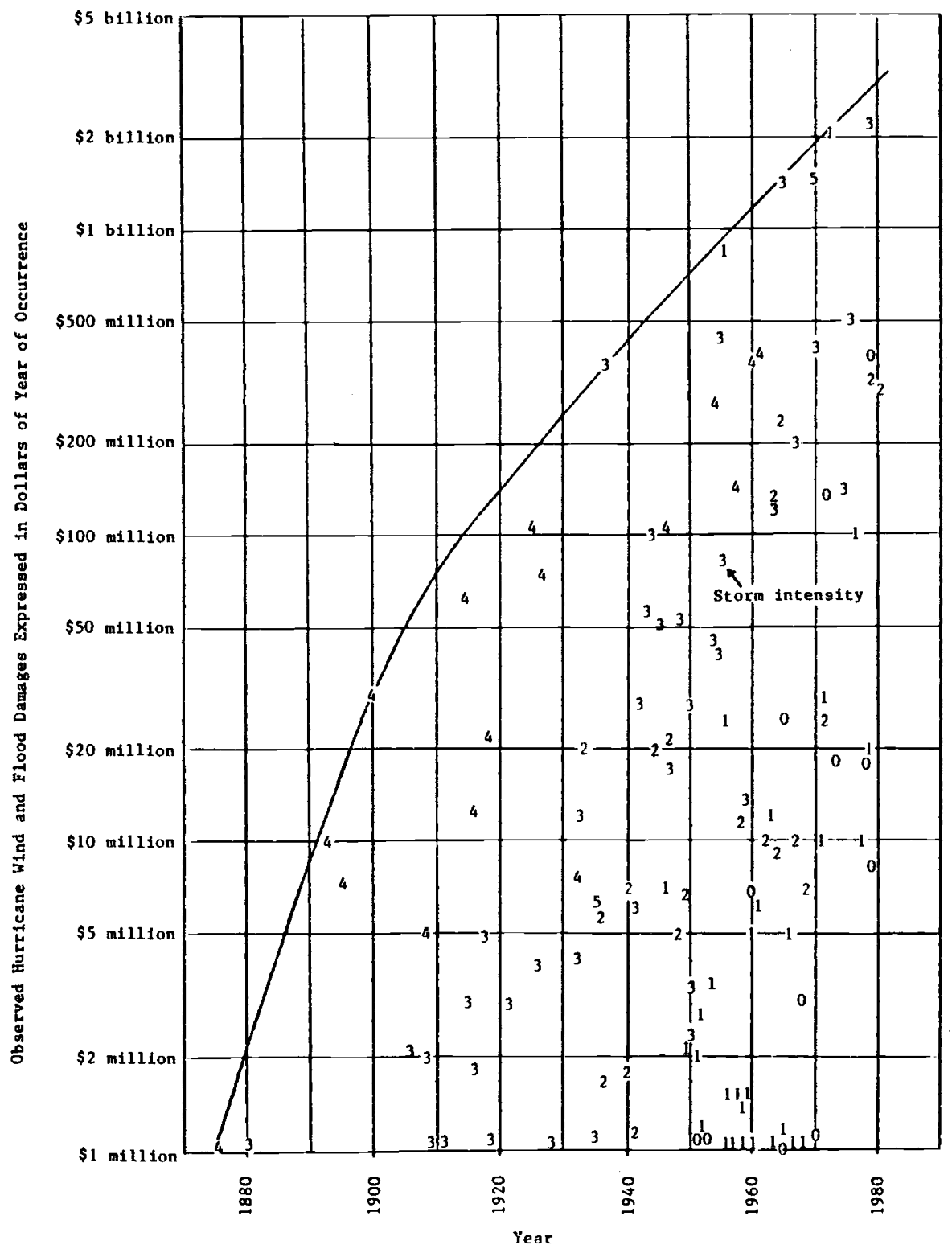

Figure $4 \mathrm{a}$ : Available estimates of total damages in dollars of the year of occurrence including insured and noninsured losses caused by wind or flood of individual hurricanes that affected the United States in the past 111 years (1871-1982). Physical intensity of the storm is plotted for each event. Refer to Table I for definition of intensity categories. 


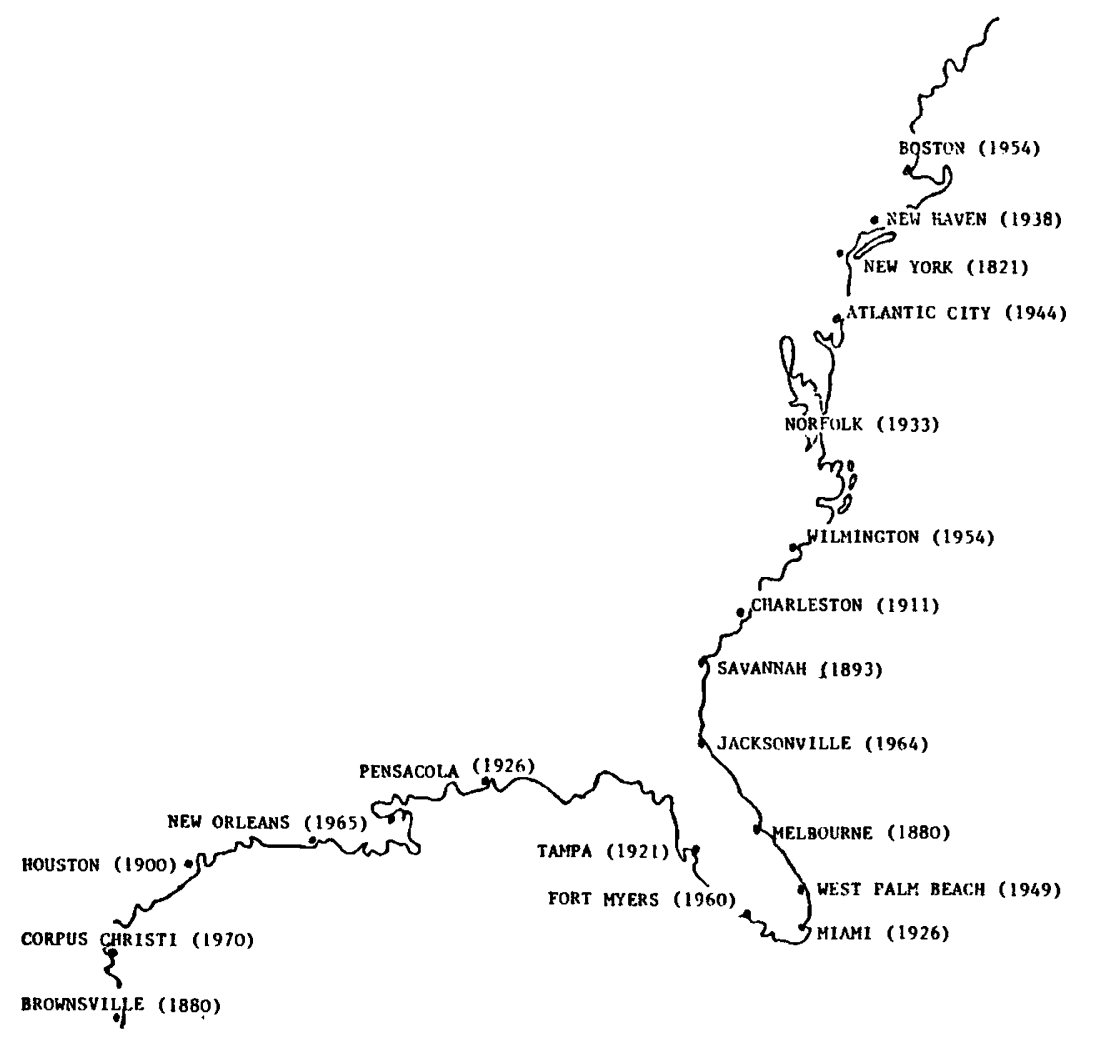

Figure $4 b:$ Most recent year in which a high intensity hurricane made a direct hit or near miss on various densely populated coastal areas of the United States.

Occasionally, this interaction leads to the production of many losses resulting in the creation of a natural disaster.

Unfortunately, past damage experience caused by natural hazards is frequently a poor measure of present or future risk because the number, location and vulnerability of exposed properties change over time; the chance occurrence (or non-occurrence) of a highly damaging storm or earthquake in a short sample of years that is usually available can cause bias because severe geophysical events occur only infrequently at any given location ; and the chance positioning of the event's severity pattern upon the spatial array of exposed properties if it does occur.

A direct extrapolation of past loss experience into the future, based on chance combinations of circumstances that led to past natural disasters, does not consistently provide insight into the character of present or future risk. What is needed is not actual 
damages that occurred as a result of a past geophysical event, but an estimate of potential damage production to the present distribution of properties from a recurrence of the past event. For example, emphasis should not be on what the 1906 San Francisco earthquake originally cost, but what it would cost if a comparable earthquake occurred today and affected the present type, number, vulnerability and value of current properties.

To illustrate difficulties inherent in the use of past hurricane experience as a sole measure of current risk, total estimated damage resulting from all causes such as wind and flood (insured and non-insured) are plotted in Figure 4 a for hurricanes that affected the United States since 1900 [6]. Losses are expressed in dollars of the occurrence year and the physical intensity of each storm is denoted by an index that ranges from 1 to 5 . A minimal intensity hurricane is designated by a 1 and one of an extreme intensity by a 5 . Refer to Table 1.

As expected, the amount of damage caused by individual storms has increased with time because of changes in the number and spatial distribution of elements-at-risk exposed to the event and their vulnerability, which includes the relative value of the property and its cost of repair. However, it is noted that for any given short period of years, there has been a consistent upward trend in the largest damage producing hurricane (events joined by a curved line in Figure 4 a). These "outlier " occurrences represent a " direct hit " or near miss by a moderate or severe intensity hurricane on a densely populated coastal strip. They occur only infrequently.

Figure $4 \mathrm{~b}$ lists the most recent year in which densely populated areas along the United States coastline have been affected by one of these direct hits or near misses. For example, a severe intensity hurricane made a direct hit on Miami, Florida in 1926. The usefulness of damage experience resulting from that occurrence as a measure of current risk, such as the probable maximum loss, is minimal. This is because of pronounced changes in the number and location of exposed elements-at-risk. Figure 5 a illustrates the rapid growth of population in the state of Florida since the storm occurred in 1926. Size of population, hence amount of property, is ten times greater. Growth in the Miami metropolitan area has been at least as large.

Figure $5 \mathrm{~b}$ shows the relative growth in one component of vulnerability as measured by an index of construction cost. This "cost of repair" has increased more than twenty times since 1926. As a result, from the standpoint of an insurance program, the pertinent question becomes "what would the damage potential be if the 1926 storm were to recur and affect the present distribution of properties with their current vulnerabilities ?"

\section{Natural hazard information needs for an insurance activity}

If past damage experience is not always a useful measure of current risk, what information can be used? Information needs regarding characteristics of the natural hazards depends upon the application. A structural engineer, who is interested in the potential effects on a particular building at a specified site, requires less information about the hazard than an insurance company that insures a large number of different types of buildings which are distributed in an irregular fashion across a hazard-prone area. The spatial array of insured buildings may vary widely by age, condition, quality of 


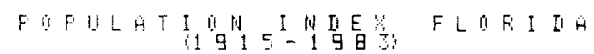

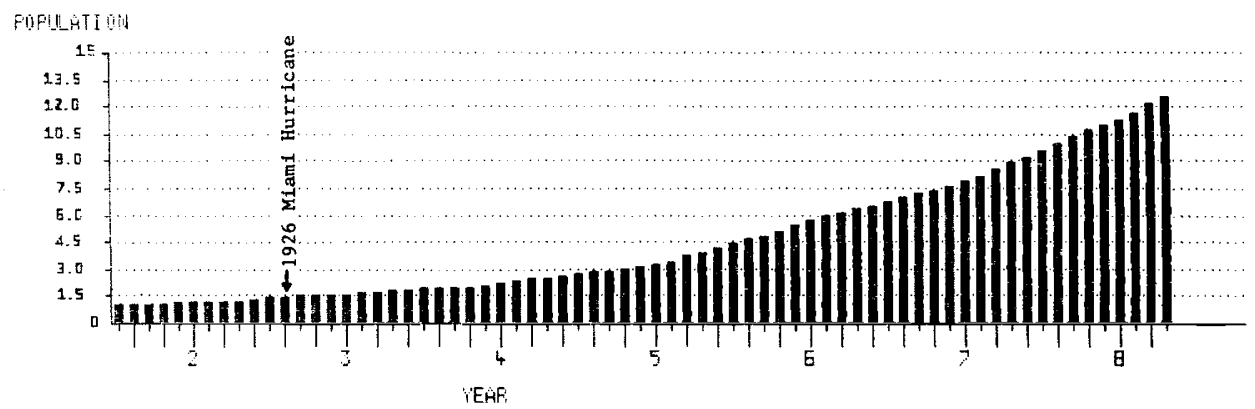

Figure $5 a$ : Relative change over time of an indicator of the number of elements-at-risk as given by the size of Florida population expressed as a multiple of the 1915 population.

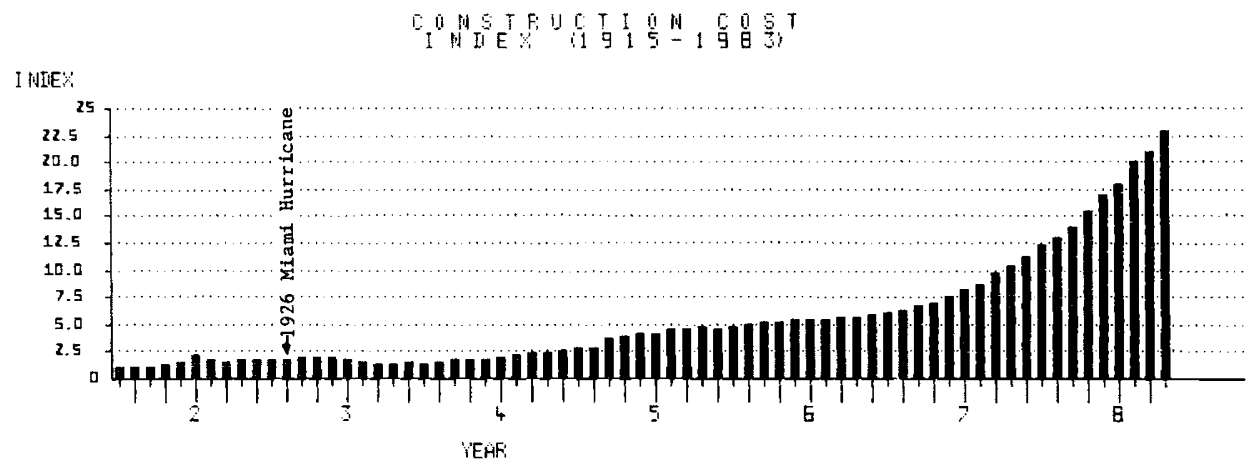

Figure $5 b$ : Relative change over time of one component of vulnerability as given by a construction cost index expressed as a multiple of the index in 1915.

construction and material, degree of exposure, and usage. Type and size of insured buildings can range from small single family dwellings to large industrial complexes of engineered design.

Ideally, to evaluate the potential impact of a natural hazard, both the structural engineer and the insurance company would require an estimate of the probability of various levels of hazard severity (for the wind hazard, wind speed) at each building site incuding the effects of local exposure conditions (for wind, topography, other buildings, trees, open fields and so forth). The estimate of wind speed severity can be expressed in terms of its expected return period, for example, on an average of once every 10 years, 25 years, 50 years or even 100 years. In making the estimate for each building site, usually no account is taken of possible spatial correlations in the wind speed pattern among adjacent sites. 
This index of the hazard's severity can be converted into a measure which is more meaningful to the insurance application. It is the expected annual loss to each building at the site due to the hazard. To obtain this measure, the vulnerability to damage of a particular type of building at various levels of hazard severity is needed along with the probability of occurrence (or return period) of each severity level. Probabilities of hazard severity and the resultant measure of average annual loss per building are both indicies of risk which are site-oriented. Development of these indicies represents a frequently used method of making natural hazard assessments which can provide information needed by the structural engineer regarding a building at a specific location and also provide an insurance program with a basis for calculating amount of premium needed to cover each of the buildings it insures.

However, there is an additional measure of natural hazard risk that is event-oriented. The insurer must take it into account, but it is of little concern to the structural engineer. This is the catastrophe producing potential of individual geophysical events. Catastrophe potential is of importance because of the tendency for geophysical events associated with the natural hazards (earthquakes, storms, floods) to simultaneously affect a large number of buildings and other property at one time. This second measure of risk is based on the premise that there may be a spatial correlation of hazard severity among various sites during any given event.

By contrast, for other insured perils such as building fires and automobile accidents, it is very unlikely that a single fire or automobile accident would affect more than a few buildings or automobiles at one time. On the other hand, a storm, flood or earthquake could significantly affect all insured property located in an area of many hundreds of square kilometers. Because of this possibility, an insurance company must attempt to estimate the magnitude of this catastrophe potential to its portfolio of insured properties and decide how much money would be needed in a reserve fund to cover the potentially large aggregate losses resulting from the occurrence of a single geophysical event.

Knowledge of the characteristics of natural hazard damage production is needed to answer the following questions that the actuary must ask :

1. What premium rate is needed to cover the average annual expected loss on each insured building?

2. How much of a cash reserve is needed in order to cover possible catastrophic losses on the particular book of business?

3. Is it advisable to reduce the risk of catastrophic losses by reinsuring some of the excess loss potential?

Natural hazard risk, in this insurance context, is dependent upon unique features of earthquakes, floods, hurricanes, tornadoes, hailstorms, winter windstorms that distinguish them from other insured perils such as fire. These unique features of infrequent occurrence and the tendency to cause many losses when they do occur make it desirable to find a supplementary means of estimating present or future risk rather than depending solely upon the traditional method of evaluating the magnitude of a hazard using past loss experience.

\section{Measures of natural hazard risk}

To cover the natural hazards two measures of risk are needed : 


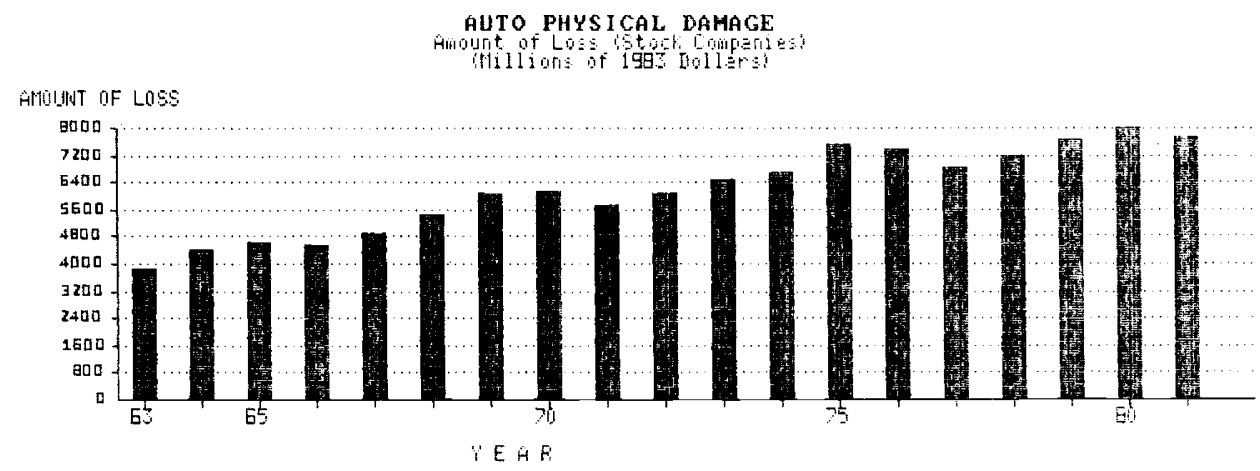

Figure 6 a

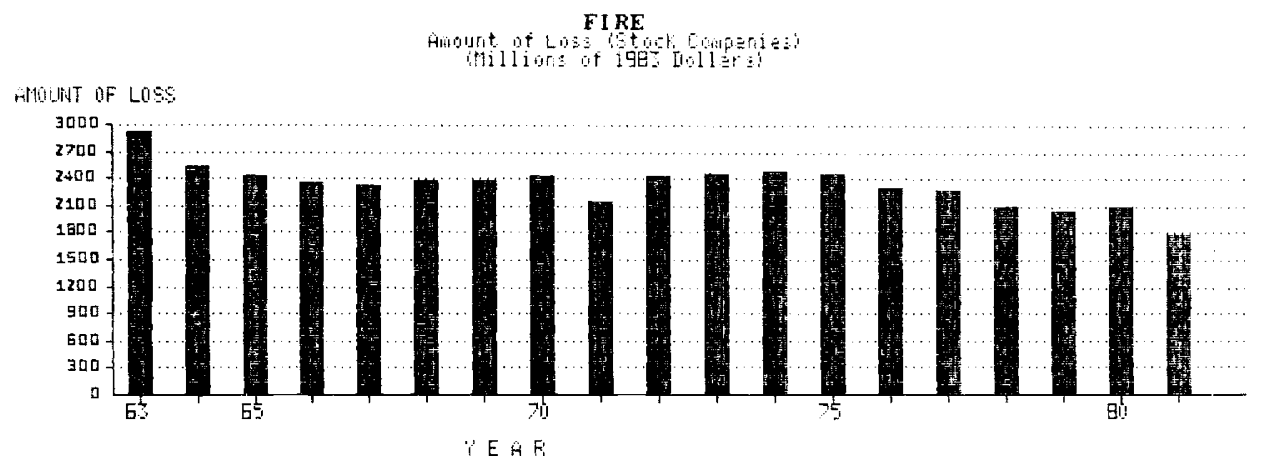

Figure $6 b$

Figure 6: Example of annual loss, expressed in 1983 dollars, resulting from the insured perils of auto physical damage (Figure 6 a) and fire (Figure 6 b). In these lines of insurance, there is little year to year variation in aggregate losses and average annual loss is the dominant measure of risk. By comparison losses due to the "natural hazard" (storm, earthquakes) perils exhibit a large year to year variation shown in Figures $2 b$ and $3 b$. Catastrophe potential is the dominant factor. Unadjusted loss data from Best Aggregates (1963-1981). Adjustment to 1983 dollars was made with a cost index [2].

1. Average annual loss per structure - pure premium. This is a measure of expected value (the actuary's first question).

2. Catastrophe potential - many losses resulting from same event. This is a measure of variability (the actuary's second and third questions) 


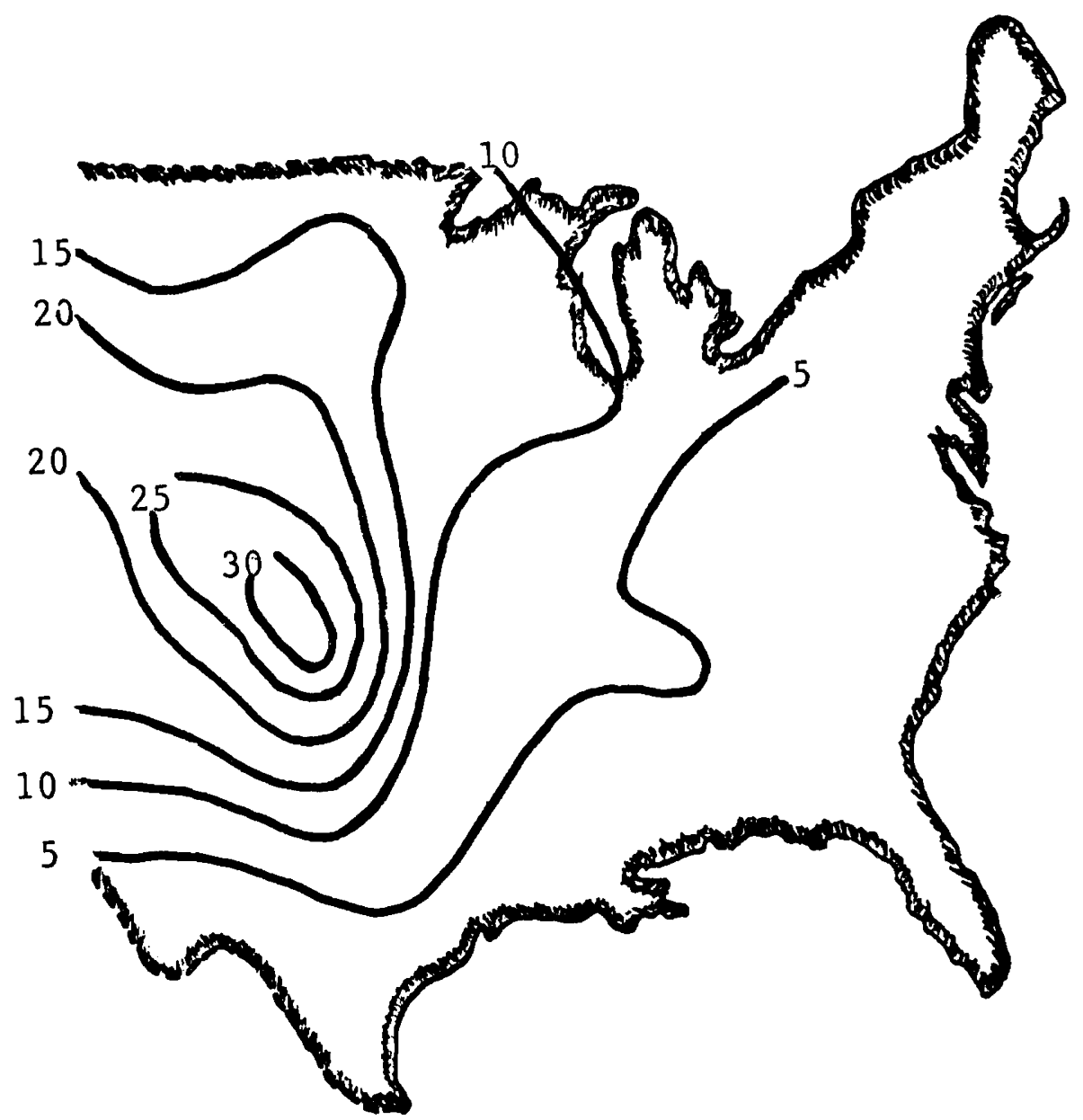

Figure $7 \mathrm{a}:$ Estimate of premium rate needed to cover the expected average annual loss per dwelling. Hazards include tornado, hail, thunderstorm wind, winter and spring (non-thunderstorm) windstorms.

Relative importance of average annual loss as compared with the catastrophe potential is different for each type of insured peril. For the fire and automobile physical damage perils, there is small year-to-year variation so that average annual loss is dominant and catastrophe potential is of lesser significance. Refer to Figure 6. An extreme case, at other end of scale, would be a natural peril for which all losses occur as a result of a single event which occurs on the average of, say, once every 50 years. In this case, catastrophe potential is dominant and average annual expected loss is a much less meaningful insurance measure. The various natural hazards lie somewhere between these extremes of frequent 


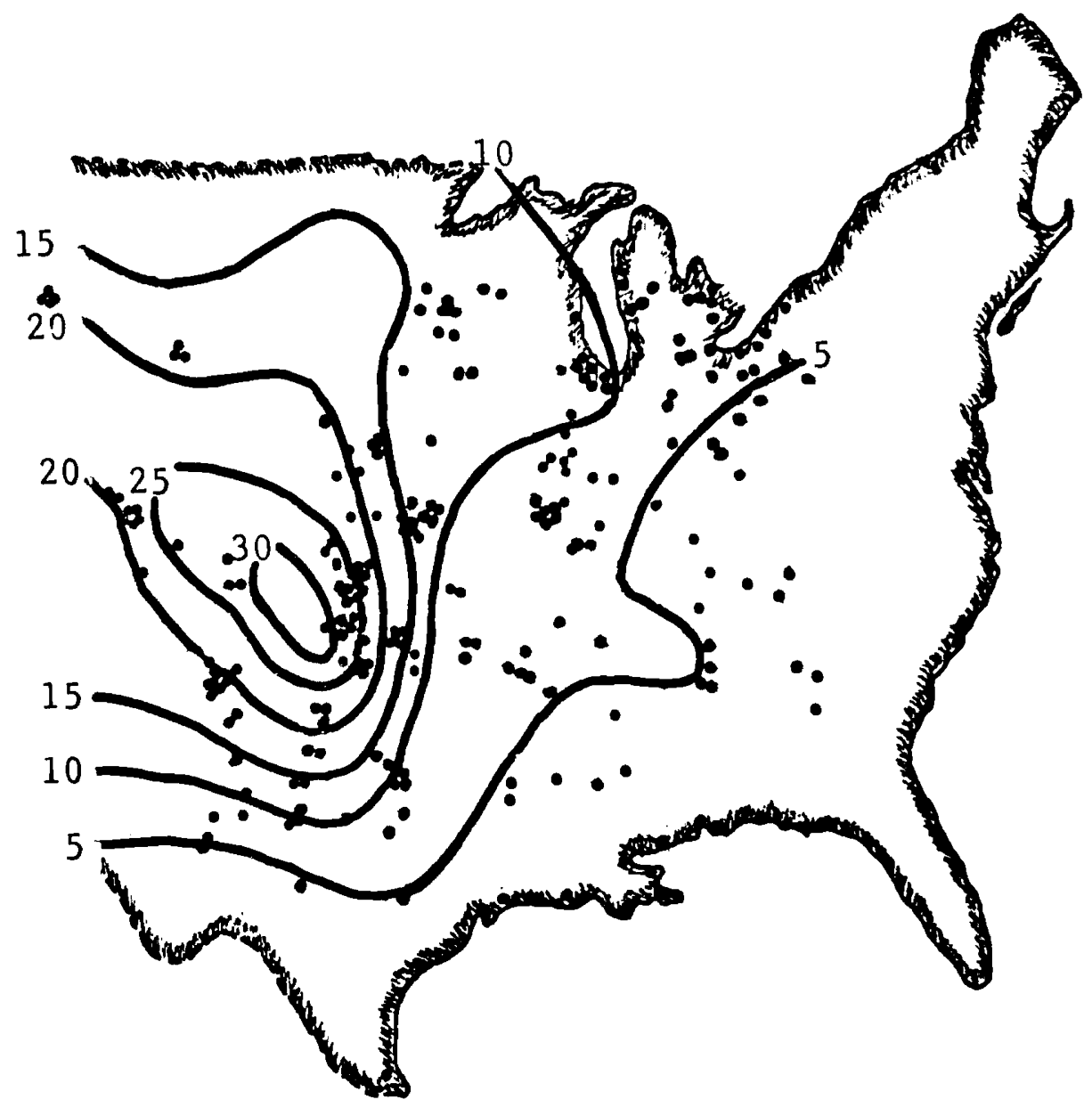

Figure $7 b$ : Location of catastrophes caused by these natural hazards during twenty years plotted on the premium pattern given in Exhibit 7 a. Each dot represents insurance industry losses exceeding one million dollars caused by a single geophysical event.

and rare damage-producing events. Refer to Figure $3 \mathrm{~b}$ for the hurricane wind hazard and Figure $2 \mathrm{~b}$ for a composite of the wind, hail and earthquake hazards.

For the natural hazards, average annual expected loss and catastrophe potential are not directly related. Knowledge of one measure does not always imply the magnitude of the other. Each must be estimated separately. An index of average annual loss per dwelling due to the thunderstorm and tornado hazard in the midwestern United States is given in Figure 7 a [9]. A plot of the location of thunderstorm or tornado caused catastrophes which produced at least one million dollars in insured damage is given in Figure $7 \mathrm{~b}$. The pattern 
of these points is displaced to the east of the area of severe storms because natural disasters are caused by the interaction of the geographical pattern of the severity of the geophysical event with the spatial array of insured structures. There are more insured properties east of the area of greatest storm frequency. Even though severe storms are less frequent in eastern regions, when they do occur the catastrophe potential is great. A severe storm is not a damaging storm unless elements-at-risk susceptible to damage are in the area affected by the storm.

\section{Methods of estimating risk}

Conventional use of loss experience may not be an adequate means of obtaining measures of future risk for the natural hazards because loss experience measured over a short period of years can be highly biased by occurrence or non-occurrence of a geophysical event during the period. Extrapolation of loss experience into the future implies that those events that happened to have occurred in the short sample period are representative of future occurrences. However, a long record of occurrences would be needed for this to be the case. In addition, property characteristics do not remain constant. Number, type, and geographical distribution change rapidly with time. Their susceptibility to damage also changes, because of time related modifications in building design, materials and methods of construction, building codes, and insurance coverages. Consequently, a dilemma exists. If the length of the sample period of past loss experience is increased, the effect of changing property characteristics is amplified. On the other hand, if the length of the sample period is decreased there is less chance of getting a non-biased estimate of frequency and magnitude of the natural hazard.

Loss experience is a resultant of an interaction of a number of factors which is not easily dissected for use in estimating future risk. Figure 8 is a block diagram of the process indicating the major factors that affect loss experience. The process is not reversible so that it is not possible to define the characteristics of the natural hazard mechanism working backwards from loss experience. Features of the insurance program and vulnerability of the insured property act as restraining filters. To provide a measure of present risk, an alternative to the sole use past loss experience is needed in which property characteristics are held constant at current conditions :

\begin{tabular}{|c|c|c|}
\hline & Past loss statistics & Alternate approach \\
\hline Natural hazard & held constant & allowed to vary \\
\hline Number, type, location of buildings & allowed to vary & held constant \\
\hline Vulnerability & allowed to vary & held constant \\
\hline
\end{tabular}

Alternate approaches to the use of loss experience for evaluating the magnitude of the natural hazard damage potential in an insurance operation to cover these hazards can be either quantitative or quantitative. One quantitative method is to construct a mathematical approximation of the natural hazard mechanism which can then be used to generate geophysical events, and attendant severity patterns, that interact mathematically with a given array of properties to produce synthetic loss experience [11]. Both measures of risk can be examined using this type of analysis : site-orientated estimates of annual expected loss per structure and event-orientated estimates of catastrophe potential. However, qualitative scenarios are still employed by most insurers for making natural hazard risk assessments. 
Figure 8: Flow charts illustrating interaction of factors resulting in natural hazard caused damages

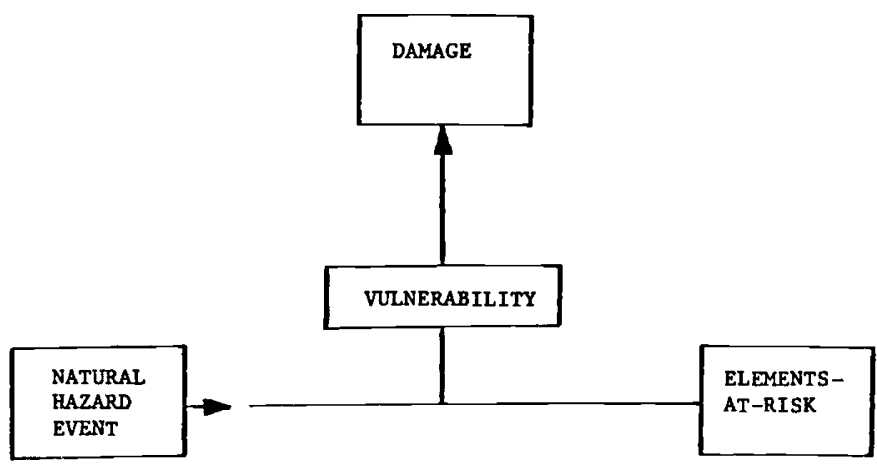

Figure $8 a$ : Interaction of vulnerability and elements-at-risk with the natural hazard event.

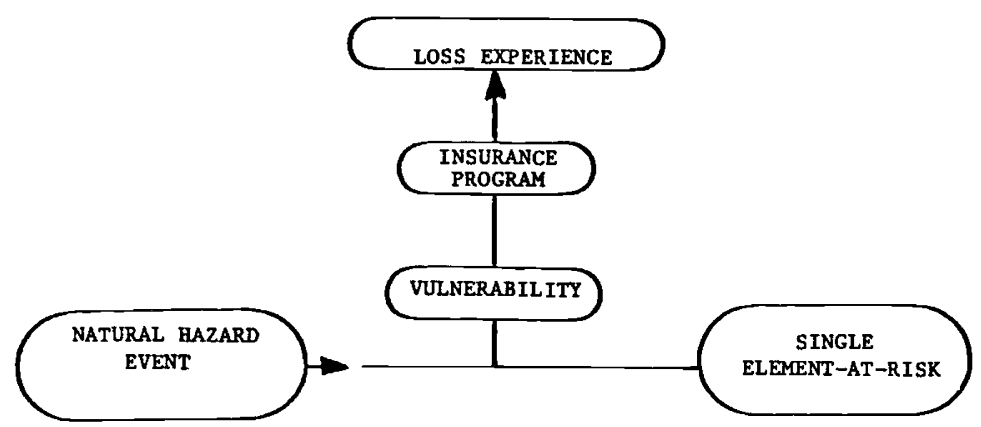

Figure $8 \mathrm{~b}$ : Interaction required in the determination of average annual loss.

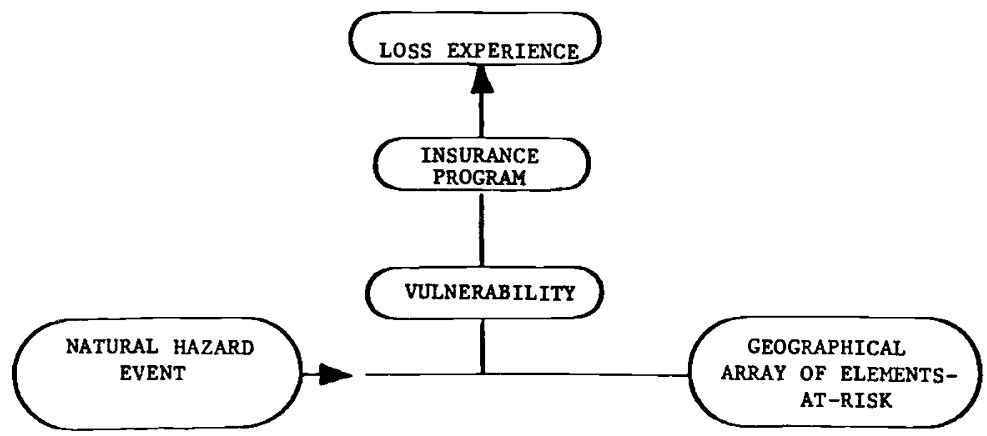

Figure $8 c:$ Interaction required in the determination of catastrophe potential. 
Both approaches attempt to utilize and synthesize additional information, not available in the sole use of past loss experience, such as :

1. Geophysical information from the physical sciences.

2. Insured property information on the insurance company's current book of business (elements at risk).

3. Loss relationships between hazard severity and resultant damage from claim records or engineering studies (vulnerability).

The quantitative approach can provide a measure of the impact of a recurrence of past geophysical events or simulated future events upon present or hypothetical future geographical arrays of property and their damage vulnerabilities [26, 35]. Occasionally, a simulated "natural disaster" is produced. Qualitative scenarios have less flexibility and capacity to incorporate bits and pieces of pertinent information from a number of different sources, but are much easier to develop and apply.

\section{Hurricane risk assessment}

There are a number of by-product hazards that can result from the passage of a hurricane. These are strong winds, coastal flooding caused by the storm surge (water pushed against the seacoast by strong onshore winds), wave wash, tornadoes, lightning and flooding caused by torrential rains. Four factors interact to determine the wind, storm surge, and flood impacts :

- The first factor is the geographical pattern of severity of the wind and flooding phenomena associated with passage of the hurricane. The spatial pattern of maximum wind speed and the extent and depth of inundation caused by the storm surge and riverine flooding are examples of these geographical patterns of storm severity.

- The second factor is the effect of local conditions in modifying the severity of the event at any given location. For the wind hazard, speed can be markedly affected by local topography configurations, such as mountains, hills and valleys, by trees and even by the presence of a town or village. For the storm surge hazard, depth and extent of tidal inundation at any given coastal location is affected by shape of the shoreline, depth of offshore waters, and presence of man-made constraints. For the flood hazard, depth and extent of inundation are affected by local topography and man-made barriers.

- The third factor is the type, spatial distribution and clustered densities of buildings and other property which are exposed to the effects of a hurricane. These are the elements-at-risk.

- The fourth factor is the vulnerability of property to loss when subjected to a given wind speed or flood depth.

The spatial interaction of these four factors determines the loss-producing potential of the hurricane-caused wind and flood hazards [14].

\section{Physical characteristics of the geophysical event}

Figure 9 a depicts the cloud pattern of a hurricane as it nears the coast of the United States. The typical location of high winds (gale force or more) associated with the storm 
Figure 9: Graphical illustration of the development of an approximation to the geographical pattern of maximum wind speed swept out during the inland passage of a hurricane.

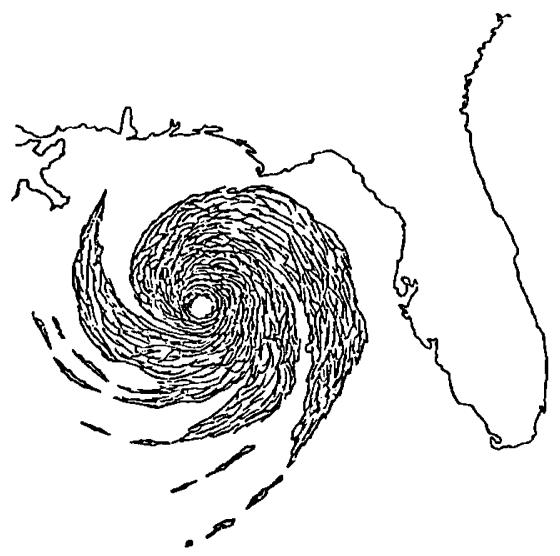

Figure $9 a$ : Cloud pattern of a hurricane approaching United States coastline.

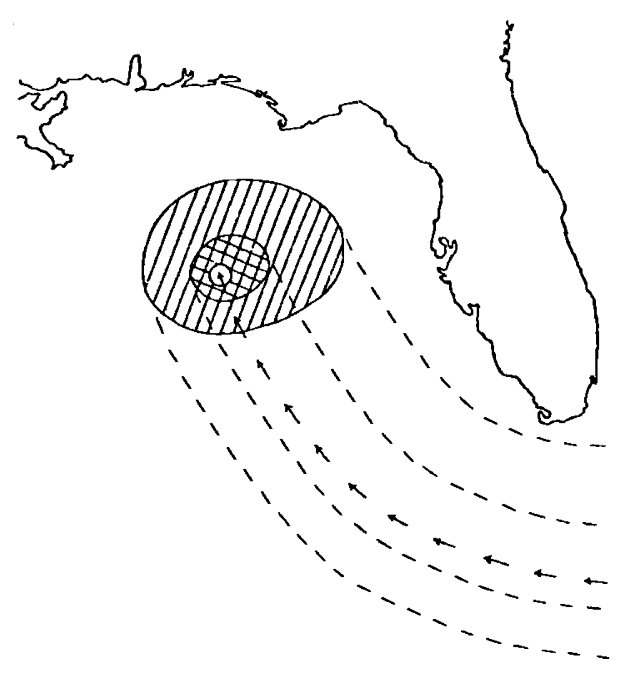

Figure $9 c$ : Geographical pattern of maximum wind swept out by the hurricane movement.

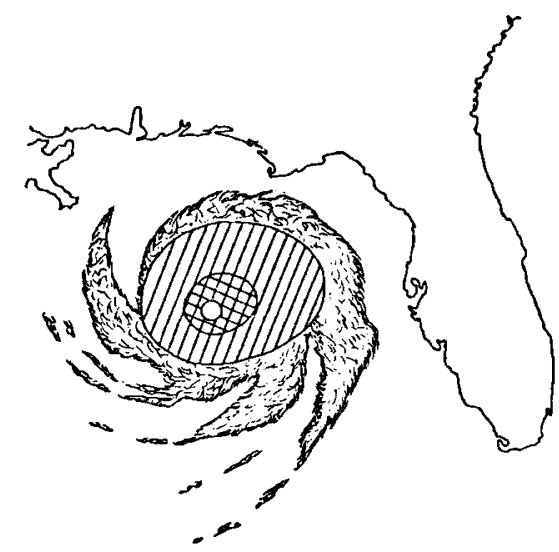

Figure $9 b$ : Geographical pattern of areas likely to experience gale winds (hatched area) and hurricane winds (double hatched area) in a hurricane.

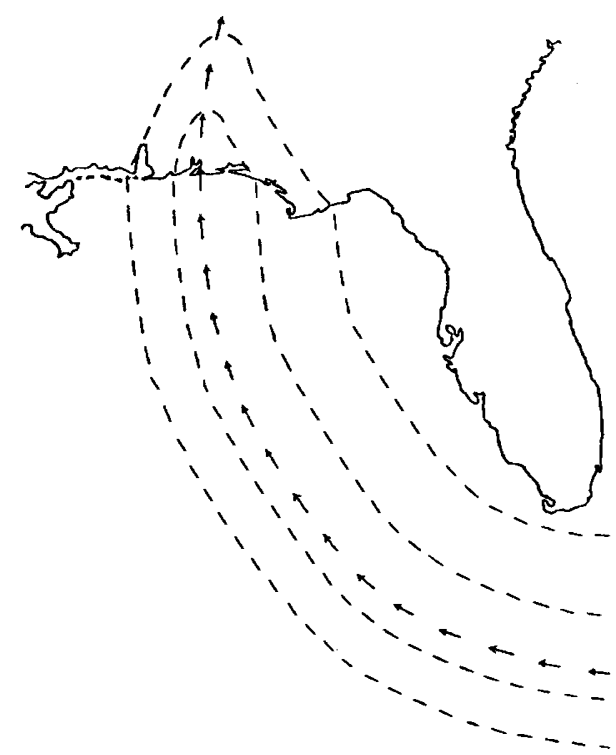

Figure $9 d$ : Geographical pattern of maximum wind caused by the hurricane as it moves inland. 


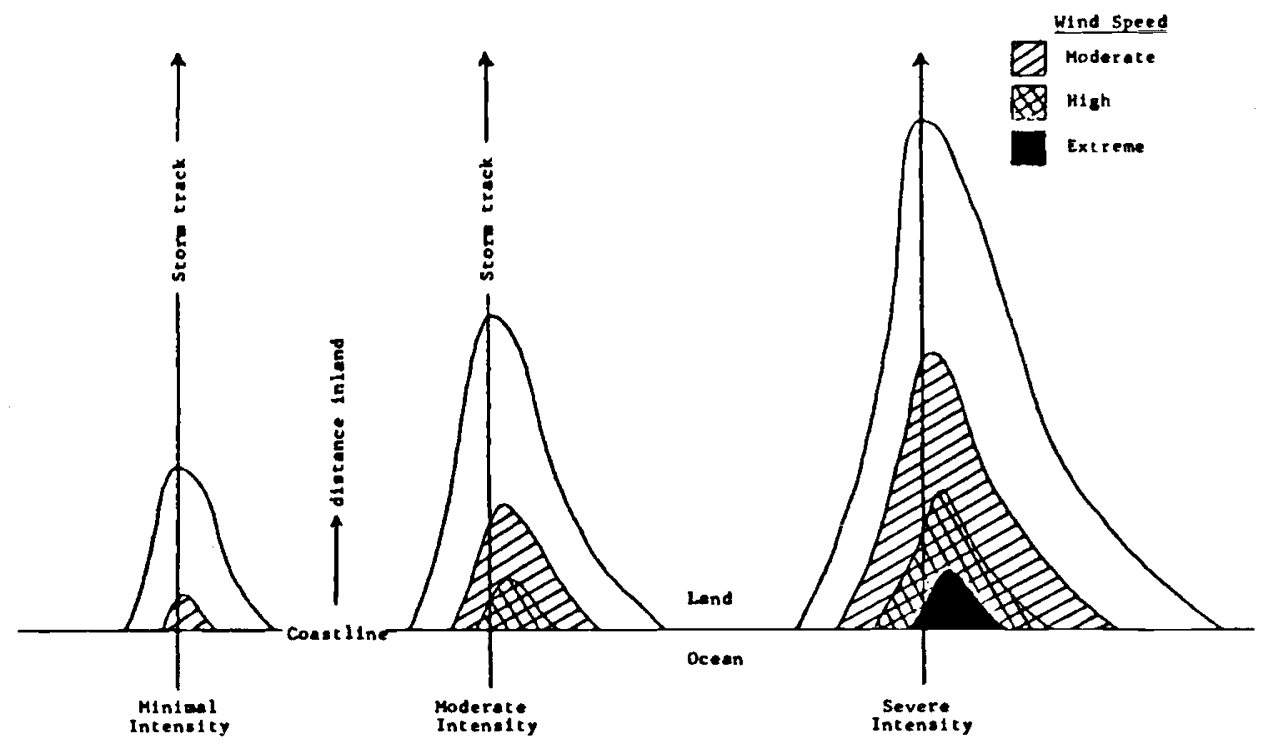

Figure 10: Relationships between typical overland patterns of maximum wind speed associated with the inland passage of a hurricane and the physical intensity of the storm.

is near the center of the storm. The size of the area depends upon the intensity of the hurricane as measured by its lowest barometric pressure. In the eye wall, sustained winds exceed hurricane force. Peak wind gusts that contribute to property damage can be $20 \%$ higher than the sustained wind. The areas of gale and hurricane force winds are usually not symmetrically distributed about the eye of a moving storm. Winds are generally stronger and more extensive to the right of the storm track (looking in the direction toward which the storm is moving), Figure $9 \mathrm{~b}$.

As these high wind sectors move along with the hurricane, they sweep out an elongated pattern representing the most likely areas affected by winds of gale or hurricane force that are associated with the passage of the storm, Figure $9 \mathrm{c}$. After the hurricane crosses the coastline and moves inland, the areas swept by high winds generally rapidly decrease in size. Contours of these "swept out" areas of strong winds are usually bell-shaped with the base on the coastline, Figure $9 \mathrm{~d}$.

Figure 10 depicts the idealized geographical pattern of maximum wind that occurs during passage of a hurricane of given intensity. The magnitude of the calculated maximum winds at any given location must be considered to be statistical in nature. The pattern shown in Figure 10 represents the expected value of maximum wind. In any given s'orm (each of which has its own particular uniqueness) there are fluctuations about these "expected "speeds due to the random variations in wind gustiness inherent in hurricanes. The effects of local conditions (Factor $\# 2$ ) in modifying the maximum wind are assumed to be negligible in this illustration. 


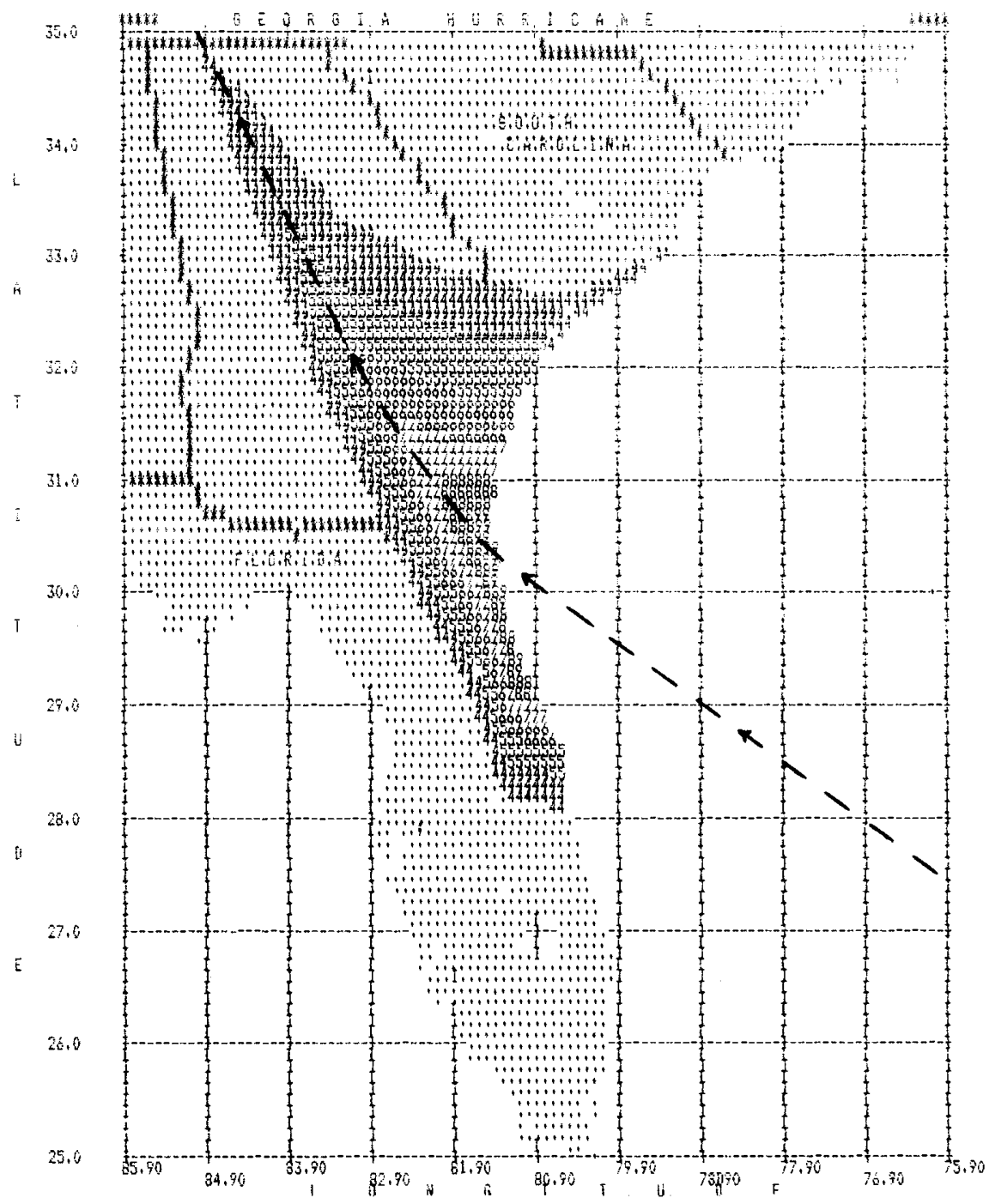

Figure 11: Example of a computer generated pattern of maximum wind speed associated with the simulated inland passage of a hurricane across southeastern United States. Printed numbers denote wind speed intervals. Each dot or number represents a one hundred square kilometer grid area. Number and characteristics of buildings in each grid area are computerized. The computed wind speed in each grid acts on these properties through vulnerability relationships to determine damage potential. Size, shape, and gradient within each computer wind pattern depends upon the combination of input parameters such as storm intensity, size, rate of movement, track direction and curvature. 
Various combinations of storm characteristics (such as storm intensity, storm size, rate of movement of the storm system, and the direction and curvature of its track relative to the coastline) can produce different sizes, shapes and wind speed gradients within the observed patterns. There are inherent consistencies and physical constraints on these wind patterns. For instance, all storms that follow a given path and have the same intensity produce wind and storm surge (coastal flooding) patterns that have some common characteristics. Figure 11 illustrates a computer generated pattern of maximum wind speed associated with the overland passage of a hurricane in the southeastern United States. It is based upon an assumed combination of storm characteristics and their interrelationships.

Physical intensity of a hurricane is an important factor in determining the size, shape, and gradient of speed in the geographical pattern of maximum wind. A measure of physical intensity can be obtained by use of the lowest barometric pressure at the storm's center. This indicator can be used to determine the probable range of highest winds that is expected to occur. For convenience, a six-unit intensity index has been used to classify the severity of tropical storms and hurricanes. It parallels the Saffir-Simpson intensity scale [7]. Refer to Table 1.

Table 1: Relationship between expected range of maximum wind speeds and physical intensity of tropical storms and hurricanes

\begin{tabular}{lllll}
\hline $\begin{array}{l}\text { Storm } \\
\text { Type }\end{array}$ & $\begin{array}{c}\text { Intensity code } \\
\text { based on lowest } \\
\text { barometric pressure }\end{array}$ & $\begin{array}{c}\text { Qualitative } \\
\text { Intensity } \\
\text { Classification }\end{array}$ & $\begin{array}{c}\text { Likely magnitudes of highest } \\
\text { winds in storm (peak gust) } \\
\text { (miles/hour) }\end{array}$ \\
\hline $\begin{array}{l}\text { Tropical Storm } \\
\text { (kilometers/hour) }\end{array}$ & 0 & Minor & less than 145 & less than 90 \\
Hurricane & 1 & Minimal & $146-175$ & $91-110$ \\
Hurricane & 2 & Moderate & $176-210$ & $111-130$ \\
Hurricane & 3 & Major & $211-240$ & $131-150$ \\
Hurricane & 4 & Severe & $241-275$ & $151-170$ \\
Hurricane & 5 & Extreme & greater than 275 & greater than 170 \\
\hline
\end{tabular}

\section{Elements-at-risk}

To quantitatively estimate the loss producing potential of a geophysical event (storm, flood, earthquake), it is necessary to computerize the geographical distributions of the elements-at-risk such as population or structures [16]. Ideally, the unit geographical area for delineating these distributions should be uniform in shape and small relative to the size of the events' severity pattern. One reason for using a computerized grid is to highlight concentrations of vulnerable population and property within relatively small geographical areas in especially hazard-prone regions.

Civil divisions (state, county, standard metropolitan areas, census track, city block, and Zip code divisions) present varying amounts of difficulties because of their non-uniform sizes and shapes. A rectangular grid system addressed in terms of uniform increments of latitude and longitude has been developed. For natural hazard simulation 
SINGLE FAMILY DWELLINGS

320

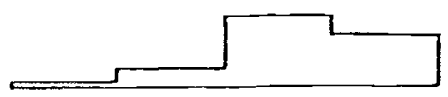

280
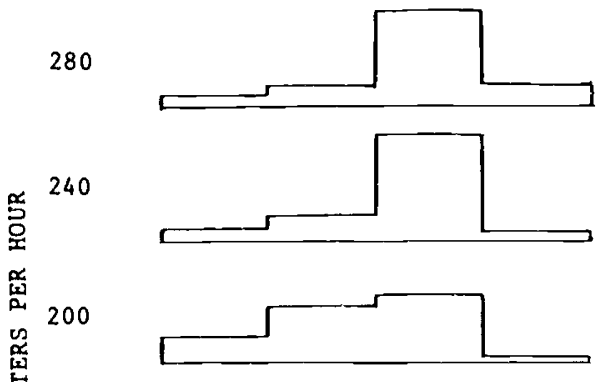

160

से

苋

120

囟
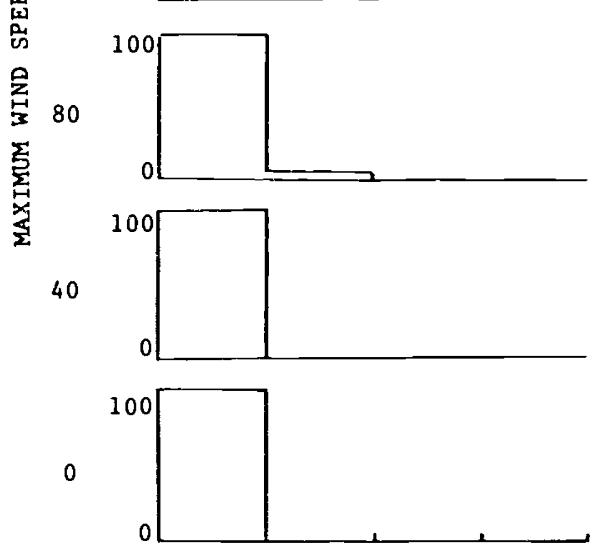

씷

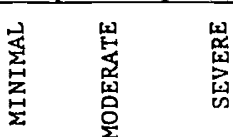

PERCENTAGE BY DAMAGE SEVERITY
SMALL COMMERCIAL BUILDINGS
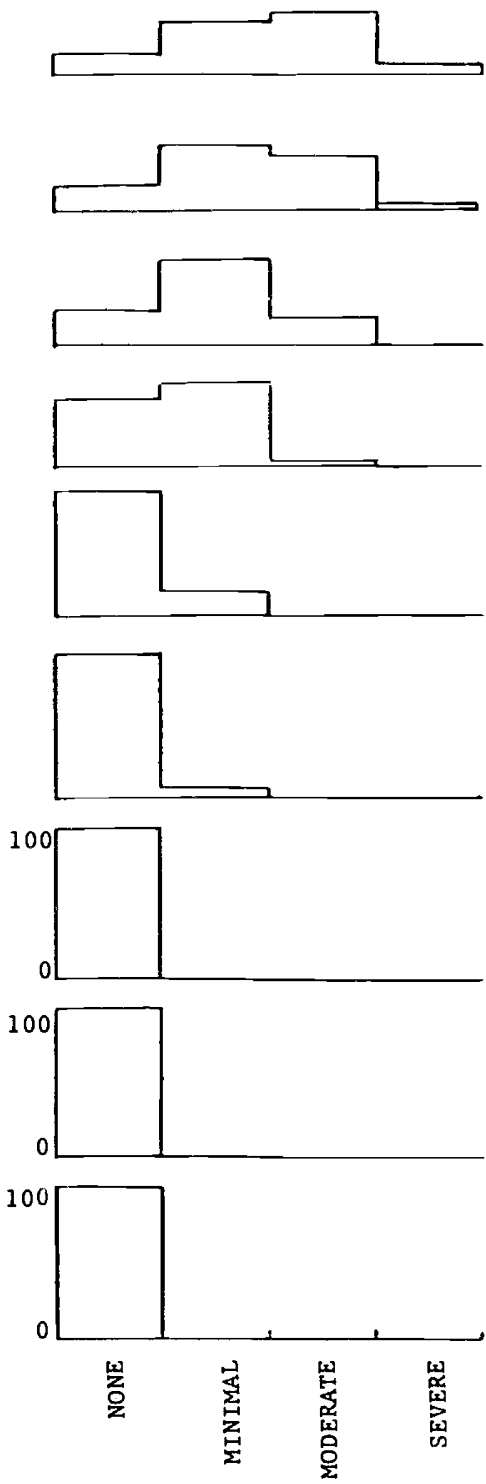

PERCENTAGE BY DAMAGE SEVERITY

Figure 12: Typical vulnerability relationship between maximum wind speed and resultant degrees of damage to a group of single family dwellings or small commercial buildings which are exposed to the indicated speeds. 
of large-scale geophysical events (hurricanes and earthquakes) in one insurance program in the United States, land area of the forty-eight contiguous states has been represented by a system of one-tenth of a degree latitude by one-tenth of a degree longitude areas. Grid area size averages 100 square kilometers. A network of about eighty-five thousand units is needed to approximate the nearly eight million square kilometers of land.

Each of these areas is addressed in computer storage so that building characteristics such as number, type, value, usage, degree of exposure, and vulnerability can be stored at each grid address. To estimate natural hazard effects on the overall population, the detailed geographical distribution of over two hundred million persons and fifty million single-family dwellings has been put into this grid system. The input process included the use of United States Census data, large-scale maps, grid overlays, and an index to 75,000 towns and cities.

A detailed geographic inventory of apartment and non-residential buildings was not available on a basis comparable to that of the single-family dwellings for the United States grid. To provide a first approximation, the number of " other residential " buildings was estimated by using an index based upon population and number of single family dwellings in each grid area. The number of non-residential buildings was approximated using relationships that were established between population, number of single family dwellings as a function of town size.

The geographical distribution of various types of insured properties can be input in a similar manner. In addition, size of the individual grid areas can be adjusted to fit the needs of the application. For an analysis of local urbanized locations, the grid size could be set equal to city blocks if an inventory of buildings, their damage susceptibilities, and local exposure information were also available on this micro scale.

\section{Vulnerability}

For buildings, the loss susceptibility to wind can be expressed in terms of two components. The first component is the percentage of buildings in a locality which would, on an average, be damaged if a wind speed of a specified magnitude were to occur. Except for extremely severe wind situations, only a percentage of buildings in a given area would be damaged because of unmeasurable differences among them in damage susceptibility due to age, type, quality of construction, and degree of exposure. As wind speed is increased, the percentage of buildings damaged increases nonlinearly.

The second component is the most likely amount of loss to those buildings that are damaged, Figure 12. As winds increase, this damage index also increases nonlinearly. These vulnerability relationships can be derived empirically using weather data and insurance claim files. Figure 13, which is a schematic representation of a damage versus wind speed relationship, stresses the statistical nature of the vulnerability factor. In Figure $13 \mathrm{a}$, the curve denotes the average damage amount expected for given maximum wind speeds. However, for any specified speed, there is a skewed frequency distribution of possible damage amounts that range widely about this average value. Frequently, vulnerability is represented in the literature by the average-value curve. No mention is made of the likely variability of loss amounts above or below the average damage which is expected when a wind speed of given severity occurs, Figure $13 \mathrm{~b}$. 

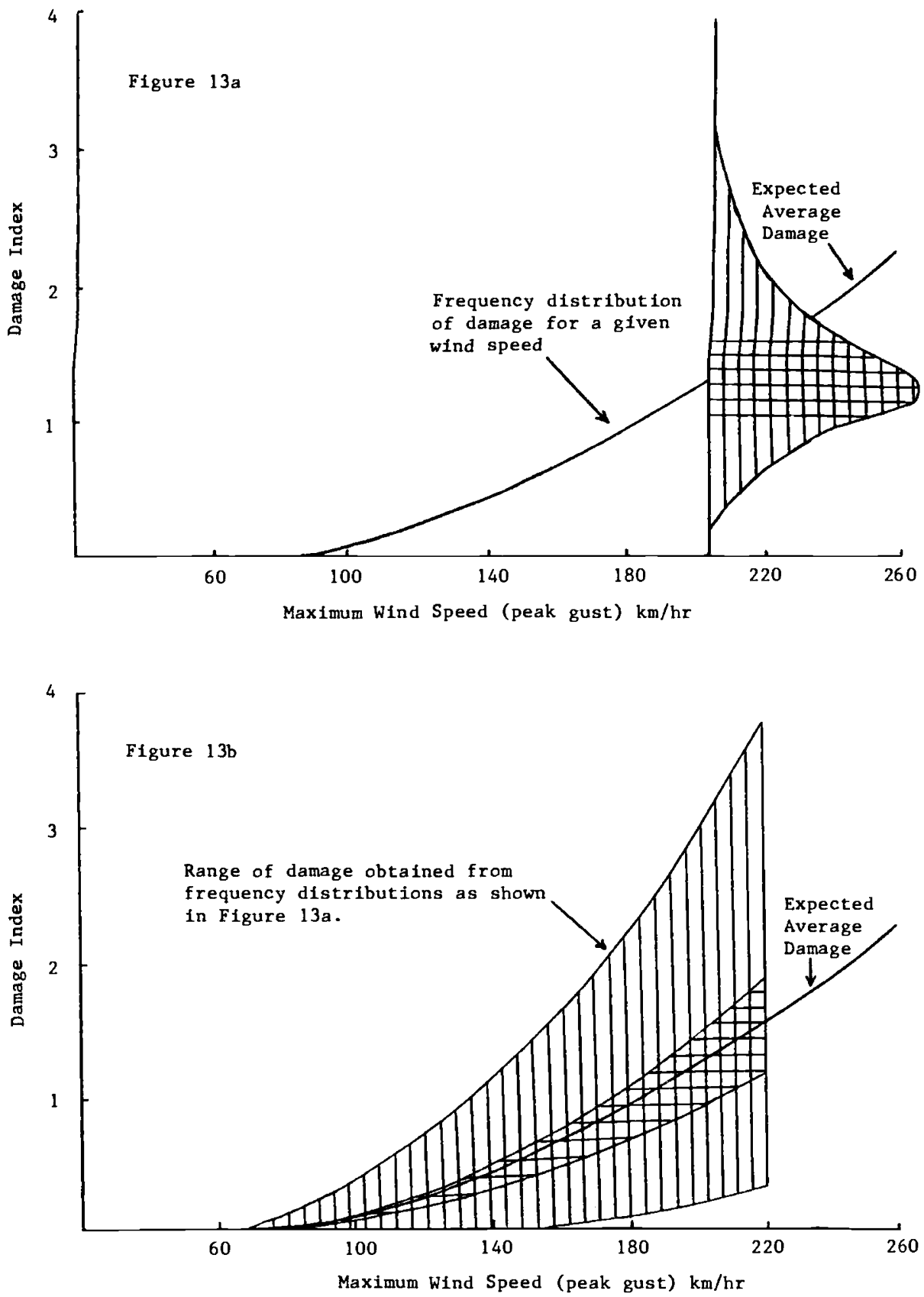

Figure 13: Illustration of the statistical nature of vulnerability relationships between wind speed and resulting damage to houses and buildings. 
A measure of the damage potential of hurricane winds to single family dwellings in the United States has been developed over a number of years. The relationships between wind speed (peak gust) and resultant damage were initially developed from a detailed analysis of residential claim files which resulted from Hurricane Donna in Florida. A total of about 1300 claims were studied. Losses were grouped by geographic area and related to extreme wind speeds (peak gusts) recorded in the area during the passage of the storm. From an analysis of these data it was possible to relate wind speed to a measure of the percentage of total exposures on which a claim was paid, and the average loss per claim.

The relationship of wind speed versus percentage of insured properties affected and loss per paid claim is non-linear which means that a small increase in wind speed when winds are exceptionally high results in a much greater increase in damage potential than a similar increase when speeds are lower. This non-linear effect also has been noted in wind-speed-versus-damage relationships in other parts of the United States when winds are not associated with a hurricane. Table 2 illustrates these relationships. The estimated loss per insured dwelling (column 4) for various maximum wind speeds is obtained by multiplying the percentage of insured properties that were damaged (column 2 ) by the average amount of the damages (column 3 ).

Table 2 : Percentage of insured dwellings damaged and the average amount of damage as a function of maximum wind speed in a county sized area (about 2,500 square kilometers) with $\$ 100$ deductible ${ }^{a}$ on insurance coverage. Relationship based on Hurricane Donna's passage across Florida in 1960.

\begin{tabular}{|c|c|c|c|}
\hline $\begin{array}{l}\text { Maximum Wind } \\
\text { Speed In a } \\
\text { County-Peak Gust }\end{array}$ & $\begin{array}{l}\text { Percentage of Insured } \\
\text { dwellings in a county } \\
\text { on which a claim is paid }\end{array}$ & $\begin{array}{l}\text { (Column 3) } \\
\text { Average amount of } \\
\text { Paid claim as a } \\
\text { percentage of value of } \\
\text { those insured dwellings } \\
\text { that were damaged }\end{array}$ & $\begin{array}{c}\text { (Column 4) } \\
\text { Average loss as a } \\
\text { percentage of value } \\
\text { based on all insured } \\
\text { dwellings in } \\
\text { a county }\end{array}$ \\
\hline (Kilometers/Hour) & (Percentage) & (Percentage) & (Percentage) \\
\hline 65 & $.2 \%$ & $.5 \%$ & $.01 \%$ \\
\hline 80 & .4 & 1.0 & .01 \\
\hline 95 & .9 & 1.7 & .02 \\
\hline 115 & 2.5 & 2.6 & .06 \\
\hline 130 & 4.5 & 3.9 & .18 \\
\hline 145 & 7.0 & 5.1 & .36 \\
\hline 160 & 11.0 & 6.8 & .75 \\
\hline 175 & 15.5 & 8.7 & 1.3 \\
\hline 195 & 22.0 & 10.7 & 2.4 \\
\hline 210 & 29.0 & 13.0 & 3.8 \\
\hline 225 & 37.5 & 15.7 & 5.9 \\
\hline 240 & 50.0 & 19.8 & 9.9 \\
\hline
\end{tabular}

${ }^{a}$ First $\$ 100$ in damages, which was paid by the home owner, is not included in statistics. 
The damage relationships were subsequently examined using claim file data from 6,000 paid claims resulting from Hurricane Donna's passage across New England and aggregate loss data from 175,000 claims that resulted from Hurricane Carol's movement through the same area (Table 3). The relationships were consistent among these storms. The percentage of insured properties with a claim, for given wind speeds, was higher in New England than in Florida caused in part by construction and building code differences. However, the average loss per claim for a given wind speed was less than in Florida due to the shorter time that winds maintain peak velocities during a hurricane passage across New England compared with Florida. The product of higher percentage of insured properties with a claim and lower loss per claim in New England yielded about the same damage potential per insured property as in Florida.

\section{Table 3 : Relationship between wind speed and damage to residential properties in New England during passage of Hurricane Carol in 1954.}

\begin{tabular}{ccccc}
\hline $\begin{array}{c}\text { Wind speed } \\
\text { (peak gusts) } \\
\text { Kilometers/hour }\end{array}$ & $\begin{array}{c}\text { Number of } \\
\text { insured } \\
\text { dwellings }\end{array}$ & $\begin{array}{c}\text { Number } \\
\text { damaged }\end{array}$ & $\begin{array}{c}\text { Percentage } \\
\text { of insured } \\
\text { dwellings } \\
\text { damaged }\end{array}$ & $\begin{array}{c}\text { Amount } \\
\text { of damage } \\
\text { per 100 } \\
\text { insured dwellings }\end{array}$ \\
\hline $115-130$ & 101,400 & 7,340 & 7.2 & $\$ 1,530$ \\
$131-145$ & 43,500 & 3,060 & 7.0 & 2,960 \\
$146-160$ & 381,100 & 64,640 & 17.0 & 5,250 \\
$161-175$ & 367,400 & 93,680 & 25.4 & 7,680 \\
$176-195$ & 25,300 & 7,510 & 29.7 & 12,090 \\
\hline
\end{tabular}

To further test the validity of the relationship between wind speed and damage, an examination was made of claims resulting from Hurricane Betsy's impact on Louisiana in 1965. The potential loss per insured dwelling, for given wind speeds, was somewhat larger than the Florida loss data resulting from Hurricane Donna would indicate. Possible reasons for this increase in loss potential were attributed to differences in the type and construction of dwelling structures between Florida and Louisiana; differences in building codes ; differences in average claim cost due to price level changes (1960-1965); and difficulties in distinguishing between wind and wave wash-coastal inundation losses.

A comparison also was made with loss experience resulting from Hurricane Camille in 1969 and Hurricane Celia in 1970. An updating of the damage potential to account for the rapid increase in the effect of inflation in recent years was made. The damage-versuswind speed relationship was updated and recalibrated using data from Hurricane Frederic in 1979 - the most recent hurricane to seriously affect the United States mainland, Figure 14. Currently, the estimate of damage potential is expressed as "percentage of value lost "where value represents amount of insurance coverage on a property. This measure is invariant to the effects of inflation if the amount of insurance coverage on a property is increasing at approximately the same rate as the claim cost (cost of repair). However, there are indications that this has not been the case since 1979. Claim costs may have been increasing at a more rapid rate than the amount of insurance coverage on a property. 


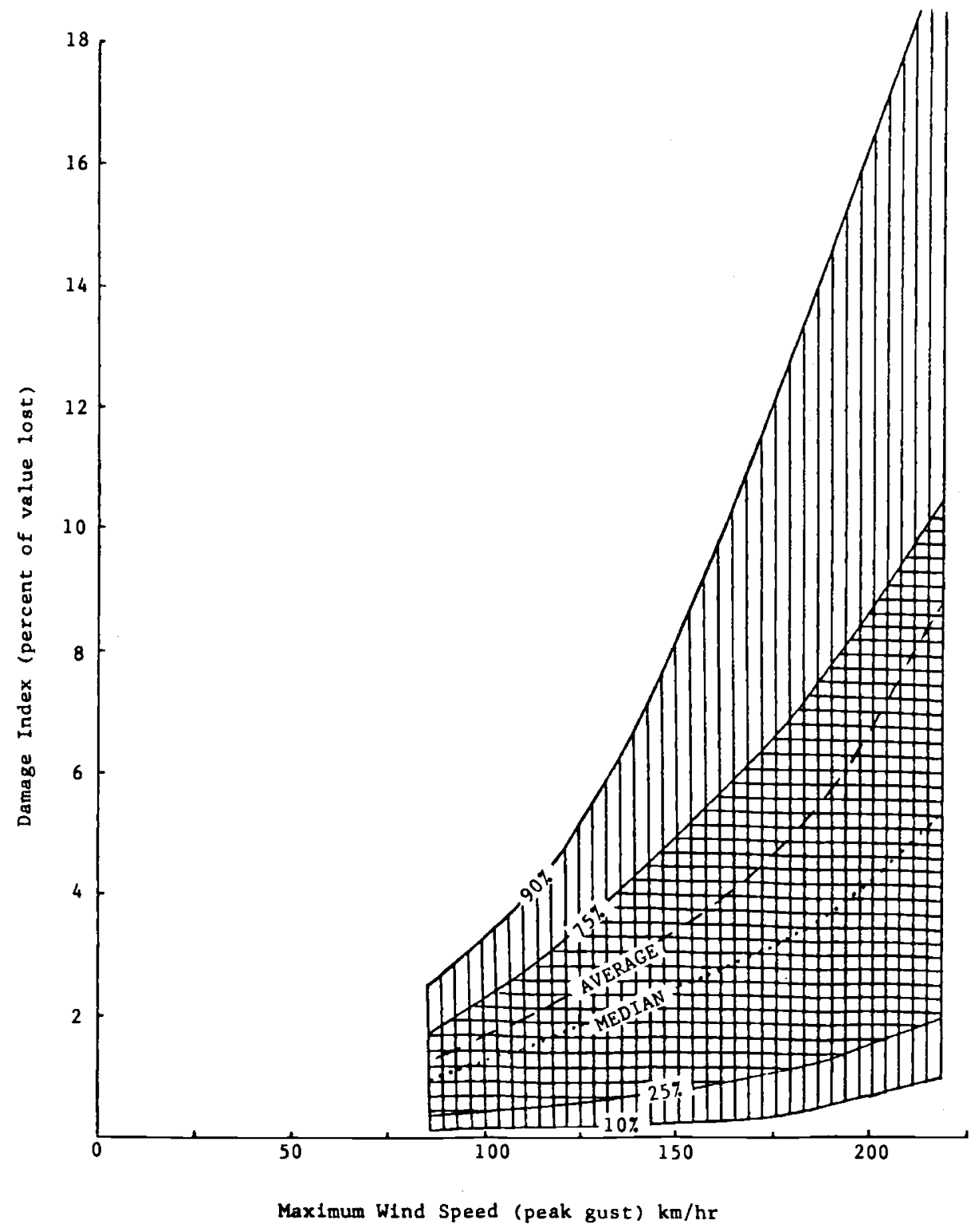

Figure 14: Vulnerability relationship between maximum wind speed and resulting damages to dwellings caused by Hurricane Frederic in the southern United States during 1979. The statistical nature of the relationship is emphasized by showing the cumulative frequency of damage amounts to dwellings exposed to various maximum wind speeds. 


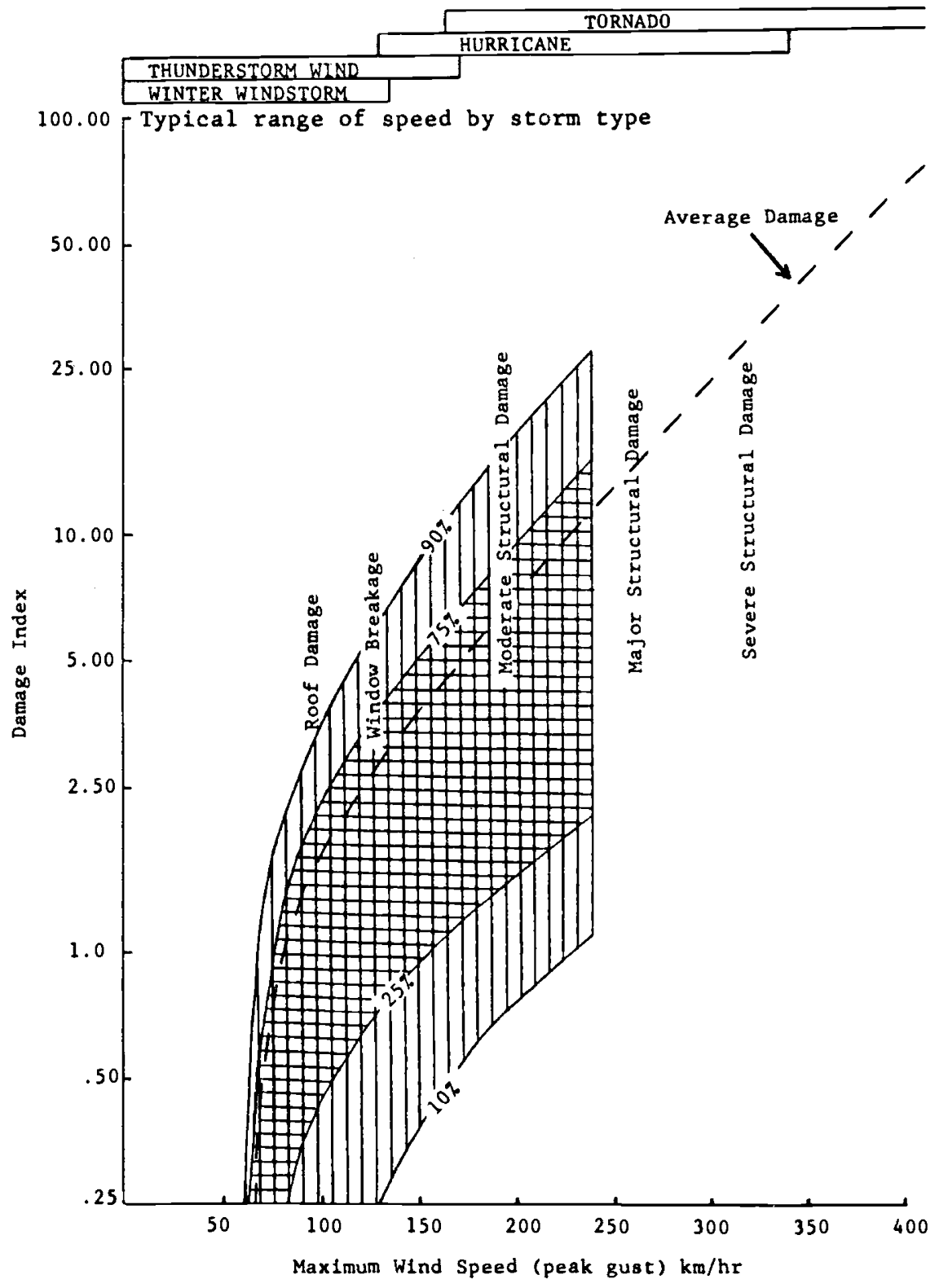

Figure 15: Generalized vulnerability relationship for one type of dwelling structure for various types of windstorms. For comparison, the cumulative frequency distributions of Hurricane Frederic (Figure 14) are superimposed. 
The large amount of variability in observed damage amounts to groups of dwellings exposed to high wind speeds is shown in Figure 14. Frequency distributions of damage amounts for given wind speeds become more skewed as maximum wind speed is increased. As a result the average damage index increases more rapidly than the median index (fifty percent of the damages less than the indicated value). Damage to buildings and other elements-at-risk is related to wind pressure which is a function of the square of the speed. As a result, damage severity increases disproportionately as wind speed is increased. For example, the relative change in damage potential is much larger when the speed is increased by an increment of 25 kilometers per hour from 150 to 175 kilometers per hour as compared with a comparable change in speed from 50 to 75 kilometers per hour. Figure 15 illustrates this non-linear relationship between wind speed and average damage index for one type of residential structure in the United States. To emphasize the statistical nature of the speed versus damage relationship in Figure 15, the cumulative distributions of damage amounts for wind speeds observed in Hurricane Frederic (Figure 14) are superimposed. Table 4 shows vulnerability relationships for several types of element-atrisk: single unit residential buildings, other residential buildings and non-residential

Table 4: Vulnerability of three types of elements-at-risk to hurricane winds.

$4 a:$ Average percentage of buildings affected in a small geographical area.

\begin{tabular}{cccc}
$\begin{array}{c}\text { Maximum } \\
\text { Wind Speed } \\
\text { in Grid Area } \\
\text { (peak gust) }\end{array}$ & $\begin{array}{c}\text { Single-unit } \\
\text { Residential }\end{array}$ & Other Residential & Non-residential \\
\hline $65 \mathrm{~km} / \mathrm{hr}$ & $0.1 \%$ & $0.08 \%$ & $0.06 \%$ \\
95 & 1.8 & 1.5 & 1.2 \\
130 & 8.4 & 7.0 & 5.6 \\
160 & 25.0 & 21.0 & 17.0 \\
195 & 51.0 & 43.0 & 34.0 \\
225 & 72.0 & 60.0 & 48.0 \\
255 & 100.0 & 83.0 & 67.0
\end{tabular}

$4 \mathrm{~b}:$ Most likely percentage of value lost of affected buildings.

\begin{tabular}{cccc}
$\begin{array}{c}\text { Maximum } \\
\text { Wind Speed } \\
\text { in Grid Area } \\
\text { (peak gust) }\end{array}$ & $\begin{array}{c}\text { Single-unit } \\
\text { Residential }\end{array}$ & Other Residential & Non-residential \\
\hline $65 \mathrm{~km} / \mathrm{hr}$ & $1.0 \%$ & $0.5 \%$ & $0.4 \%$ \\
95 & 1.7 & 0.9 & 0.8 \\
130 & 2.9 & 1.8 & 1.7 \\
160 & 3.9 & 2.4 & 2.3 \\
195 & 5.5 & 3.5 & 3.4 \\
225 & 9.3 & 6.0 & 5.9 \\
255 & 16.0 & 11.0 & 10.9 \\
\hline
\end{tabular}




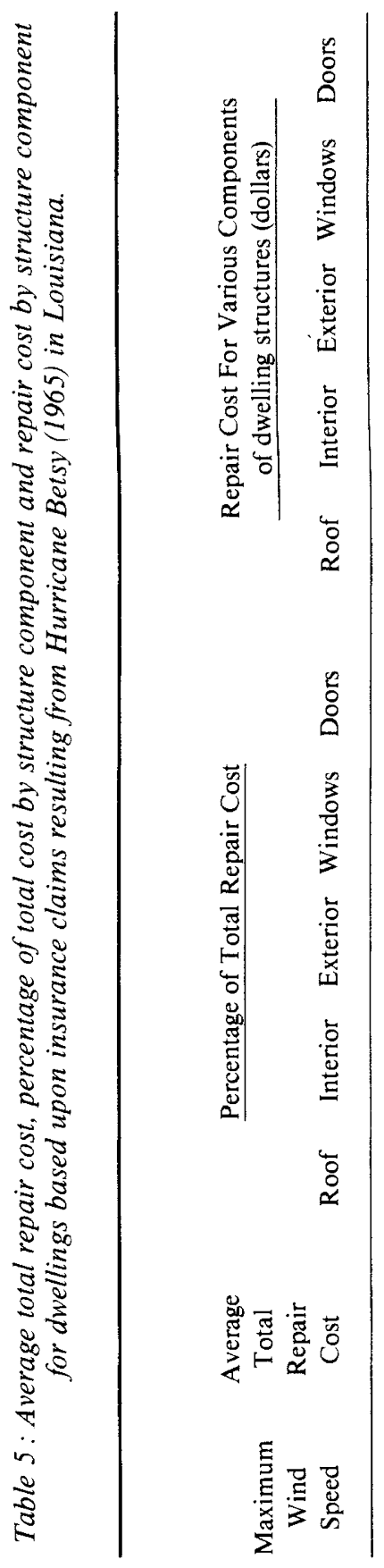

$$
\begin{aligned}
& \text { 0.0000-minavidio } \\
& \text { o } 0000-4 \text { m }
\end{aligned}
$$

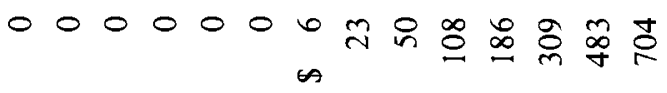

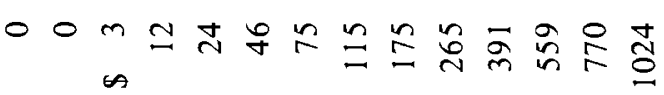

$$
\begin{aligned}
& \text { ○ ๙ } \\
& \text { 0 } 0 \text { O }
\end{aligned}
$$

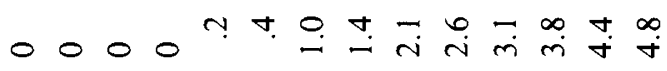

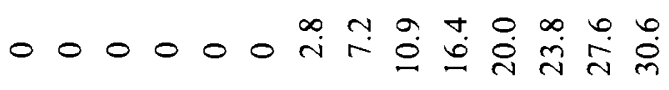

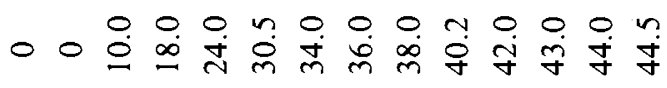

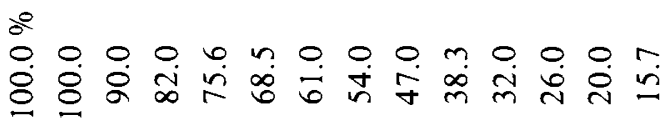

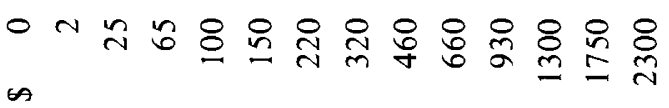

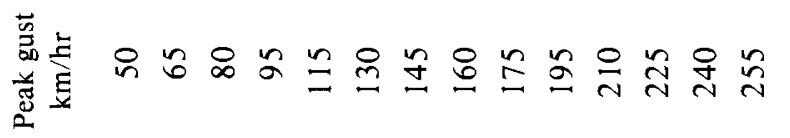




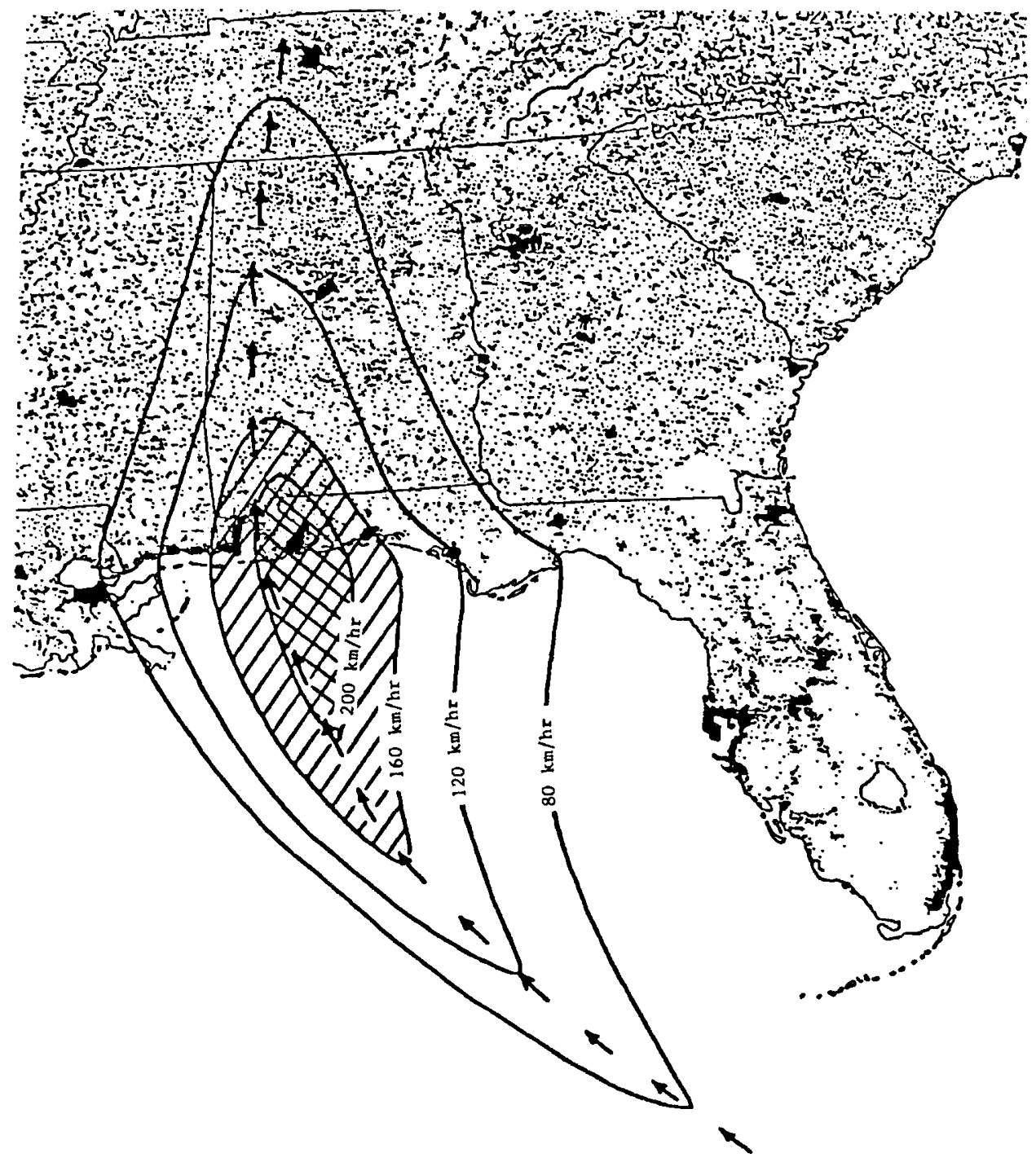

Figure 16 a: Geographical pattern of maximum wind speed (peak gust) associated with a hurricane that develops over the Gulf of Mexico and eventually moves onshore. Hatched areas overlap locations exposed to the highest wind speeds. 


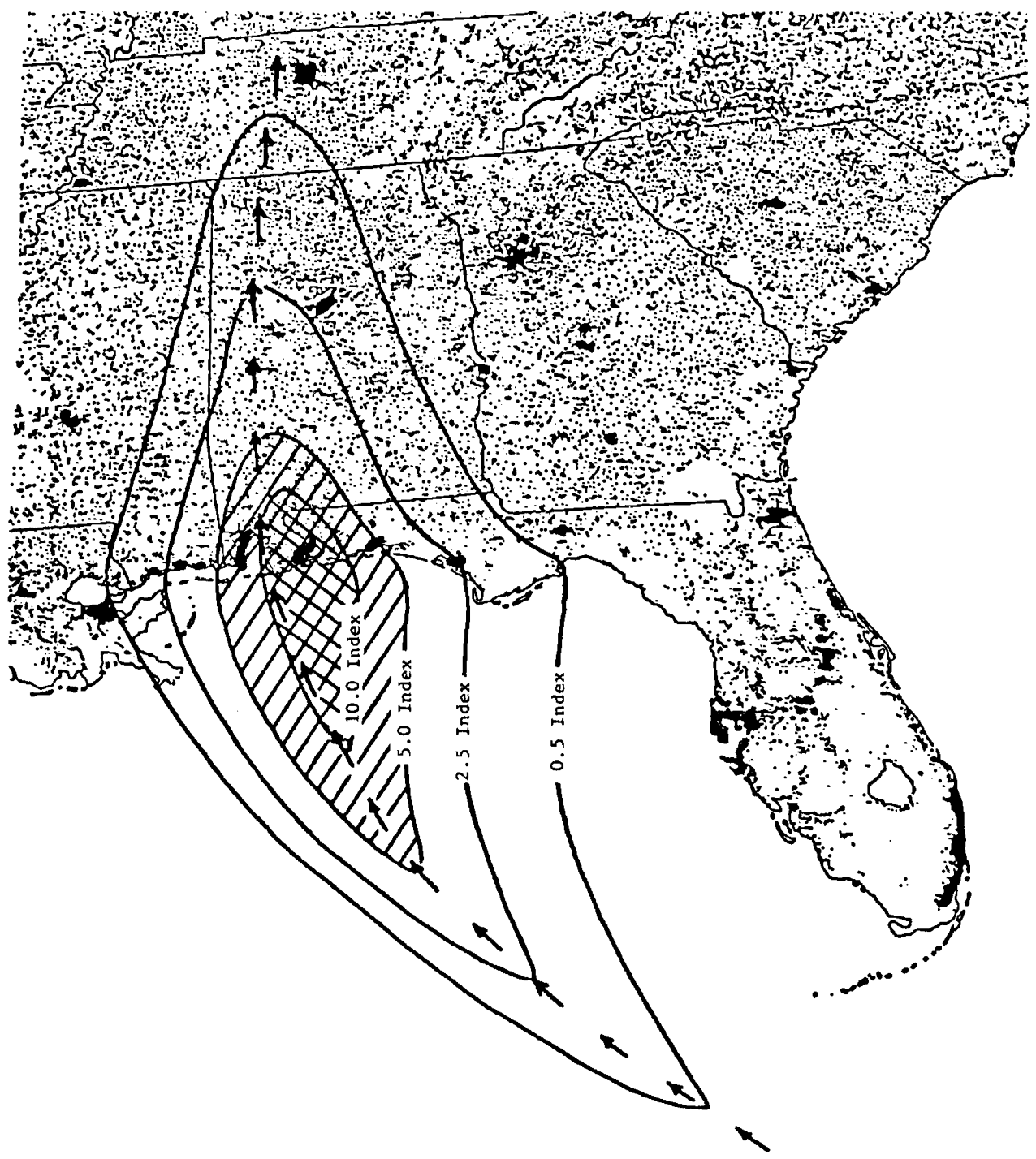

Figure 16b: Example of the use of a statistical measure (average) of vulnerability relationship, such as shown in Figure 15, to convert the geographical pattern of maximum wind speed into a pattern of damage producing potential. Note that the damage index for very high wind speeds (hatched and cross-hatched areas) is disproportionately large because wind speed-versus-damage relationships are typically non-linear. 
buildings. The two-stage statistical relationship is represented. Each different element-atrisk has its own wind speed-versus-damage relationship. For many of them, the shape of the curves are similar to one another, but the wind speed at which significant damage begins can be very different. For instance, damage curves representing other elements-atrisk may be similar to the one shown in Figure 15, but shifted to the left or right of it on the wind speed scale ( $\mathrm{x}$-axis).

Examples of elements-at-risk that have different damage thresholds can range from light aircraft that are parked but not tied down (high susceptibility, low wind threshold for damage) ; mobile homes, not anchored; wood frame residential structures, steel frame industrial buildings, multi-story office buildings; to ore-filled railroad cars (low susceptibility, high wind threshold for damage). Similar types of relationships between wind speed and resultant damage to various components of a dwelling are given in Table 5 .

For some types of insurance coverages, it is necessary to estimate the casualty producing potential of a natural hazard. Table 6 presents a simple vulnerability relationship which is based on past experience in the United States. It is a ratio of expected number of casualties to the total number of persons in areas affected by various maximum wind speeds. The death rate is assumed to be $3.5 \%$ of the number of casualties.

Table 6: Vulnerability relationship of population to hurricane wind.

\begin{tabular}{ccr}
\hline $\begin{array}{c}\text { Maximum } \\
\text { wind speed } \\
\text { (peak gust) }\end{array}$ & \multicolumn{2}{c}{$\begin{array}{c}\text { Number of casualties per } \\
\text { number of persons } \\
\text { in areas affected by high winds }\end{array}$} \\
\cline { 2 - 3 } $65 \mathrm{~km} / \mathrm{hr}$ & $1 \mathrm{per}$ & $5,000,000$ \\
95 & $1 \mathrm{per}$ & 300,000 \\
130 & $1 \mathrm{per}$ & 50,000 \\
160 & $1 \mathrm{per}$ & 10,000 \\
195 & $1 \mathrm{per}$ & 3,000 \\
225 & $1 \mathrm{per}$ & 1,000 \\
255 & 1 per & 400 \\
\hline
\end{tabular}

Mitigation of the potential effects of hurricane winds upon various elements-at-risk can be accomplished, at least in theory, by improving building codes and their enforcement, modifying methods of construction, using different building materials and protective devises. It has been observed, for example, that there is a decrease in vulnerability to wind damage of mobile homes when tiedowns are properly attached to the structure. Use of some of these mitigation methods could possibly be coupled to an insurance program as incentitives to reduce premium rate (cost) of coverage. In practice, it is very difficult to achieve these mitigation objectives because of a number of reasons.

One need for obtaining the vulnerability factor in an insurance operation is to use it to supplement past loss experience in estimating average annual loss per building and for determining the catastrophe potential. To illustrate implication of the relationship between hazard severity and vulnerability, a conversion factor (such as given in Figure 15) can be used to translate the wind speed pattern shown in Figure 16 a into a geographical pattern of damage producing potential as shown in Figure $16 \mathrm{~b}$. 


\section{Simulation of damage producing potential of a hurricane}

All hurricanes do not have the same intensity, hence damage producing potential. A large percentage of these storms are of only minimal or moderate strength. Occasionally a hurricane will attain a severe or extreme rating. Refer to Table 1. To establish a relationship between a storm's intensity rating on a physical scale and its overall damage producing potential, a series of hurricanes (each with a different central barometric pressure) was simulated to sweep across a coastal plain. A hypothetical uniform distribution of property of maximum possible density was exposed, Figure 17 a. Resulting calculated damage production of each storm suggested that aggregate loss producing potential caused by the storm's overland wind pattern (shown in Figure 16 a) increases very rapidly with an increase in storm intensity [21].

This explosive increase in damage producing potential is due in part to the empirical indication that damage production is related to wind pressure which increases with the square of the speed so that a small increase in strong winds can multiply the potential damage production. In addition, the size of the land area affected by the very strong speed portion of the wind pattern (hatched area in Figure 16 a) generally expands with an increase in hurricane intensity as measured by the lowest barometric pressure. Damages produced in shoreline areas, where winds will be highest, contribute a disproportionately large share of the hurricane's overall loss production. When other conditions are held constant, the simulation results suggest that severe or extreme intensity storms are much more potent wind damage producers than those of only minimal or moderate intensity. For one type of building, the damage index is as follows :

$\begin{array}{lc}\begin{array}{c}\text { Hurricane } \\ \text { Intensity }\end{array} & \begin{array}{c}\text { Index of Overall Wind } \\ \text { Damage Production }\end{array} \\ \text { Minimal } & 50 \\ \text { Moderate } & 150 \\ \text { Major } & 300 \\ \text { Severe } & 500 \\ \text { Extreme } & 1000\end{array}$

\section{Portion of a hurricane's damage producing potential that is actually realized}

Fortunately, only a very small percentage of the overall loss producing potential of a hurricane is ever fully realized. One reason is that population and buildings are not uniformly distributed with maximum possible density along an exposed coastline. The New York metropolitan area in the northeastern United States comes closest to having a dense population uniformly distributed on a long stretch of a coastal plain. A severe intensity hurricane was simulated to move across the north Texas coastline and make a a direct hit on the Houston metropolitan area. Although about three million people reside there, only a small percentage of the total damage producing potential of the storm would be realized. In general, the realized percentage of a storm's overall damage producing potential depends upon its path relative to populated areas denoted by the density map in Figure $17 \mathrm{~b}$ [15]. 


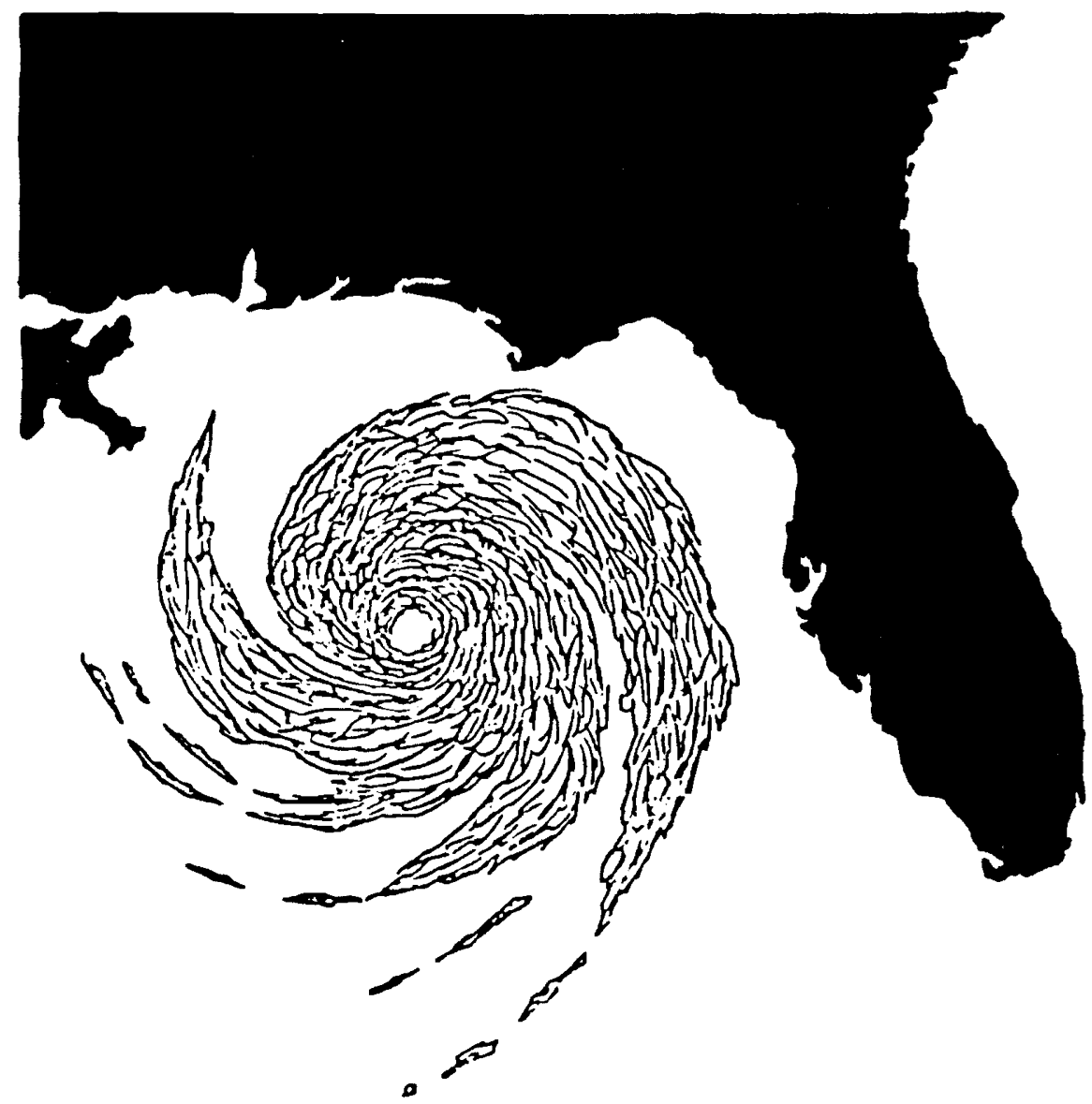

Figure 17 a: Estimation of the relationship between a hurricane's physical intensity and its overall damage producing potential. A series of hurricanes, each with a different intensity, was simulated to move inland across an area with a hypothetical uniform maximum density distribution of buildings and other property.

The combination of storm intensity and track is of major importance in determining level of realized loss potential. Even though a storm's intensity at landfall is held constant along with its size and speed, realized damage potential can vary up to several orders of magnitude by altering the simulated storm's path and landfall location a few tens of miles. The amount of a hurricane's damage producing potential that is realized is highly dependent on the combination of storm intensity and its track relative to populated coastal areas. Realized damage potential of a severe intensity hurricane that moves inland across 


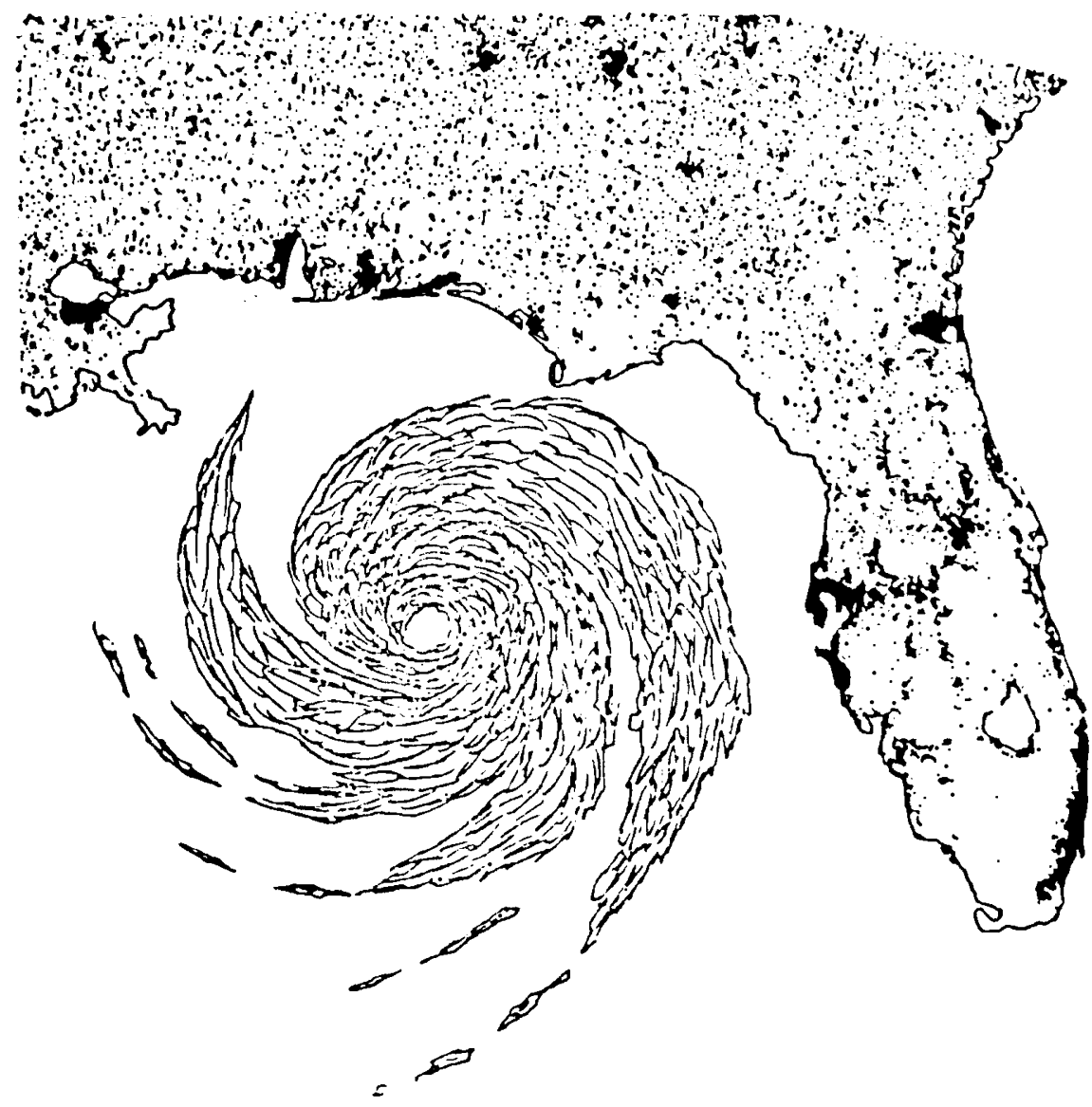

Figure $17 b$ : Estimation of the percentage of a hurricane's total damage producing potential that is actually realized depends upon the particular positioning of the storm's maximum wind pattern on the irregular geographical distribution of population and property represented by darkened areas on the map.

a sparsely populated coastal plain can be less than that of a minimal or moderate intensity storm that makes a direct hit upon a densely populated coastline, Figure 18 . There is not a one-to-one relationship between a storm's intensity and the amount of damage that it actually produces.

Figure 19 illustrates the wide variation in percentage of realized damage potential of simulated hurricanes which have the same physical intensity, but different landfalls. These storms were simulated to move inland from each of a large number of landfall locations 


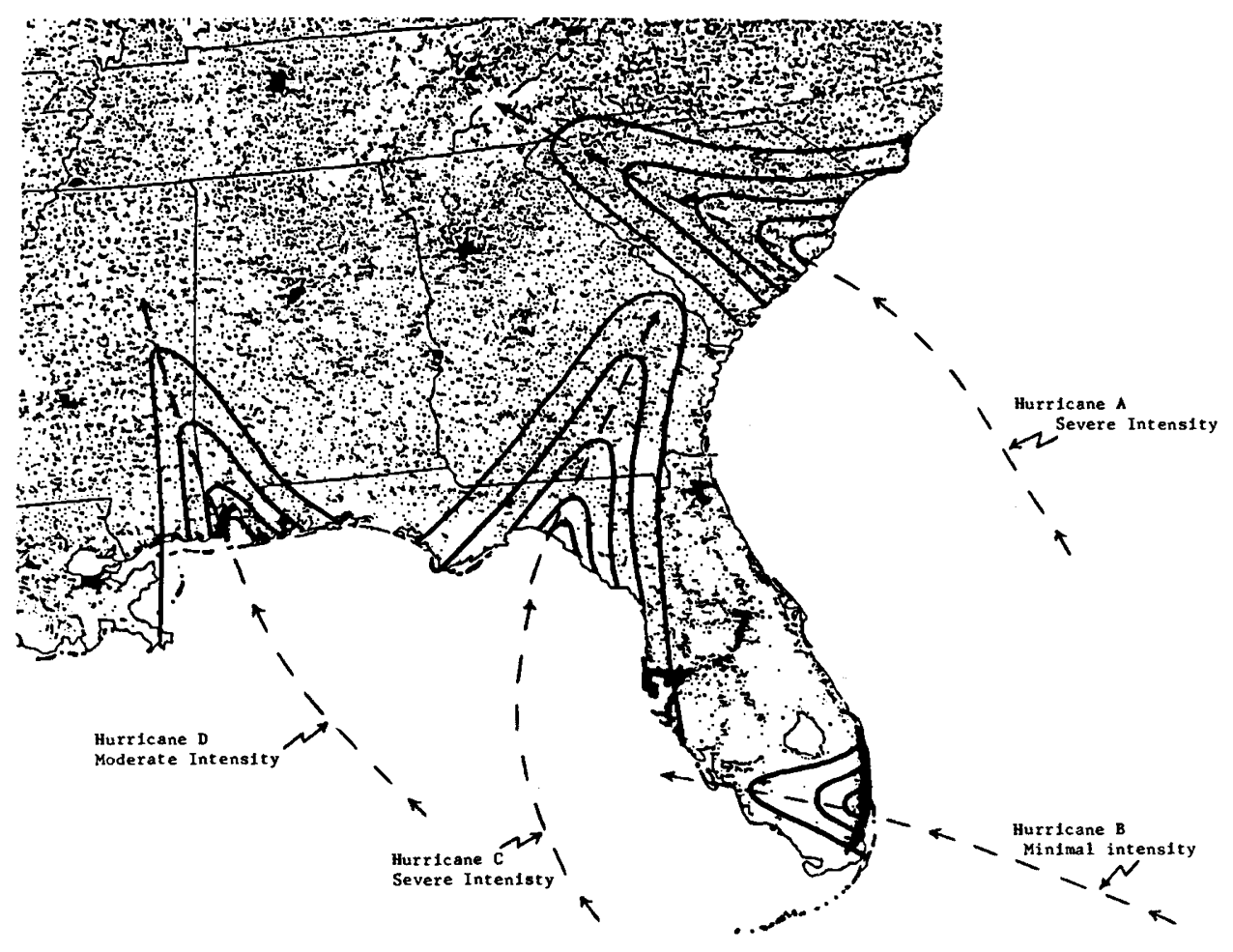

Figure 18: Illustration of the importance of considering the combination of a hurricane's intensity and its track relative to the geographical array of population, and hence buildings, in estimating its impact potential. Severe intensity hurricanes $A$ and $C$ which move inland across sparsely populated coastal regions can have a much lower impact potential than a moderate intensity hurricane (D) that affects a populated coastline or even a minimal intensity storm $(B)$ that moves across a highly urbanized coastal strip.

on the Florida coastline. Length of the arrow represents the relative size of realized potential and orientation of the arrow denotes the direction of storm movement inland. The large variation in realized damage potential in Florida is caused by the geographical distribution and density of population and buildings in Florida. A concentration of population and property along the immediate shoreline markedly increases the impact risk. For example, the high realized damage potential in southeastern Florida is caused by the concentrated strip of urbanized area which hugs the coast from Miami to West Palm Beach. Another area of maximum damage potential occurs on the central coast of western Florida. This is due to the population and building concentration in the Tampa metropolitan area on the Gulf coast. The overall potential for damage production of these 


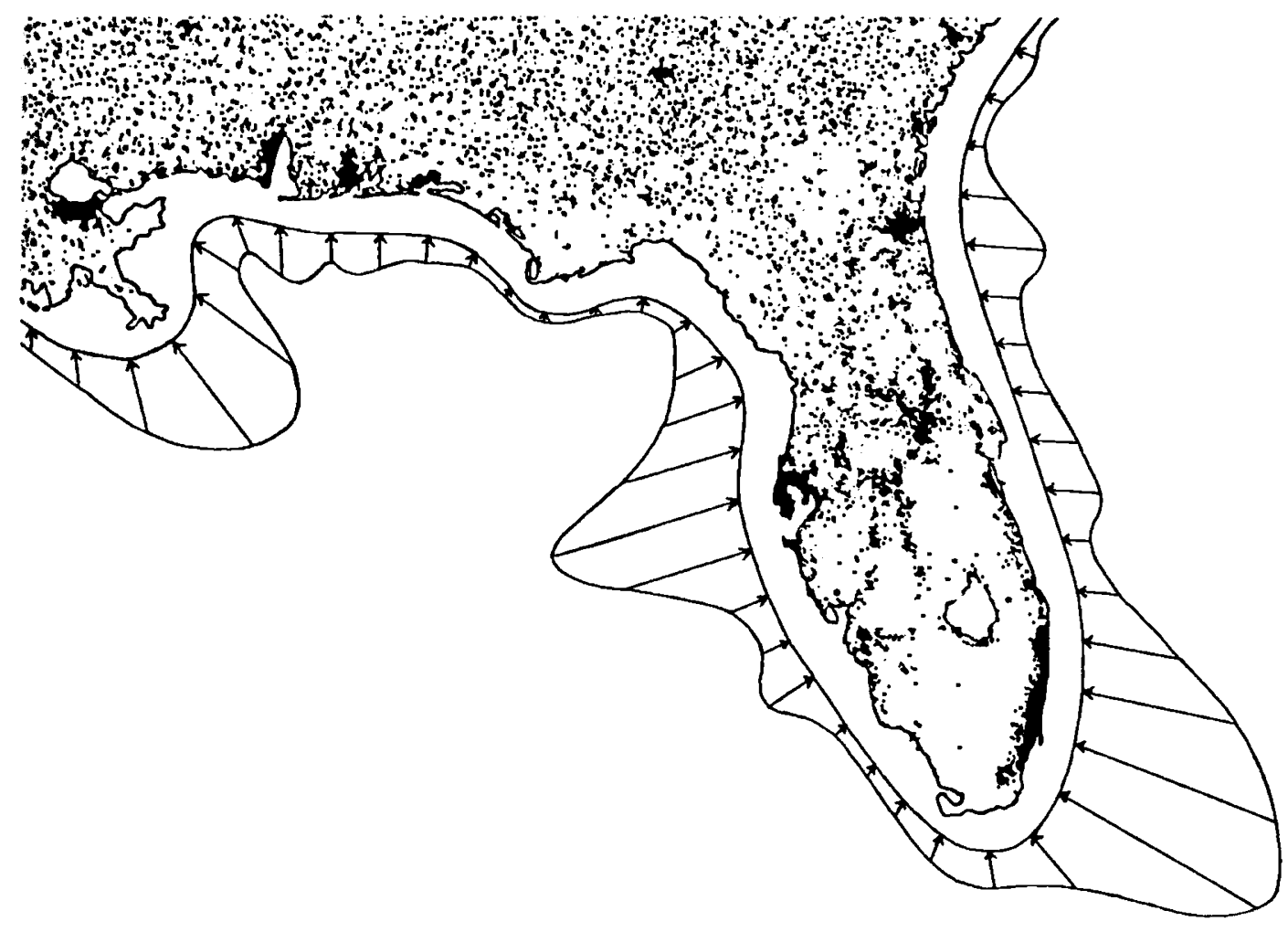

Figure 19: Illustration of the large variation in a hurricane's damage producing potential that can be attributed to its track relative to the spatial array and density of population and buildings when its intensity is held constant. A hurricane of fixed intensity was simulated to move inland, in succession, from each of a large number landfalls in the southeastern United States. The direction of the track is indicated by the arrow. The length of the arrow represents the storm's realized damage producing potential which varies from very low west of the Florida peninsula to very large on its southeastern side where Miami is located.

simulated hurricanes is identical for each landfall location. The "realized" potential varies markedly. If the intensity of the hurricane is changed, the relative length of the arrows would also change.

A natural disaster of great severity will result if, by chance, a severe storm passes over or near a densely populated coastal area. However, the occurrence of a severe intensity hurricane does not always imply that a natural disaster of great severity will result. There is a large range of possible impacts dependent upon various possible combinations of a storm's physical characteristics such as intensity, size, speed and path relative to the 
irregular geographical distribution and vulnerability of exposed coastal towns and cities. Some of these combinations can result in the production of natural disasters.

\section{Use of damage estimates based on chance combinations of intensity and track of past storms}

Damage production of a hurricane is highly dependent upon the interaction of its wind pattern with the spatial arrangement and vulnerability of the elements-at-risk. The combination of intensity and storm track relative to populated areas determines the degree of interaction and hence the portion of a hurricane's overall damage producing potential that is actually realized. There are a multitude of possible combinations of storm intensity and track, each of which could produce a different damage potential.

Chance combinations of intensity and track of the hurricanes that have affected any given region in the historical past represent individual " draws" from the large population of combination possibilities. As a result, sampling difficulties inherent in small sample statistics apply. Consequently, complete dependence upon these chance combinations and their resulting damage production as sole specifiers of the present level of risk from the hurricane hazard can yield misleading indications. The less frequent the occurrence of a hurricane in a particular geographic area, the greater the problem in using a sample of one or a few chance events in the past as a measure of the entire population of present possibilities.

To illustrate this point, past combinations of intensity and storm track have been analyzed in a coastal section of the United States where storm frequency is moderately high. In Figure $4 \mathrm{~b}$, the year 1900 was the most recent time that a major or severe intensity hurricane made a direct hit or near miss upon the Houston, Texas metropolitan area. Since 1900, there have been eight additional storms that moved across the coastline within 100 kilometers on one side or the other of the coastal city. However, the combination of intensity and storm track of each of these storms was such that the calculated damage production to present properties and their current vulnerabilities in Houston from a simulated recurrence was much less than that produced by a repeat of the 1900 Storm.

There is evidence that preferred tracks of hurricanes in some areas are related to storm intensity. Frequency and tracks of minimal, major, severe and extreme intensity storms that occurred over the Gulf of Mexico, Caribbean Sea and the western Atlantic Ocean are shown in Figure 20. An inspection of Figure 20 a suggests that the probability of occurrence of minimal intensity storms is equally likely anywhere along the 200 kilometer section of Texas coastline near Houston. The same is true for major, severe and extreme intensity hurricanes, Figure $20 \mathrm{~b}$. Therefore, the particular combinations of intensity and track of the nine storms that crossed that section of Texas coastline in 1900 or after can be considered to be chance ocurrences within the 200 kilometer strip.

Figure 21 shows the landfall location and track direction of each of these storms. a relative index of damage producing potential to the current properties in the Houston area from a recurrence of each storm was calculated and is plotted. The spatial array and density of exposed property is represented by the dots and darkened areas on the map. A simulated repeat of the 1900 Storm which had a near miss of Houston produced an index of nearly 40 damage units to present elements-at-risk. The 1915 Storm had an index of about 20 units and the seven other storms had indices that were less. 


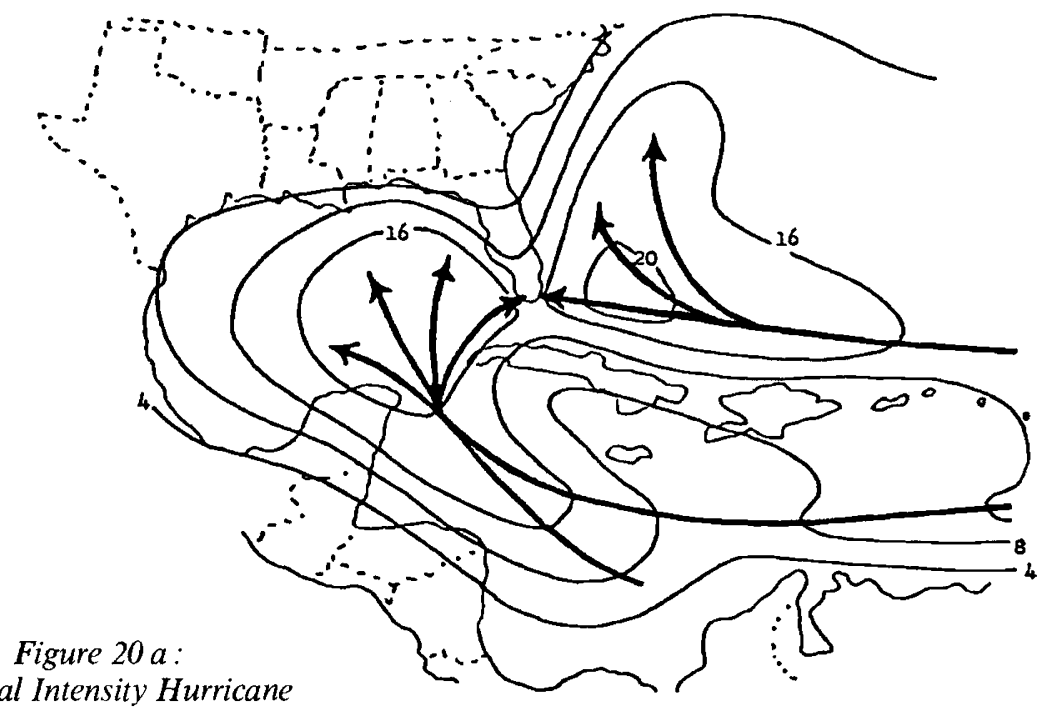

Minimal Intensity Hurricane

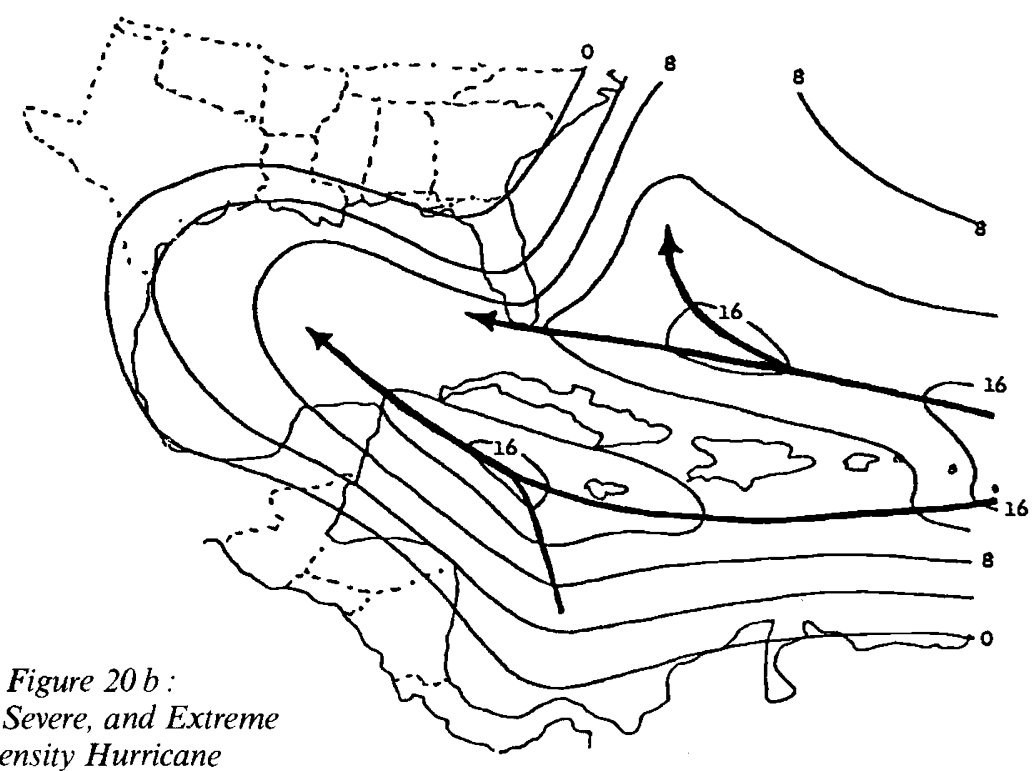

Major, Severe, and Extreme

Intensity Hurricane

Figure 20: Number of times since 1871 that minimal intensity (Figure 20 a) and major, severe, and extreme intensity hurricanes (Figure 20 b) moved through one degree latitude by one degree longitude grids in the Gulf of Mexico, Carribbean Sea and western Atlantic Ocean. 


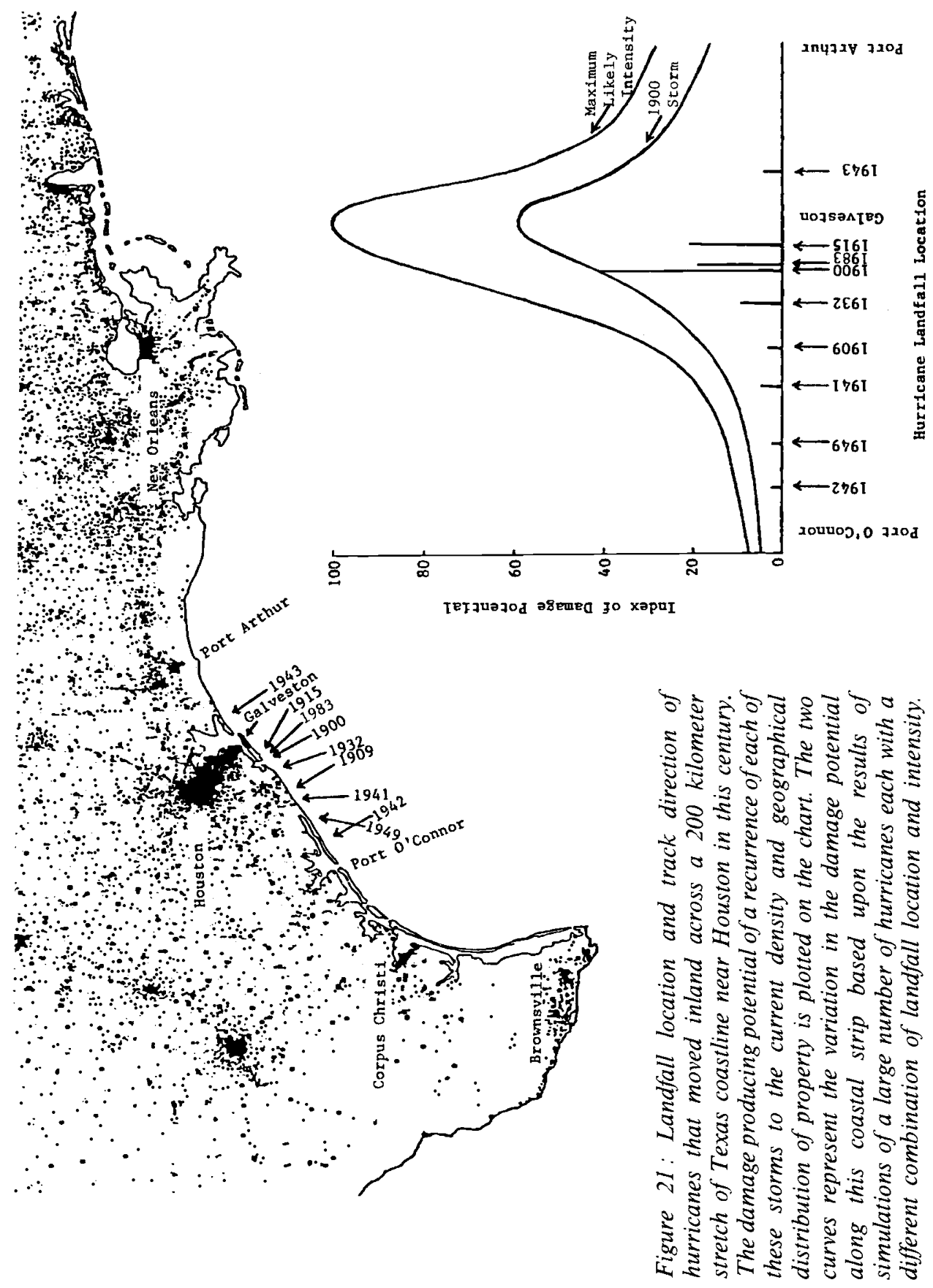


If this were the only information that was available to estimate catastrophe potential, it would be set at about 40 units (equal to that produced by the largest damage producer - the 1900 Storm). However, because the particular intensity and track combinations that occurred with the nine past storms can be taken as chance "drawings" from the large number of possible combinations, damage indexes from other combinations can be considered. Holding the intensity of the 1900 Storm constant, and varying its landfall location in small increments along the 200 kilometer coastal strip, results in a series of simulated damage indexes traced out by the lower curve in Figure 21 . Any one of these combinations is as likely to occur as the one that actually took place. If the track of the 1900 Storm had carried it directly across Galveston and Houston, its damage potential index would have been 60 rather than 40 units. On the other hand, if the same storm had a landfall at the extreme end of the 200 kilometer strip near Port O'Connor, its damage index would have been only about 5 units.

By increasing the 1900 Storm's intensity to maximum likely levels and again allowing landfall location to vary along the strip, the simulated damage indexes of the overlapping wind pattern with the elements-at-risk for each landfall would trace out the upper curve in Figure 21. This optimal combination of intensity and track would produce a damage index of 100 units as a measure of catastrophe potential which would be two and a half times larger than that experienced in Houston by a recurrence of any storm in the 20 th century. These results suggest that the use of the chance combinations of intensity and track of past storms do not always provide a realistic indicator of present risk as measured by catastrophe potential.

The probability of occurrence of moderate (or lesser) intensity hurricanes is much greater than that for the severe or extreme intensity storms that are depicted in the curves in Figure 21. Therefore, storm frequency, intensity and track interactions should be considered when estimating damage impacts. For instance, the more frequent hurricane of lesser intensity that may have a nearly optimal damage producing track can develop a larger damage index than the less frequent but intense storm that happens to move onshore further away from its optimal path. Additional information on present risk to Houston properties can be obtained by comparing the damage index resulting from a recurrence of past storms with the index of other simulated storms which have combinations of intensity and track that did not happen to occur in the historical past, but which are equally likely. Simulated catastrophe potentials depend upon two considerations : the likelihood that a storm of given intensity will move onshore somewhere within the 200 kilometer strip and the probability that its landfall location and track direction will be close to the optimal level of conditions for maximum damage realization.

\section{Approximation of the damage producing potential of the hurricane wind hazard}

One method of examining the usefulness of information, obtained by the conventional use of past damage experience in an insurance program, is to compare the estimated measures of risk (average annual damage and catastrophe potential) with " actual "values derived from an analysis of long-term damage producing expectancies. To illustrate this comparison, southeastern Florida was chosen because over the past century this geographical area has had the highest frequency of hurricane occurrences on the United 
States mainland [3]. This high frequency provides a large sample of past "drawings " of storm intensity and track pairings from the pool of possible combinations. Therefore, this coastal area provides the best chance of obtaining useful information about present risk with the use of past experience. Other coastal segments, where frequency is less, would have a smaller chance of providing this information.

The darkened 200 kilometer long stretch of coastline in southeast Florida on the Figure 22 maps denotes the densely populated area which includes the cities of Miami, Fort Lauderdale, and West Palm Beach where about three and a quarter million people live requiring nearly one and a half million housing units. The convergence of several preferred tracks over southern Florida results in a mixture of storms that affect the area with widely varying combinations of intensity and track. Figure 20 a shows the paths and frequencies of minimal intensity hurricanes and Figure $20 \mathrm{~b}$ gives the same for major, severe and extreme intensity ones. A total of seventy-three storms affected southeast Florida in the 111 -year period beginning in 1871 when systematic recordings of hurricane occurrences were begun [31,32]. Athough information on the characteristics of the earlier hurricanes is not complete, the material that was compiled is assumed to be sufficiently detailed for purposes of this illustration $[5,36]$.

The frequency distribution of the storms by intensity category was as follows :

\begin{tabular}{|c|c|c|c|}
\hline Storm Type & $\begin{array}{l}\text { Intensity } \\
\text { Code }\end{array}$ & $\begin{array}{l}\text { Intensity } \\
\text { Description }\end{array}$ & $\begin{array}{l}\text { Number of storms affecting } \\
\text { southeast Florida between } 1871 \text { and } 1982\end{array}$ \\
\hline Tropical Storm & 0 & Minor & 23 \\
\hline Hurricane & 1 & Minimal & 19 \\
\hline Hurricane & 2 & Moderate & 19 \\
\hline Hurricane & 3 & Major & 6 \\
\hline Hurricane & 4 & Severe & 5 \\
\hline \multirow[t]{2}{*}{ Hurricane } & 5 & Extreme & 1 \\
\hline & & & 73 storms \\
\hline
\end{tabular}

The annual frequency of occurrence varied widely. In nearly sixty percent of the years in the period, no tropical storms or hurricanes occurred. There were six times that stretches of four to six years occurred with no storms. However, in six years, three storms occurred and one year had four:

\begin{tabular}{lc}
$\begin{array}{l}\text { Number of } \\
\text { Occurences } \\
\text { Per year }\end{array}$ & $\begin{array}{c}\text { Number of } \\
\text { Years }\end{array}$ \\
\hline None & 63 \\
One Storm & 32 \\
Two Storms & 9 \\
Three Storms & 6 \\
Four Storms & 1 \\
$\quad$ Total & 111
\end{tabular}



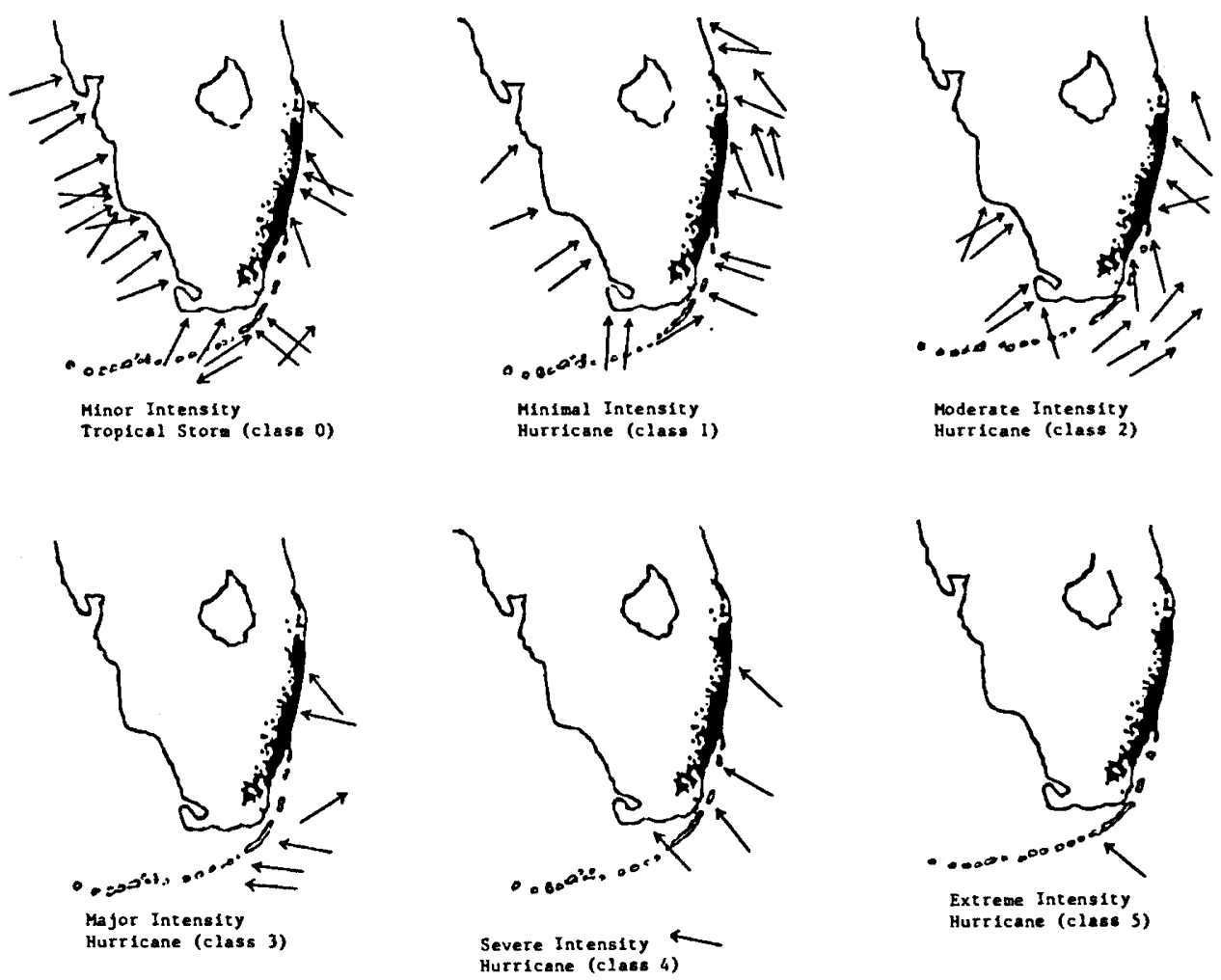

Figure 22 : Landfall location, track direction and physical intensity of seventy-three tropical storms and hurricanes that caused high winds in a 200 kilometer long coastal strip on the southeastern tip of the Florida peninsula during a 111-year period (1871-1982). This strip is a densely populated seashore area with continued rapid growth. Definition of storm intensity categories is given in Table 1.

A plot of the combination of intensity and track for each of these storms is given in Figure 22. Note that in south Florida, landfall and preferred track direction is related to storm intensity. Less intense storms approach from the southwest while the more intense ones come from the southeast. Geographical patterns of maximum wind speed associated with the passage of each of these storms were constructed using available observations and simulation modeling.

A simplified vulnerability relationship was used to convert these patterns of maximum wind speed into ones of damage producing potential : 


\begin{tabular}{cc}
$\begin{array}{c}\text { Maximum wind } \\
\text { peak gust } \\
\text { (kilometers/hour) }\end{array}$ & $\begin{array}{c}\text { Index of } \\
\text { damage } \\
\text { production }\end{array}$ \\
\hline 80 & 40 \\
115 & 110 \\
145 & 370 \\
175 & 1200 \\
210 & 3070 \\
240 & 6130 \\
275 & 10000
\end{tabular}

Recurrence of each of the seventy-three storms was simulated. Interactions of the individual wind patterns with the current properties in the 200-kilometer strip were evaluated and an overall damage index for each storm was obtained. As might be expected, the average damage index increased with an increase in storm intensity. However, because of the chance combinations of intensity and track relative to the 200-kilometer stretch of dense population, there was a wide range in the size of the damage index in each storm intensity category :

\begin{tabular}{lclrrc} 
Storm Type & $\begin{array}{c}\text { Number } \\
\text { of storms }\end{array}$ & $\begin{array}{c}\text { Maximum Winds } \\
\text { in storm } \\
\text { (kilometers/hour) }\end{array}$ & $\begin{array}{c}\text { Average } \\
\text { damage } \\
\text { index }\end{array}$ & $\begin{array}{c}\text { Range in } \\
\text { damage } \\
\text { index }\end{array}$ & $\begin{array}{c}\text { Percent of } \\
\text { total damage } \\
\text { production in } \\
111 \text {-years }\end{array}$ \\
\hline Minor & 23 & less than 145 & 45 & $20-90$ & $3 \%$ \\
Minimal & 19 & $146-175$ & 235 & $20-875$ & 12 \\
Moderate & 19 & $176-210$ & 575 & $25-2555$ & 30 \\
Major & 6 & $211-240$ & 1225 & $100-2930$ & 20 \\
Severe & 5 & $241-275$ & 2010 & $240-6300$ & 35 \\
Extreme & $1{ }^{a}$ & greater than 275 & - & - & - \\
& & & & & $100 \%$
\end{tabular}

${ }^{a}$ Combined with severe storms.

There is considerable overlapping of the ranges of damage index by storm intensity category. For instance, at least one minimal intensity storm had a larger damage index (875) than a severe storm (240) because of differences in their respective combinations of intensity and storm track.

Figure 23 shows the damage index of those storms that made landfall on or near the 200 kilometer strip of properties. The storm intensity code is given for each occurrence. However, it should be noted that the simulated damage index was based upon actual lowest barometric pressure (when available) of each storm, whereas the intensity code denotes only a category with a wide range of possible intensities [27, 28].

The direct hit of the severe intensity 1926 Storm produced the largest index (6300). Calculated damage indices for other combinations of the 1926 Storm intensity and possible landfall positions on the strip trace out the lower curve. The upper one depicts the damage index of the 1926 Storm if its intensity is increased to maximum likely levels [33]. This results in a maximum damage index of 9500 units. If a storm with maximum likely 


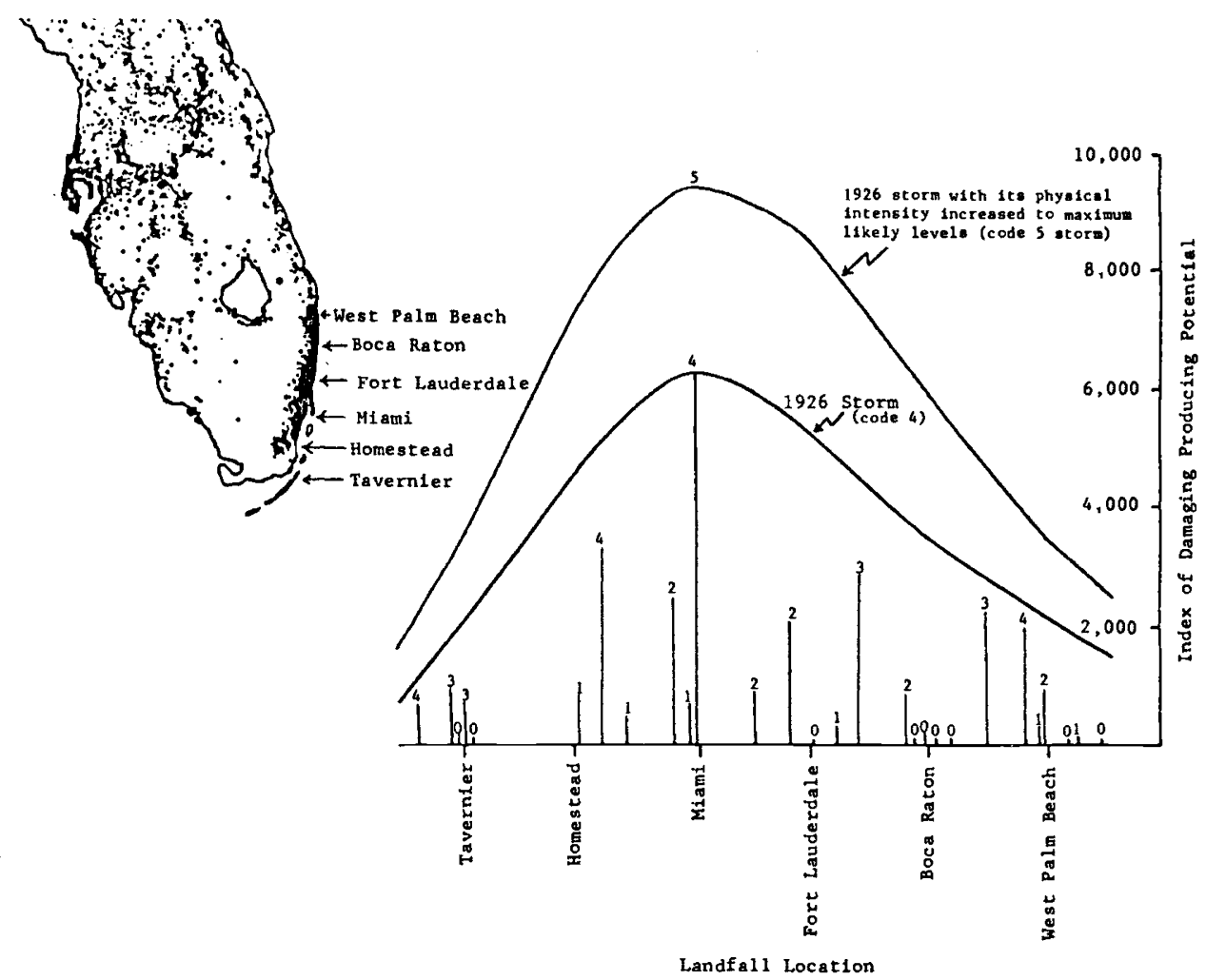

Figure 23 : Index of damage producing potential to current properties on the 200 kilometer coastal strip in southeast Florida. The plotted index values are based on a simulated recurrence of past storms (Figure 22) that made landfall on or near the strip. A physical intensity code (Table 1) for each storm is also given. The 1926 Hurricane had a landfall location that maximized damage potential to the exposed properties in the strip, a direct hit. The lower curve represents the index for this storm if its landfall location is changed and intensity is held constant. The upper curve denotes the index for a storm similar to the one in 1926, but with increased (maximum likely) physical intensity. Benchmark locations on the strip are named and mapped for reference purposes.

intensity were to make landfall near Tavernier and maintain its strength as it moved northward exposing the entire coastal strip to the storm's maximum winds, the damage index would be 12,000 damage units.

The average annual damage (one measure of risk) to the current southeast Florida properties based on the simulated recurrence of the seventy-three storms in the 111-year period is 330 damage units. Catastrophe potential (the second measure of risk) is represented by the largest damage producers : 


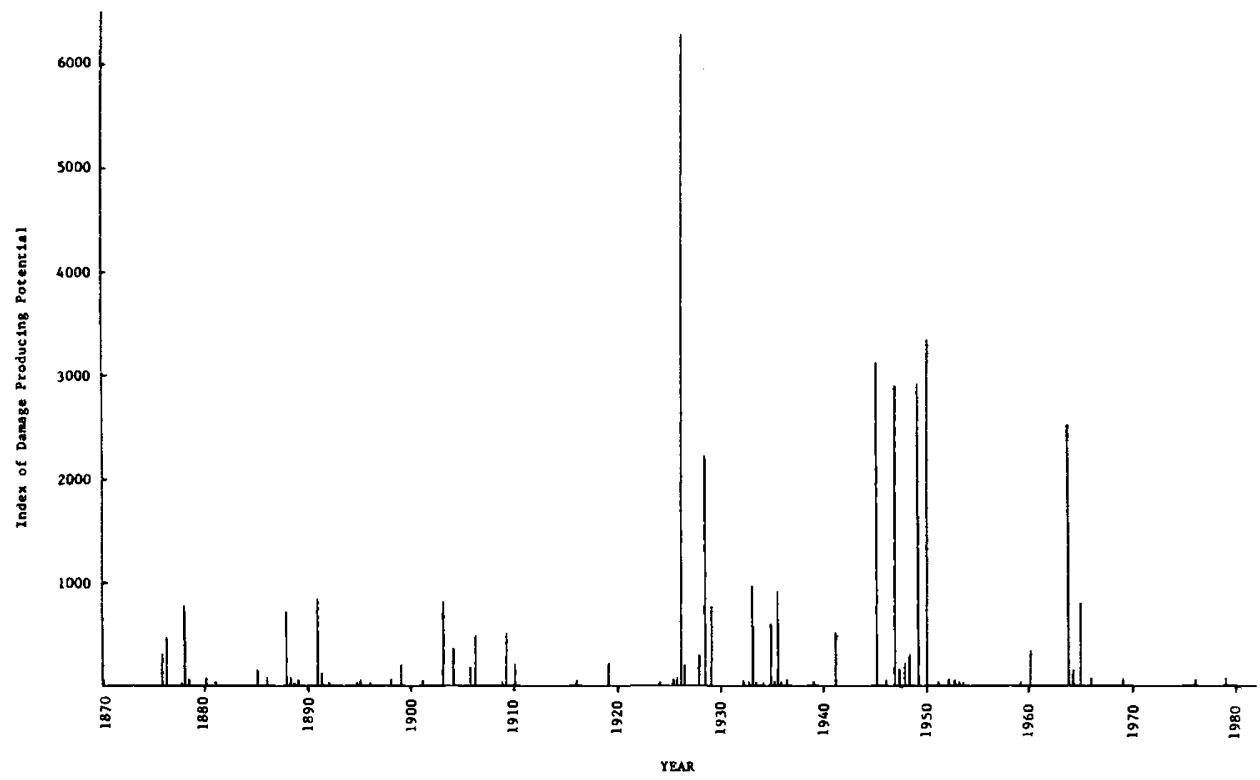

Figure 24: Time sequence of damage producing potentials to the current geographical distribution and vulnerability of property in the 200-kilometer strip in southeast Florida. The potentials are based on a simulated recurrence of each of the seventy-three storms that occurred in the past 111-years. These impacts are plotted in accordance with the original year of the storm's occurrence. Six of the seven largest impact producing events occurred within twenty-five years of one another and were not uniformly distributed throughout the 111-year period.

\begin{tabular}{ccc}
$\begin{array}{c}\text { Rank } \\
\text { of } \\
\text { Storm }\end{array}$ & $\begin{array}{c}\text { Individual Storm } \\
\text { damage index }\end{array}$ & $\begin{array}{c}\text { Cumulative percentage of } \\
\text { total damage produced } \\
\text { in the 111-year period }\end{array}$ \\
\hline 1 & 6300 & 17 \\
2 & 3200 & 26 \\
3 & 2930 & 34 \\
4 & 2550 & 41 \\
5 & 2370 & 48 \\
6 & 2240 & 54 \\
7 & 1950 & 59 \\
8 & 1000 & 62 \\
9 & 940 & 64 \\
10 & 880 & 67
\end{tabular}

Figure 24 is a time sequence of the damage index of each of the seventy-three storms to the current properties in southeast Florida. The largest damage producing hurricanes 
were not uniformly distributed throughout the 111-year period. Six of seven largest impacts occurred within a twenty-five year period. The sequence of damage occurrences shown in Figure 24 is assumed to be a reasonable approximation of the "actual " damage producing character of the hurricane wind hazard in southeast Florida. Estimates of the average annual damage and catastrophe potential using past damage experience of a hypothetical insurance program to cover this hazard will be compared with these " true 'values.

\section{Estimation of average annual loss and catastrophe potential}

It is assumed that there is a single insurance program covering current properties in southeast Florida against the hurricane wind hazard. It is also assumed that the time sequence of actual damage production of the hazard to these properties can be represented by the series given in Figure 24. It is used to depict the loss experience during the "111-year" period that the program is assumed to be in existence. Estimates of the "actual "values of the average annual damage and catastrophe potential can be made using available past experience during each of the one hundred and eleven " years " that the hypothetical program is in operation.

Time variations of the estimate of the "actual " average annual damage are shown in Figure 25 using loss experience measured over the past 5, 10, 20 and 40 year periods. For example, to estimate the average annual damage at the end of the hurricane season in 1970 using a 5-year interval, experience resulting from storm occurrences in the five-year period 1966 to 1970 was averaged and plotted for the year 1970 on the chart. At the end of the next hurricane season in 1971, the estimate was based on the interval for 1967 to 1971 and so forth.

The estimates are expressed as multiples of the "actual " average annual damage of 330 damage units which is based on the entire 111 -year period. The estimate based on a five-year period ending in 1971 would have been only about 0.1 of the "actual "value. At the other extreme, the five-year period ending in 1949 would have yielded an estimate which was 6.2 times greater than the long-term expected value. An inspection of the 5-year chart shows that in most of the years, the actual value is either drastically under or overestimated. The pronounced effect of the chance occurrence or non-occurrence of a highly damaging storm in the short sampling periods is obvious.

When a 10-year averaging period is used, the year-to-year shifts in the estimates are somewhat smaller. Annual variability in the estimates becomes much smaller when longer sampling periods such as 20 or 40 years are used. However, the dilemma, which was pointed out earlier, arises as to whether to use a longer period in order to obtain a representative sampling of damaging storm occurrences or to keep the sample short to minimize the effect of rapid time changes on damage production in the number, type, spatial distribution, and vulnerability of elements-at-risk. In this oversimplified illustration, it is assumed that there are no time changes in the elements-at-risk and vulnerability of southeast Florida properties during the passage of the "111-year" period. In actual practice, the usefulness of unadjusted damage experience based upon longer periods such as 20 or 40 years is severely limited by changes with time of the elements-at-risk and vulnerability. In this illustration, a 10 -year sampling period is chosen as a compromise between long and short sampling periods. 
MULTIFLE ISF ANERTIIE

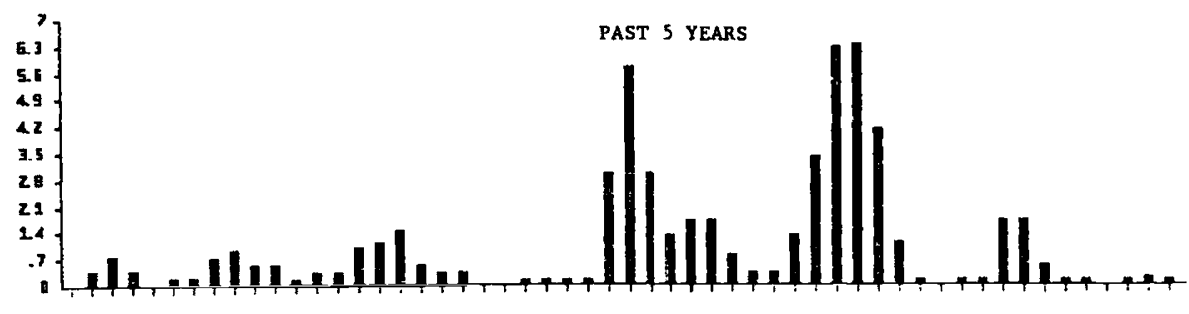

BULTIFLE OF ANERAGE

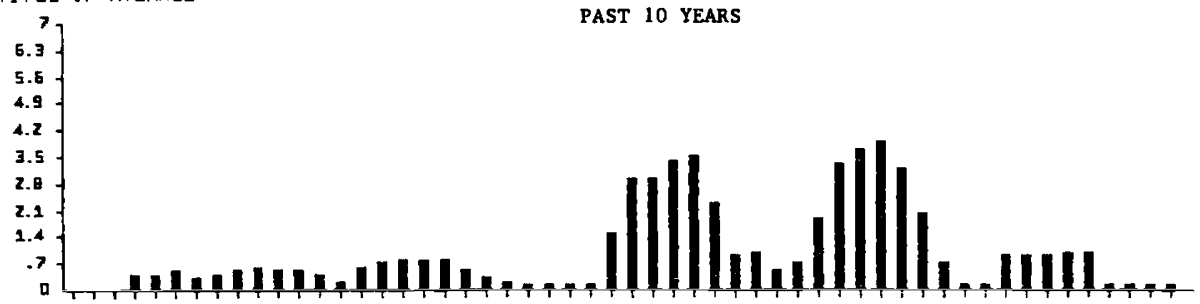

NULTIFLE OF AMERAGE

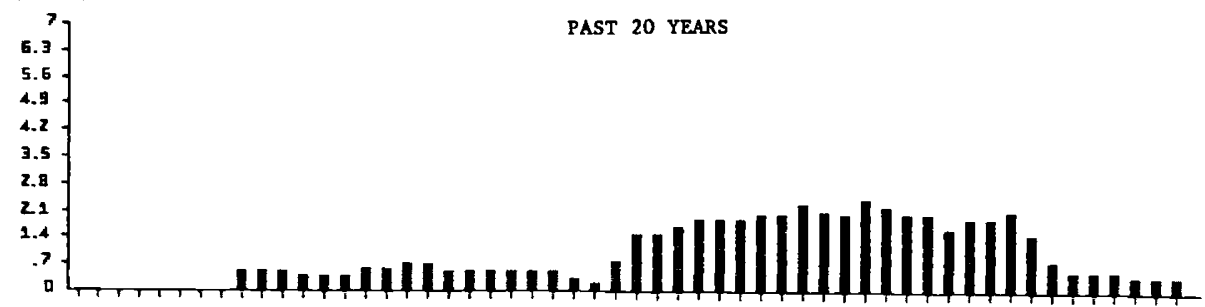

MULTI FLE OF ANEFiGGE

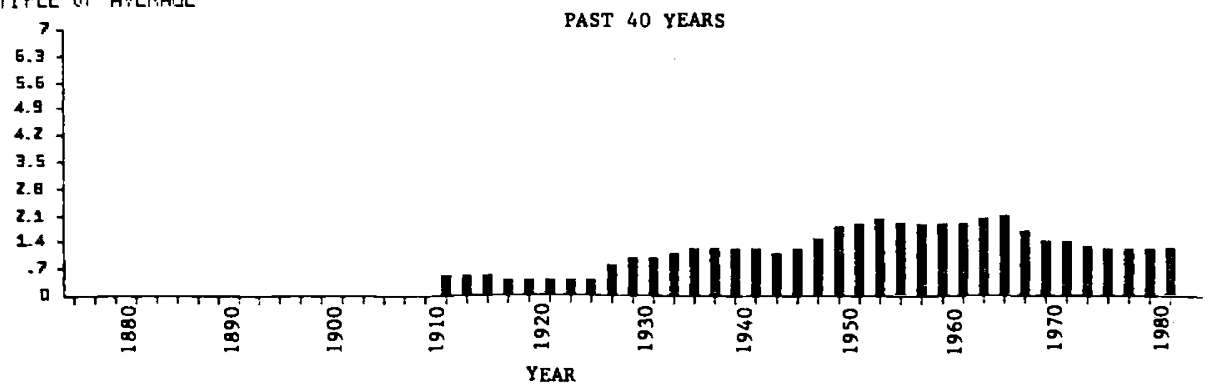

Figure 25 : Illustration of inherent difficulty involved in using damage experience in a short period of past years to estimate long-term average annual damage. A realistic estimate of this risk measure is needed in the management of an insurance program which covers the storm, flood, and/or earthquake perils. Average annual damages to properties based on the past 5 years, 10 years, 20 years, and 40 years are expressed as multiples of the long-term (111 year) average annual damage potential. 

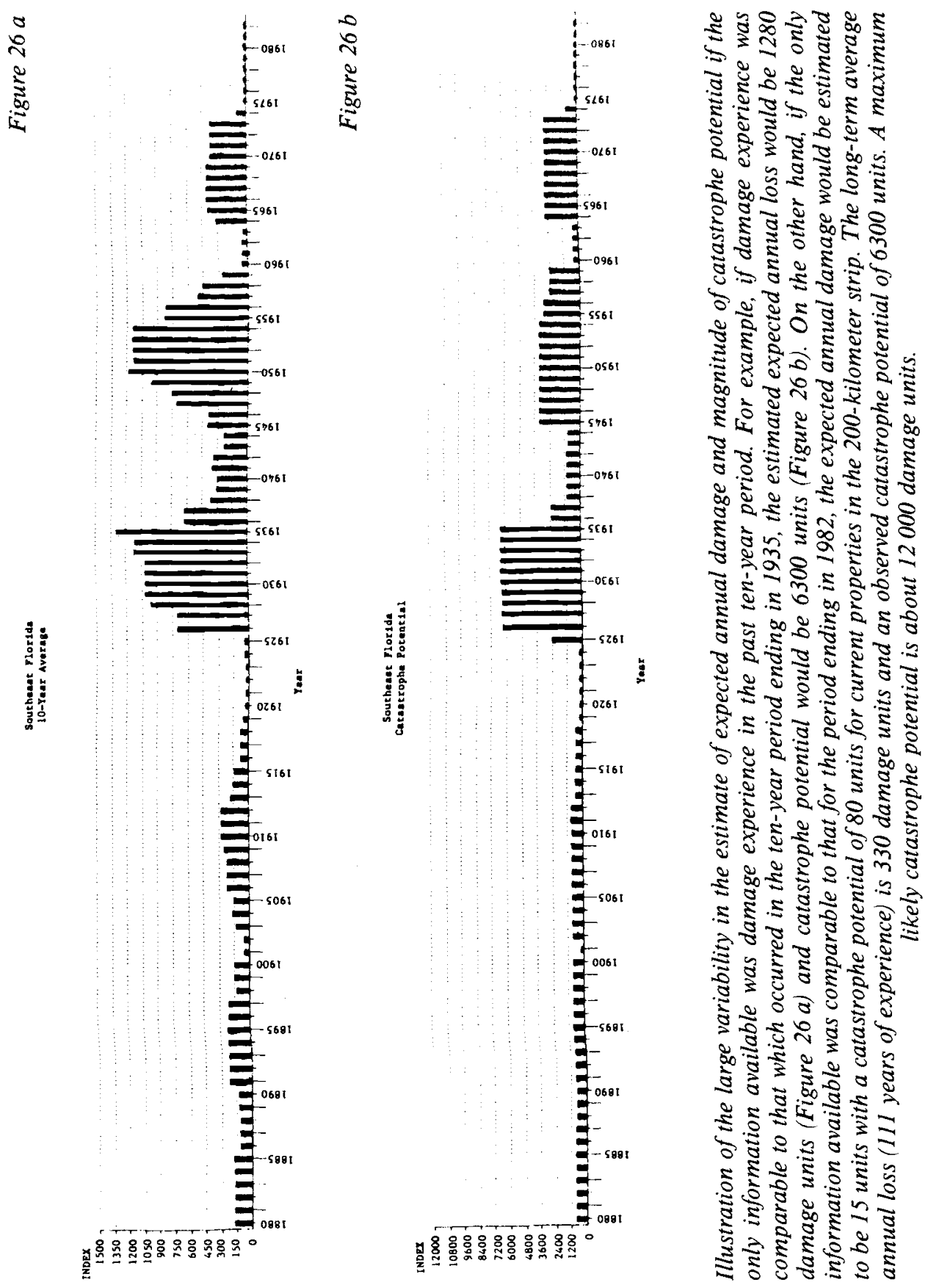
Figure 26 provides a comparison between the estimated and "actual" values of average annual damage expectancy (Figure 26 a) and catastrophe potential (Figure $26 \mathrm{~b}$ ) to current properties in southeast Florida using a 10-year sampling period. Estimates of the actual annual average damage vary from nearly four times too large if experience comparable to that of the mid-1930s is used. The estimates would be over twenty times too low if ten-year experience ending in any of the last eight years since 1975 is used.

Annual estimates of the catastrophe potential using the previous 10-years experience as the criteria would range from 6300 damage units for experience comparable to that incurred by a simulated repeat of the 1926 Storm. At the other extreme, the indicated level of catastrophe potential based on 10-year periods ending in any of the past eight years, since 1975 , would yield an estimate of only 150 damage units. This is more than forty times less than that produced by the simulated recurrence of the 1926 Storm ; sixty times less than the estimated damage production of a hurricane with the 1926 Storm's track and an intensity increased to maximum likely levels; and eighty times less than the maximum likely damage production of 12,000 units by an extreme storm that moves directly northward along the southeast Florida coastline. In about $65 \%$ of the years of the 111-year sample, the estimated magnitude of catastrophe potential, using 10-year intervals of past experience, is at least six times less than that "actually" produced by the 1926 Storm.

These comparisons between estimated and " actual " risk measures suggest that, even in an area with a high frequency of storm occurrences, the use of short periods of past damage experience does not consistently provide representative estimates of risk as given by average annual damage and catastrophe potential. Possible utilization of relationships similar to the examples for Houston and Miami metropolitan areas (Figures 21 and 23) for providing a supplementary insight into natural hazard risk suggests that selected information from the physical sciences can be useful for risk assessments.

Figure 27 provides an additional example of the type of information that can be obtained which is not available in the sole use of past damage statistics. It illustrates the interrelationships of hurricane intensity, frequency and track that must be approximated, either quantitatively of qualitatively, when comparing the relative levels of risk to coastal metropolitan areas from the hurricane wind hazard. In the graph, it is assumed that the optimal track, for maximum damage realization to the spatial configuration of elements-at-risk, is taken by simulated hurricanes that affect the metropolitan areas of New York, Miami and Tampa, Florida. Physical intensity of these storms was varied and an index of relative damage production to elements-at-risk in the metropolitan areas for each intensity setting was computed. For this illustration, it was assumed that the type and vulnerability of elements-at-risk in each of the metropolitan areas was identical. The only difference being their relative numbers and locations relative to the coastline.

It is noted that an extreme intensity storm could produce an index of over 50,000 damage units in New York City. However, the probability of such an event affecting the area is very small because of the city's location on the far northern edge of the frequency pattern and preferred track system of Atlantic hurricanes. Tampa and Miami, Florida, on the other hand, are in the high frequency zone. Refer to Figures 28 and 29. When the probability of storm occurrence is taken into account, a hurricane of only major intensity in New York has about the same probability of occurrence as one of extreme intensity in 


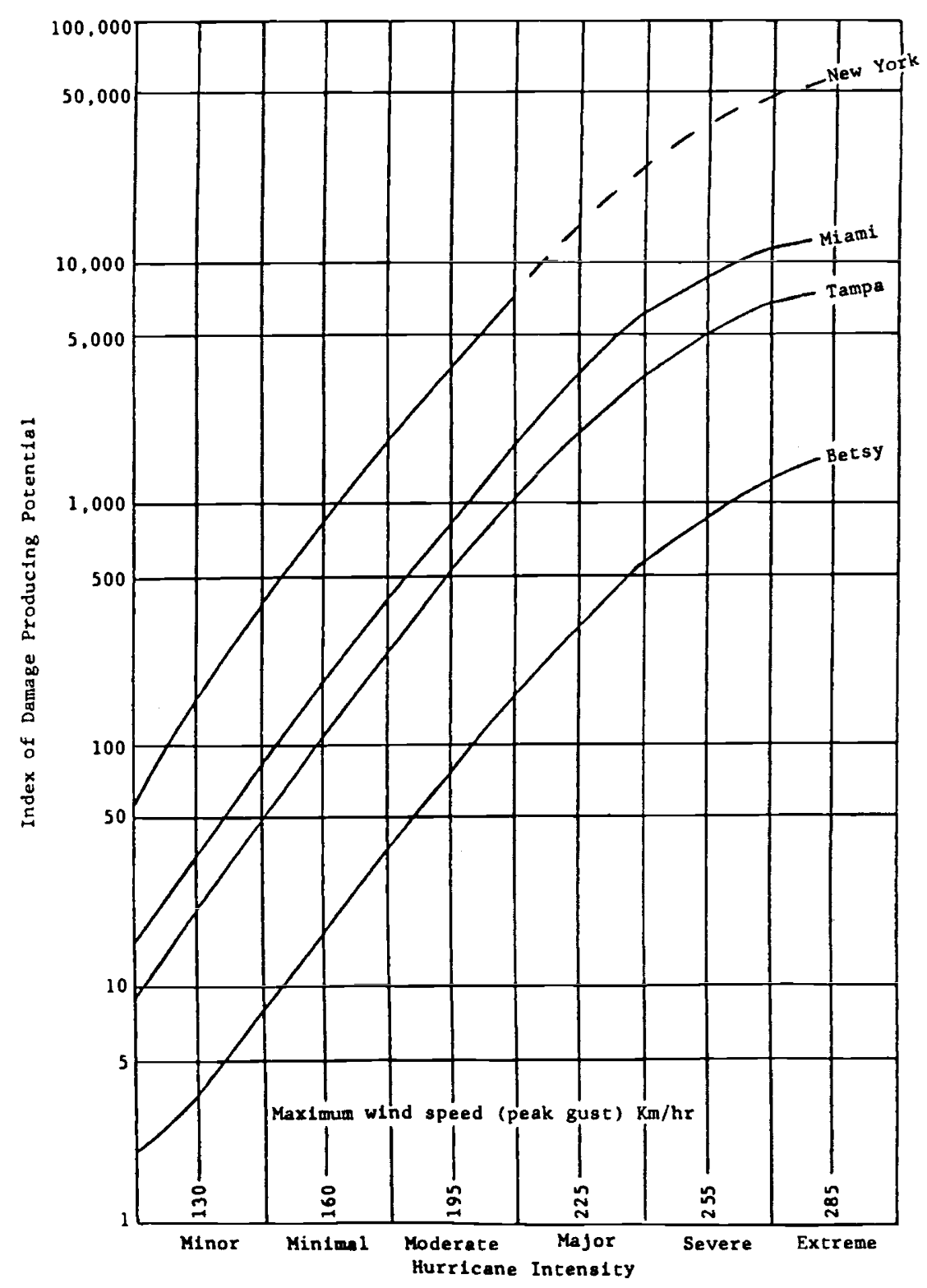

Figure 27: Variation in an index of a hurricane's damage producing potential when the track of the storm, required to make a direct hit on a densely populated coastal area is held constant and physical intensity is allowed to vary. These risk curves have been prepared for all localities on the United States coastline. 


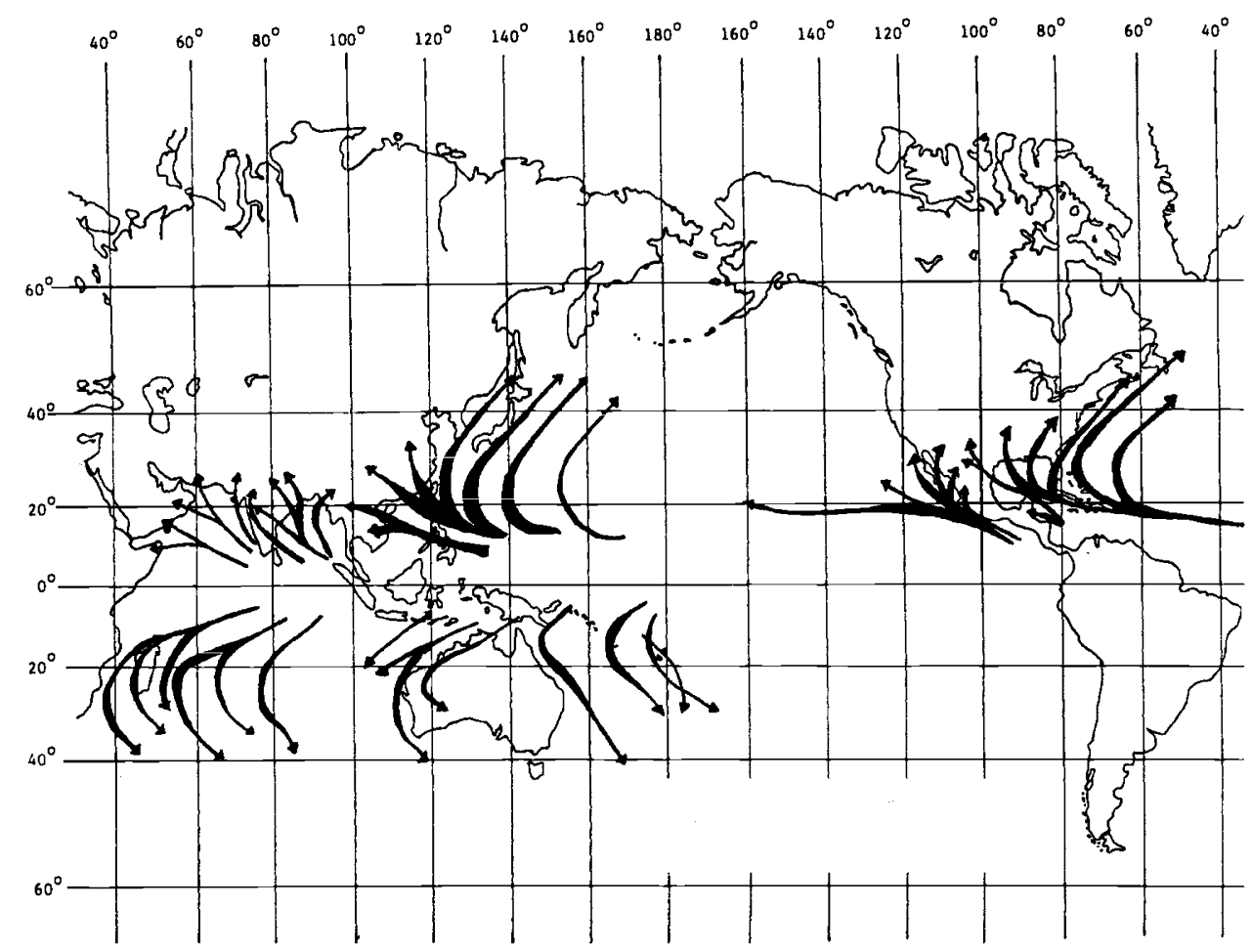

Figure 28: Preferred storm tracks for tropical storms.

Width of the arrow denotes storm frequency [4].

Miami, so that the index of potential damage production could be larger in Miami than in New York at the same level of probability. For reference, the damage producing potential of Hurricane Betsy, that severely affected the New Orleans, Louisiana area, in 1965 also is plotted based upon its actual intensity, landfall location and path direction relative to metropolitan New Orleans. A shift in its track of a few tens of miles would have optimized the wind damage production potential and increased its damage index.

\section{Estimation of the combined hurricane wind and flood risk.}

It may be desirable in an insurance program to reduce the large year-to-year fluctuations in damage production resulting from the coverage of only one natural hazard. One method might be to cover additional natural perils whose events occur independently of the already insured hazard. In the discussion of the hurricane wind hazard, a possible extension could be a joint coverage of both the wind and flood hazards caused by hurricanes. 


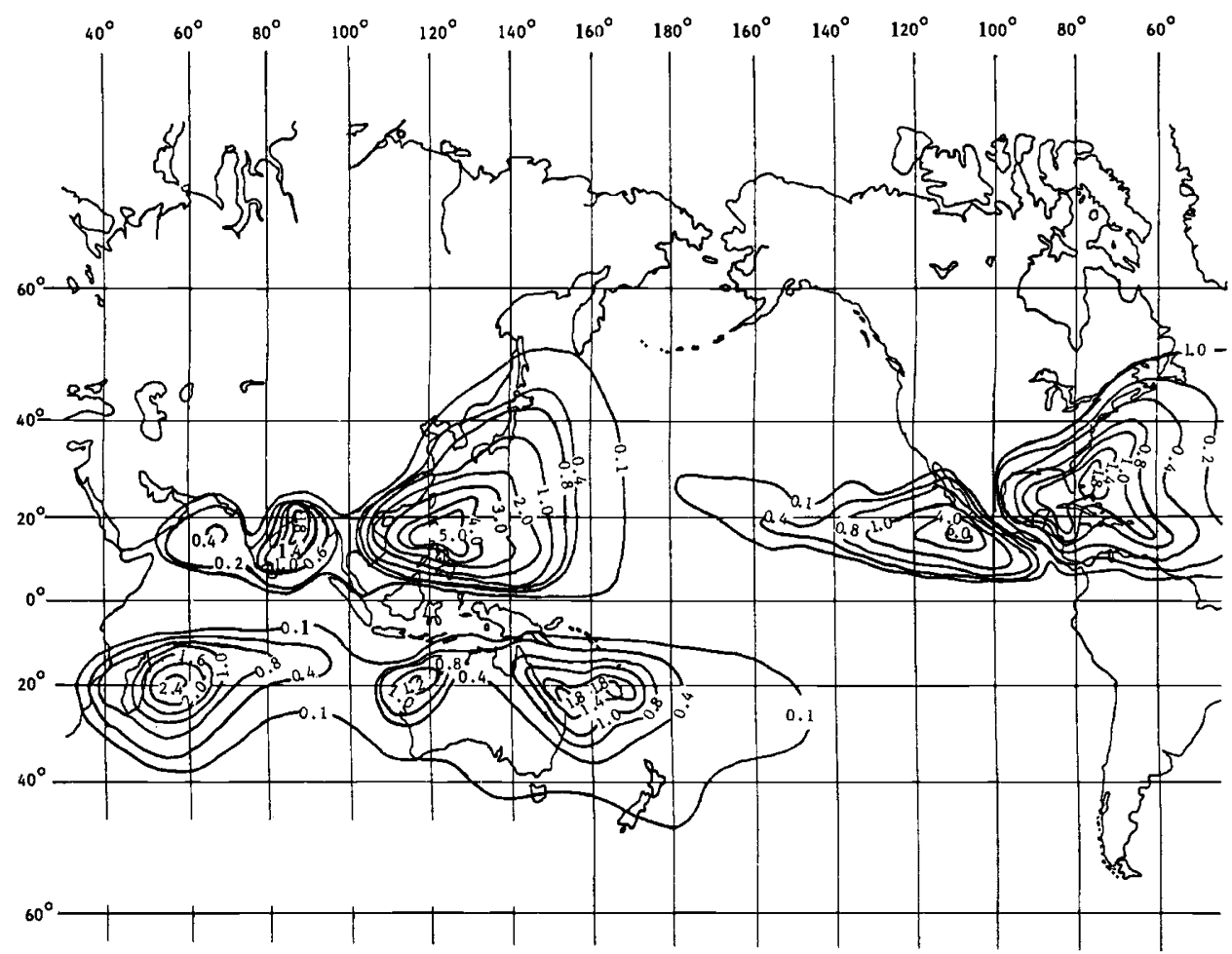

Figure 29: Average annual number of tropical cyclones per five degree grid area.

Unfortunately there is sufficient dependence between the occurrence of damages caused by the hurricane wind and flood hazards for the same difficulties to arise when short periods of past experience are used to make risk assessments of these combined hazards. Figure 30 shows the relationship between a storm's physical intensity and its resultant total (insured and non-insured) damage production caused by hurricane winds and floods in the United States. It is based upon information given in Figure 4 a with damages expressed in 1983 dollars. An inspection of the chart suggests that there is a relationship between a storm's intensity and resultant damage, namely :

\begin{tabular}{lc}
$\begin{array}{l}\text { Storm } \\
\text { Intensity }\end{array}$ & \multicolumn{1}{c}{$\begin{array}{c}\text { Median damage } \\
(1983 \text { dollars })\end{array}$} \\
\hline Minor & 5 million (extrapolated) \\
Minimal & 15 million \\
Moderate & 55 million \\
Major & 200 million \\
Severe & 700 million \\
Extreme & 2500 million (extrapolated)
\end{tabular}




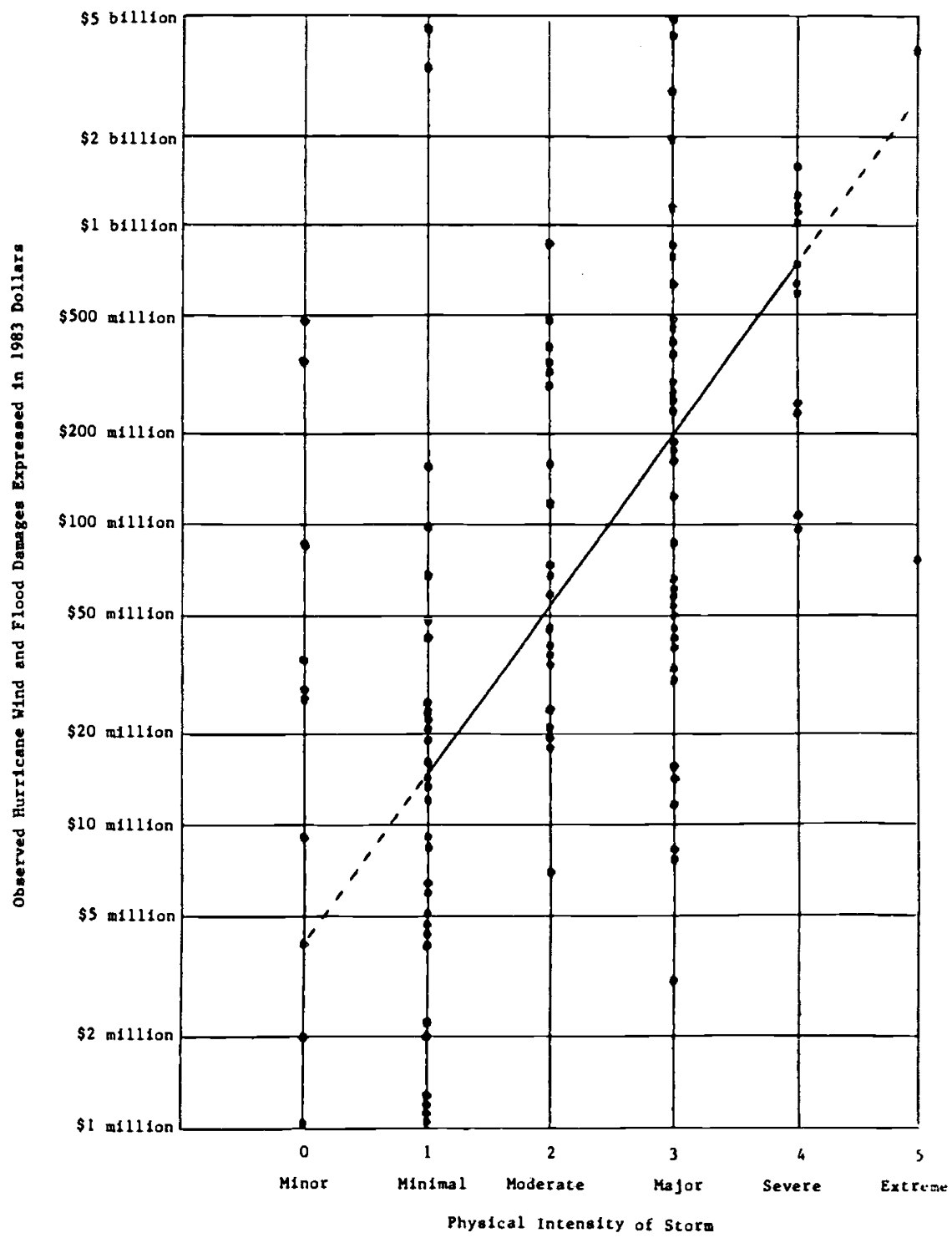

Figure 30: Relationship between a hurricane's physical intensity and its resultant total (insured and non-insured) damage production caused by the wind and flood perils. This chart is based on information in Figure 4 a with damages expressed in terms of 1983 dollars. The physical intensity of the storm is held constant and variation in actual damages depends upon the track of the hurricane relative to the spatial array of exposed properties and other physical characteristics. 
There is, however, a large variation in damage amounts about these median values. One reason is the chance overlapping of the geographical severity patterns of flood and wind upon the spatial arrays of the elements-at-risk resulting in the actually realized damage production. This effect was discussed earlier. The second reason for the large variation is that total rainfall caused by a hurricane is not closely related to the storm's physical intensity. Note, for example, that a number of tropical storms (minor intensity) and minimal intensity hurricanes caused excessively large amounts of damage. A substantial portion of these losses can be attributed to rain-induced floods and not wind or coastal inundation due to storm surge.

\section{Risk assessment of the storm surge hazard}

Flooding caused by a tropical storm or hurricane can be separated into two categories : rain-induced floods and coastal floods, including wave wash effects, caused by the storm surge. A storm surge is defined as an increase in water level above normal tidal action, associated with storm conditions which can cause coastal flooding. Along the Gulf and lower eastern coastline of the United States, a storm surge usually accompanies the passage of a hurricane. Further north along the coast, winter storms are the most likely cause. It may be as small as 1 to 2 feet above normal tide levels or may exceed 20 feet as happened when Hurricane Camille moved across the Mississippi coastline in 1969. Storm-surge caused damages exceed wind-caused losses in many hurricanes. The depth of the hurricane surge, as it sometimes is called, is closely dependent upon a storm's intensity and a complicated set of interactions between the path, intensity, speed, and size of the hurricane with sea bottom and coastline configurations [25]. Local conditions can cause a variation in surge depth of a number of feet within a distance of only a few miles.

Determination of those elements-at-risk, that are exposed to coastal flooding, is based on their location relative to ocean linked bodies of water such as bays, estuaries, rivers as well as direct contact with the seacoast. Elevation above sea level and intervening topography are also important considerations. Possible mitigation practices to reduce the impact of the storm surge hazard are strictly enforced coastal land use and building codes, protective barriers, construction procedures such as the use of stilts. Use of some of these mitigating procedures could be incorporated into the type and price of an insurance coverage.

Table 7: Vulnerability of elements-at-risk in an affected coastal area expressed as the percentage of insured value of the structure which is lost (damaged).

\begin{tabular}{cccc}
\hline $\begin{array}{c}\text { Average Storm } \\
\text { Surge Depth } \\
\text { (meters) }\end{array}$ & $\begin{array}{c}\text { Single-unit } \\
\text { Residential } \\
\text { Buildings }\end{array}$ & $\begin{array}{c}\text { Other } \\
\text { Residential } \\
\text { Buildings }\end{array}$ & $\begin{array}{c}\text { Non-residential } \\
\text { Buildings }\end{array}$ \\
\hline .3 & $18.0 \%$ & $9.0 \%$ & $4.5 \%$ \\
.9 & 40.0 & 20.0 & 7.3 \\
1.5 & 56.0 & 28.0 & 9.3 \\
2.1 & 72.0 & 36.0 & 11.0 \\
2.7 & 86.0 & 43.0 & 12.3 \\
3.4 & 100.0 & 50.0 & 13.6 \\
\hline
\end{tabular}


Vulnerability relationships are composed of two parts for buildings. First, the percentage of the total number of buildings in an exposed coastal area that would be affected by the storm surge is based upon relationships between computed maximum surge depth, mean high water, distance to open water, land character, coastline configuration and elevation of the coastal area and building location. The second part is the "most likely" amount of damage when a building is affected. Measures of flooding severity, in this case, the depth of water and if there is wave action. Table 7 shows the variation in vulnerability by type of elements-at-risk.

For vulnerability of population, the percentage of the number of people affected in a coastal area is based on the assumption that evacuation did not take place :

\begin{tabular}{ccc}
$\begin{array}{c}\text { Average } \\
\text { Storm Surge } \\
\text { Depth (meters) }\end{array}$ & \multicolumn{2}{c}{$\begin{array}{c}\text { Ratio of Casualties } \\
\text { to Number of Persons } \\
\text { in Affected Coastal Area }\end{array}$} \\
\hline .3 & l per & 100,000 \\
2.1 & 1 per & 10,000 \\
4.3 & 1 per & 1,000 \\
6.1 & 1 per & 100 \\
7.6 & 1 per & 10
\end{tabular}

Figure 31 shows the computed pattern of storm surge depth produced by a simulated hurricane. Using this method, an analysis of the "realized" damage production caused by the storm surge (similar to that which is illustrated for the wind hazard in Figure 19) has been made. Damage potential was calculated for closely spaced landfalls on the 5000-kilometer coastline of the United States bordering the Gulf of Mexico and Atlantic Ocean for storms of a number of different intensities.

A wide variation in realized damage production was noted as with the wind hazard but the spatial patterns were not the same because of differences in the locations of exposed elements-at-risk, their vulnerabilities and physical characteristics, such as local offshore seabottom conditions, that can modify the severity of the coastal flooding event. However, the dependence of both wind and storm surge on a hurricane's physical intensity tends to emphasize the general correlation of damage production of these two hazards. Two important natural hazards that are usually independent of one another are earthquakes and hurricanes so that occurrences of their events do not necessarily coincide and the magnitudes of their catastrophe potential are not automatically additive.

\section{Risk assessment of the earthquake hazard}

An assessment of risk in an insurance program that covers the earthquake hazard is dependent upon the same factors that were discussed in connection with the hurricane wind hazard; namely, physical characteristics of the event, local conditions that can modify the event's severity, type and geographical distribution of the elements-at-risk, and their vulnerability to damage or loss when an event of given severity occurs [10].

Figure 32 shows the simulated ground motion severity pattern of an earthquake in southern California for a particular type of structure when the effect of local ground conditions and ground motion frequency are included. Various types of structures are 


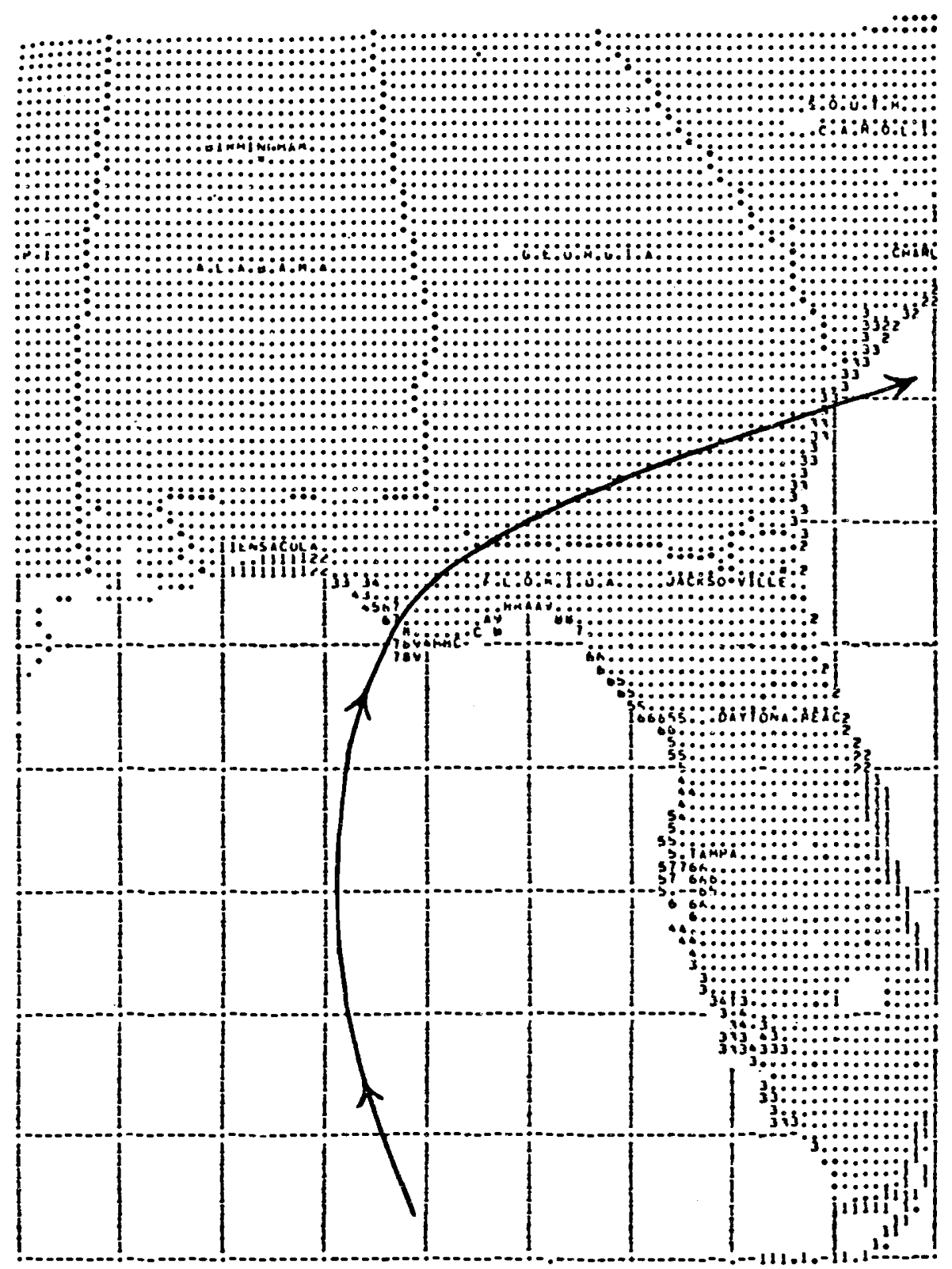

Figure 31 : Computed pattern of storm surge depths above sea level measured in feet (0.3 meter) associated with a simulated northward moving hurricane which skirts the western coast of Florida and makes landfall on the Florida panhandle. 


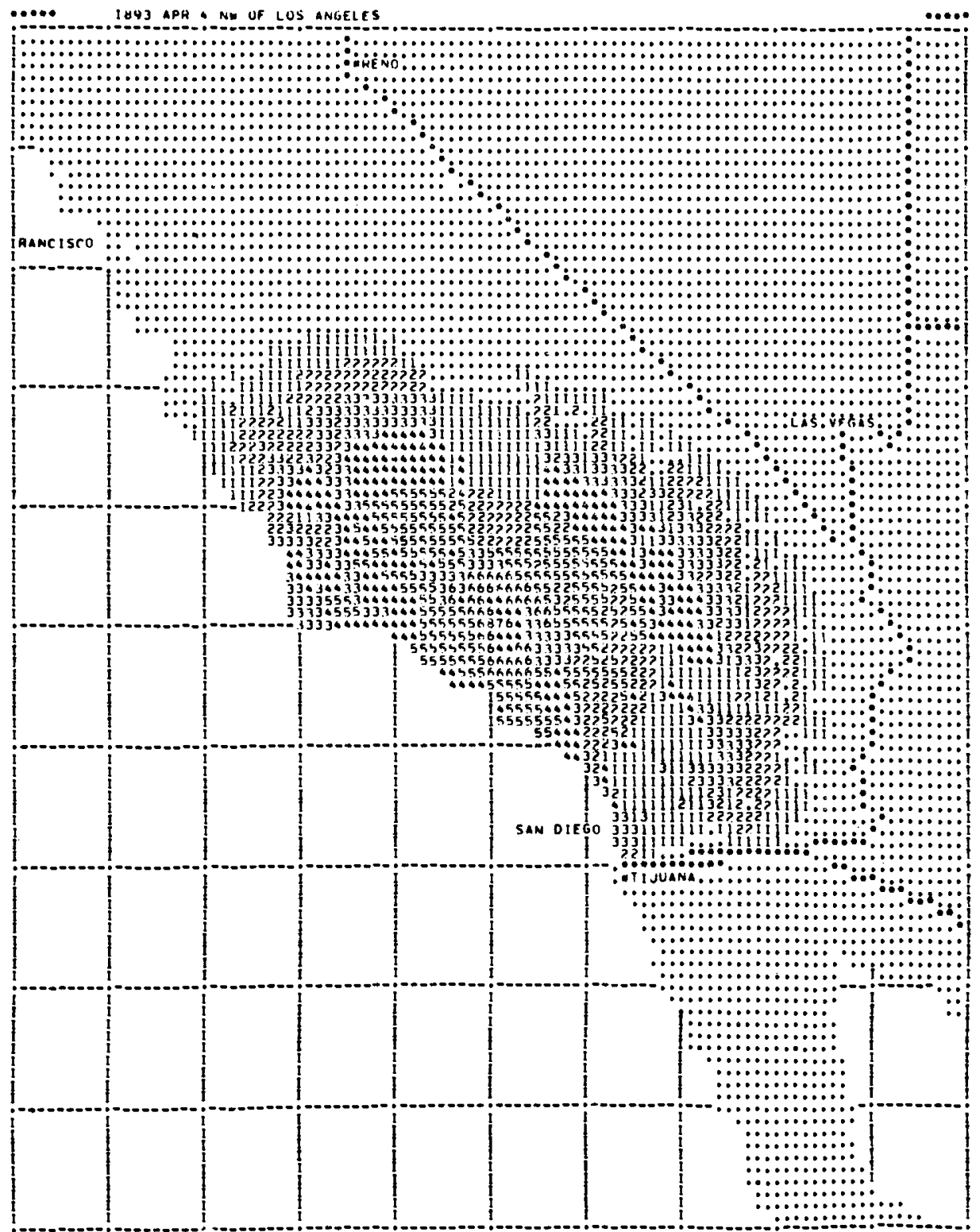

Figure 32 : Ground motion severity, expressed in Modified Mercalli Units, of the simulated recurrence of an 1893 earthquake near Los Angeles based on, the combination of earthquake magnitude and epicenter location. Effect of local ground conditions on ground motion severity is included. Richter magnitude was estimated at 6.3. 
tuned to different frequencies of ground motion. Because of the uniqueness of features of individual geophysical events, such as hurricanes, floods or earthquakes, it is not possible to exactly duplicate observed severity patterns using a computer derived approximation. The rationale for using the mathematical approximation is that it can be made to represent inherent physical consistencies and constraints on pattern size, shape, contour spacing and overall levels of severity which are determined by the geophysical event's intensity. For example, there are consistencies in the severity patterns of all Richter magnitude 5 earthquakes that distinguish them, for example, from the patterns of Richter 7 magnitude earthquakes. In a statistical sense, the calculated patterns of the earthquake's ground motion represent the "expected value" of motion at each given affected location. The simulated pattern will not compare in all aspects with the observed ground motion severity patterns for any given earthquake. However, if severity patterns of a number of earthquakes of identical physical characteristics were available and a composite of them was constructed, the pattern generated by the model would provide a reasonable approximation of the averaged one.

To establish a relationship between an earthquake's magnitude on a physical scale and its overall damage producing potential, a series of earthquakes (each with a different Richter magnitude) was simulated to occur in an area in which a uniform distribution of property of maximum possible density was exposed. A comparison of results indicates that the damage index increases more rapidly with a change in the physical intensity of an earthquake than does a wind damage index due to an increase of a hurricane's physical intensity.

\begin{tabular}{cc}
$\begin{array}{c}\text { Earthquake Magnitude } \\
\text { (Richter Scale) }\end{array}$ & $\begin{array}{c}\text { Index of Overall } \\
\text { Damage Production }\end{array}$ \\
\hline 5 & 1 \\
6 & 30 \\
7 & 260 \\
8 & 1000
\end{tabular}

Overall casualty and damage impact potential of an earthquake depends upon its magnitude. The Richter scale provides an approximate single parameter measure of overall loss producing potential when it is assumed that the populations-at-risk are uniformly distributed with maximum possible density in the affected area. However a combination of measures such as stress drop, seismic moment, type and rate of faulting, and the directional radiation of seismic waves may in the future provide a better indication of an earthquake's total damage producing potential than is obtained by the current use of its Richter magnitude. The estimated overall damage potential increases disproportionately as Richter magnitude of the earthquake is increased. Reasons for this nonlinear tendency include the fact that the magnitude scale is logarithmic; the geographic area affected by strong ground motion usually increases rapidly with an increase in the earthquake's magnitude ; and vulnerability relationships between building damage and the intensity and duration of strong ground motion are nonlinear in form.

As with hurricanes, the haphazard spatial distribution of population and structures causes the production of a disaster to be a complicated resultant of the overlapping of the earthquake's severity pattern with the geographic spread of these populations-at-risk. The 
percentage of total loss potential of a given geophysical event that is actually realized is directly related to this overlapping process [18]. Most earthquakes do not result in the production of a natural disaster for two reasons. First, the magnitude is not sufficiently large to produce potentially damaging ground motions. Second, if the damage producing threshold is exceeded, the epicenter location is not near enough to populated areas for the damage potential to be significantly realized.

A comparison of the estimated and " actual " average annual damage to dwellings in the city of San Francisco due to the earthquake hazard was obtained by a simulation analysis of the damage producing potential to current dwellings caused by a recurrence of eighty earthquakes that affected the area in the 170 year period between 1800 and 1969 [8].

To estimate the "actuai " level of average annual damage in an insurance program to cover the earthquake hazard, the "past" 20-years of damage experience was used:

\begin{tabular}{ccc} 
20-year Period & 1828 & $\begin{array}{c}\text { Relative size of the } \\
\text { estimated average annual } \\
\text { damage as a multiple of } \\
\text { the "actual " long-term value }\end{array}$ \\
\hline $1808-1827$ & 1848 & 33 times smaller \\
$1828-1847$ & 1868 & 2 times greater \\
$1848-1867$ & 1888 & 2 times smaller \\
$1868-1887$ & 1908 & equal \\
$1888-1907$ & 1928 & 4 times greater \\
$1908-1927$ & 1948 & 12 times smaller \\
$1928-1947$ & 1968 & 66 times smaller \\
$1948-1967$ & 5 times smaller
\end{tabular}

In the estimation of catastrophe potential, nearly eighty-five percent of the total simulated damage in the 170-year period was attributable to four earthquakes:

\begin{tabular}{|c|c|}
\hline & $\begin{array}{c}\text { Percentage of total damage } \\
\text { production in } 170 \text {-year period }\end{array}$ \\
\hline 1906 Earthquake & $33 \%$ \\
\hline 1838 Earthquake & 21 \\
\hline 1868 Earthquake & 17 \\
\hline 1836 Earthquake & 13 \\
\hline & $84 \%$ \\
\hline
\end{tabular}

These simulated catastrophe potentials can be expressed as multiples of the long-term (" actual ") average annual damage :

1906 Earthquake

1838 Earthquake

1868 Earthquake

1836 Earthquake
Multiple of " actual" average annual damage

73 times greater

40 times greater

19 times greater

10 times greater 
An alternative explanation is that it would take a period of seventy-three years for the average annual damage to accumulate and equal the losses incurred in a single event - the 1906 San Francisco Earthquake. The combination of event magnitude and location relative to populated areas is as important for earthquake damage production as is the combination of storm intensity and track for hurricane wind damage production. However, for larger earthquakes, there is less randomness in the possible combinations of earthquake intensity and location as compared with chance combinations discussed in connection with the hurricane wind hazard. Larger earthquakes usually occur only in fault zones and magnitude of the next event may be related to the length of the time period since the last large one occurred.

Risk assessment of the earthquake hazard for an insurance program can be aided by use of relationships derived from information from sources other than past damage experience. Figure 33 is an example based upon the simulated recurrence of past earthquakes that had various combinations of magnitude and distance from the center of downtown Los Angeles. The casualty producing potential of an earthquake is a function of, among other variables, its magnitude and location relative to populated areas. The impact of the recurrence of the forty-four earthquakes that affected the Los Angeles metropolitan area since 1769 and had an estimated Richter magnitude of 5 or greater was simulated to illustrate the relationships. In these simulations, impact was based on the geographical distribution of the elements-at-risk (population), and a nonlinear vulnerability relationship between the total number of persons exposed to each earthshock severity category and the expected number of casualties in the category : the greater the earthshock severity, the greater the percentage of those exposed that could become casualties. Most casualties occur as a result of building damage.

The casualty producing potential of each earthquake was expressed as an index. The forty-four indices were plotted and a smoothed family of curves was obtained. Figure 33 shows these curves as they relate to location and magnitude. The chart suggests that a Richter magnitude 5.5 earthquake located 80 kilometers from the center of Los Angeles has the same index of casualty producing potential (100) as a Richter 6.5 earthquake with its epicenter 240 kilometers away. It also indicates that the casualty potential decreases rapidly, when the magnitude of an earthquake is held constant, but its location is moved further away. For a Richter magnitude 5.5 earthquake, the index is 100 for a distance of $80 \mathrm{~km}$ and 10 for a location of $240 \mathrm{~km}$.

The relative importance of various natural hazards as damage producers varies from country to country $[17,19,20,22,26]$. Refer to Figures 28 and 29. In the United States, earthquakes are not as frequent damage producers as hurricanes. In Figure 2 a only a very few of the insurance coded catastrophes were attributed to the earthquake hazard. The amount of insured damages (Figure $2 \mathrm{~b}$ ) in these catastrophes was minimal. It should be noted however that windstorm covered properties are more numerous than those covered for earthquake. Earthquake catastrophe potential may be larger for the rare but highly damaging combinations of earthquake magnitude and location that places a severe intensity event under or near a densely populated area [1].

\section{Natural hazard risk assessment for a new insurance program}

A discussion of current procedures for estimating risk measures (average annual damage and catastrophe potential) in the operation of the National Flood Insurance 


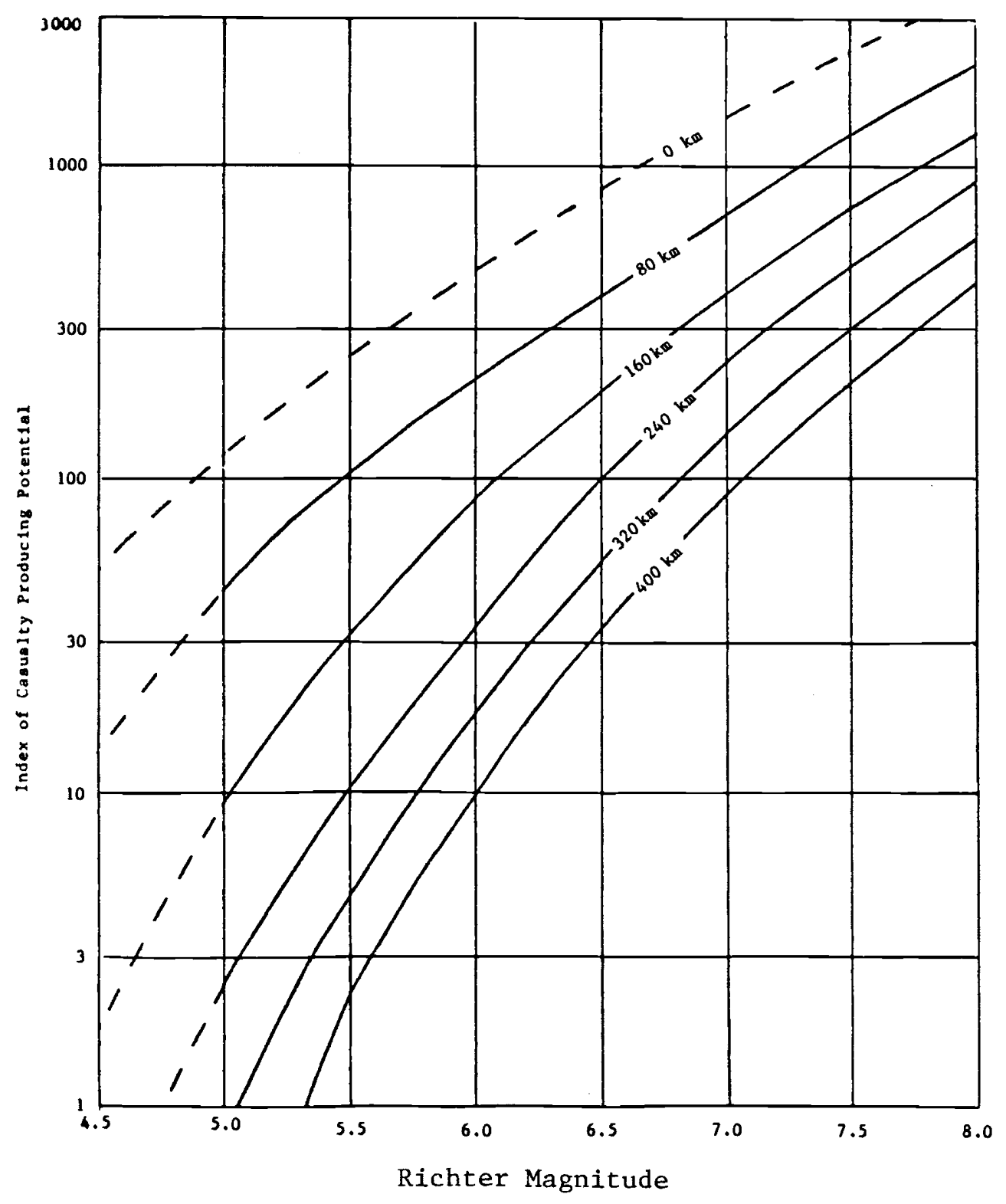

Figure 33: Index of casualty producing potential related to the combination of an earthquake's Richter magnitude and location of faulting relative to the Los Angeles metropolitan area based on a simulated recurrence of forty-four earthquakes. 
Program in the United States is given in another paper in this series. However, a brief outline is given here of methods that were used to estimate these measures during development of the flood program when past insurance loss experience was not available as a basis for the estimation [30]. This illustration stresses the need to use alternative information sources when a new program is being considered. A quantitative assessment of flood risk was prepared for the U.S. Department of Housing and Urban Development using computer simulation models to provide a means of estimating the overall magnitude of the inland and coastal flooding hazard to the fifty million dwellings in the United States [23]. Very little actual damage experience was available. Results of the assessment were used during the development of the joint insurance industry-federal government National Flood Insurance Program.

\section{Elements-at-risk and their vulnerability to floods}

A total of 5540 cities in the United States were determined to have flood problems. The number of dwelling structures in each city was taken from U.S. Census information. A percentage of these structures was determined to be on the flood plain based upon studies of flood-prone cities by Federal agencies. Pertinent information, including vulnerability and elements-at-risk (population, dwellings and commercial buildings), was distributed among six hazard zones in each of the flood prone places. Hazard zones were defined in terms of return period of floods of various depths. The most hazardous zone had a flood return period of less than five years. The least hazardous zone a return period of more than one hundred years. Vulnerability was defined in terms of expected amount of damage to the structure and its contents for various depths of flood water above the first floor of the building. Casualty and social disruption curves were used as measures of vulnerability to the population.

Table 8 is an example of one of the vulnerability relationships that were used.

Table 8: Vulnerability of an element-at-risk (dwelling) to inland (riverine) flooding expressed as the percentage of the insured value of the structure which is lost (damaged).

\begin{tabular}{cccc}
\hline $\begin{array}{c}\text { Depth Above } \\
\text { First Floor (meters) }\end{array}$ & $\begin{array}{c}\text { Percentage of } \\
\text { Value Lost }\end{array}$ & $\begin{array}{c}\text { Depth Above } \\
\text { First Floor (meters) }\end{array}$ & $\begin{array}{c}\text { Percentage of } \\
\text { Value Lost }\end{array}$ \\
\hline 3 & $6.5 \%$ & 3.4 & $29.0 \%$ \\
.9 & 13.5 & 4.0 & 32.0 \\
1.5 & 19.0 & 4.6 & 36.5 \\
2.1 & 23.0 & 5.2 & 46.5 \\
2.7 & 26.0 & 5.8 & 60.0 \\
\hline
\end{tabular}

Potential number of casualties was related to the number of damaged residential structures by multiplying number of dwellings damaged by a ratio of one casualty per 170 damaged dwellings. For flash floods, the casualty rate increased to one per 85 dwellings damaged. These rates were derived from tabulations of flood information by the American Red Cross. 
Estimates of expected average annual damage and catastrophe potential were obtained using computer simulation procedures for a number of different scenarios about the characteristics of an insurance program that would most effectively cover the flood hazard in the United States. The characteristics that were considered included the definition of the peril, types of property to be protected, extent of coverage, type and amount of deductible, reinsurance arrangement and so forth. The simulation models were constructed using information from a number of different sources including the physical sciences and engineering.

A stochastic generation of "floods" at each of the 5540 towns during each "year" of a simulated sequence of years was employed. Occurrence or non-occurrence of a flood in a given year at a particular place was based upon an empirical set of probabilities. If a "flood" occurred, its magnitude was determined by a second stochastic generation. With this information, the projected depth of water in each hazard zone was specified and the damage impact to exposed elements-at-risk was determined using vulnerability relationships. Characteristics of the resulting damage statistics including the frequency and severity of "natural disasters" were obtained using a long series of simulated twenty-year sequences holding the type, number, and geographical distribution of the elements-at-risk and their vulnerabilities constant at current levels. After the flood insurance program was developed and made operational, the basis for estimating the average annual damage and catastrophe potential was gradually shifted from the use of this "synthetic" damage experience to actual experience.

\section{Estimation of the overall effects of mitigation practices on the flood hazard}

The simulation model was subsequently modified to provide a basis for estimating the effects of various mitigation adjustments to the flood hazard [24]. The purpose of the mitigation analysis was to determine the present level and future trend in flood damage potential to elements-at-risk and their vulnerabilities located in the 5540 towns and cities in the United States that were reported to have a flood problem. The present level was determined on the basis of the present mix of mitigation adjustments to the flood hazard. The trend was based on the probable change in mix of these mitigation adjustments in the future if there was no explicit effort to alter the pattern. In the second stage of the analysis, the effect of changing old or adding new mitigation adjustments on the magnitude and trend of the damage potential index was analyzed.

In order to determine the present level of damage-producing potential of the flood hazard, it was necessary to determine the adjustment or combination of mitigating adjustments to the flood hazard currently in effect at the locations. The percentage of places with different types of mitigation adjustments was as follows : no flood protection $(61.7 \%)$, dam only $(5.4 \%)$, land use only $(1.5 \%)$, levee only $(21.8 \%)$, dam and land use $(0.4 \%)$, land use and levee $(3.1 \%)$, dam and levee $(4.6 \%)$, and dam, land use and levee $(1.5 \%)$. Modification in the mathematical "flood generator", the distribution of elements-at-risk in the hazard zones, and the vulnerability relationships were made as a means of representing the effect of these adjustments on the flood loss-producing potential at each town or city. 
To determine the future trend of aggregate damage at the more than 5500 locations, probable growth rates by hazard zone were applied to elements-at-risk and hypothesized time-related changes in the future were incorporated into the vulnerability relationships. In addition, it was necessary to develop a means of estimating the "normal " year-to-year change in mitigation adjustment combinations at various places when there was no explicit effort to alter the time-phased pattern of adjustments.

Table 9 is a change-of-state probability matrix which was derived from available information. Use of it is illustrated by assuming that a place has no flood protection in a given year, then the probability that it will still not be protected in the following year is about 90 out of 100 . The probability that the place will be protected by a levee in the next year is 3 out of 100 . Determination of the future trend in damage potential, when the "normal" time sequencing of flood adjustments is in effect, was obtained by simulating aggregate damage experience during each year of a series of twenty-year periods under these assumptions. The trend in the production of " natural disasters " was also tabulated. The final stage of the analysis was to use simulation modeling as a vehicle for measuring the effect on aggregate damage potential of modifying old adjustments, introducing new adjustments and altering the time sequencing of mitigation adjustments implied in Table 9. A large number of twenty-year periods was computed using various combinations of adjustments including improved warning systems and flood proofing. Comparisons were made between the present level and future trend of "loss experience" based on current adjustment patterns and "loss experience" resulting from the use of the modified or new adjustment combinations.

Table 9: Estimated probability of changing from one set of flood adjustments to another set in a given year at each town or city.

\begin{tabular}{|c|c|c|c|c|c|c|c|c|}
\hline \multirow[b]{2}{*}{$\begin{array}{c}\text { Type of Adjustment } \\
\text { (Year } t \text { ) }\end{array}$} & \multicolumn{5}{|c|}{ Type of Adjustment (Year $t+1$ ) } & \multirow[b]{2}{*}{$\begin{array}{c}\text { Levee } \\
\text { \& Land } \\
\text { Use }\end{array}$} & \multirow[b]{2}{*}{$\begin{array}{c}\text { Dam \& } \\
\text { Levee }\end{array}$} & \multirow[b]{2}{*}{$\begin{array}{c}\text { Dam, } \\
\text { Levee \& } \\
\text { Land Use }\end{array}$} \\
\hline & $\begin{array}{c}\text { No } \\
\text { Protection }\end{array}$ & Dam & $\begin{array}{l}\text { Land } \\
\text { Use }\end{array}$ & Levee & $\begin{array}{l}\text { Dam } \\
\& \text { Land } \\
\text { Use }\end{array}$ & & & \\
\hline No protection & .9027 & .0125 & .0225 & .0300 & .0020 & .0100 & .0200 & .0003 \\
\hline Dam & - & .9590 & .0000 & .0000 & .0300 & .0000 & .0100 & .0010 \\
\hline Land use & - & - & .9795 & .0000 & .0085 & .0100 & .0000 & .0020 \\
\hline Levee & - & - & - & .9360 & .0000 & .0500 & .0100 & .0040 \\
\hline Dam \& land use & - & - & - & - & .9995 & .0000 & .0000 & .0005 \\
\hline Levee \& land use & - & - & - & - & - & .9850 & .0000 & .0150 \\
\hline Dam \& Levee & - & - & - & - & - & - & .9995 & .0005 \\
\hline Dam, levee \& land use & - & - & - & - & - & - & & 1.0000 \\
\hline
\end{tabular}

Results of the analysis suggest that if there were no change in the present level of mitigation adjustments over the next twenty years, the average annual flood damages at the more than 5,500 towns and cities would be about $20 \%$ larger than if the historical trend in constructing control and protection works were to hold, neglecting the effect of increasing inflation on cost of repair. If land use management was adopted, flood losses 
would be reduced to 90 percent of current levels. Flood-proofing buildings would effect a reduction to $94 \%$ of present damage levels. Adoption of flood warning systems would reduce the level of damage to $87 \%$ of current levels. A combination of land use management and flood-proofing would reduce flood damages to $88 \%$ and deaths to $56 \%$ of present average annual levels. A combination of flood warnings, flood-proofing and land use restrictions were simulated to reduce damages to about $75 \%$ of current levels. Possible uses of these mitigating adjustments in conjunction with an insurance program, based upon results of the simulation analysis, are discussed by Gilbert White in his assessment of research on the flood hazard in the United States [37] and in the context of the other natural hazards [38].

The estimated annual damage (insured and non-insured) due to riverine flooding in the United States for the period 1903-1974 is given in Exhibit 34. Damages are expressed in dollars of the year of occurrence. To highlight the years with a high catastrophe potential, a "normal year" damage amount was estimated and is shown as the lower curve. The upper curve represents annual damages that are two-and-a half times larger than the " normal annual damage". Damages in those years that exceeded the upper curve are outliers and represent years with high levels of catastrophe potential. Even with the flood hazard, there is a large year-to-year variation in losses. However, a comparison of the time sequences of damages of the flood hazard (Figure 34) with that of the hurricane wind hazard (Figure $3 \mathrm{~b}$ ) suggests that the average annual damage is a more representative risk measure for the flood hazard than it is for the hurricane wind hazard.

\section{Discussion}

Information on both elements-at-risk and their vulnerability is an essential component in the determination of natural hazard risk needed to operate an insurance program designed to cover these hazards (storms, floods, earthquakes). However, the sole use of past damage experience with traditional actuarial procedures does not consistently provide an adequate measure of present or future risk. A large percentage of natural hazard-caused losses occur as a result of a moderate or severe geophysical event that, by chance, occurs in or near a dense geographic clustering of the elements-at-risk.

If this interaction causes a large number of losses, the result is called a natural disaster. In any given area, the occurrence of a natural disaster is a relatively rare event. Usefulness of loss experience based on these events decays rapidly with time because of changes in the number, geographical distribution and density of elements-at-risk in hazard prone areas. Vulnerability to damage of the various elements-at-risk also changes with time due to increased values of properties and costs of their repair resulting from current inflationary trends.

Supplementary approaches to risk assessment can either be quantitative or qualitative in character. Assessments based on qualitative scenarios are the easiest to make, but generally provide less information that the more cumbersome and time consuming quantitative approaches. As discussed in this paper, one quantitative approach is based upon an evaluation of the effect of mathematically superimposing the geographical severity patterns associated with geophysical events upon the spatial array of population, property, or buildings at risk. Geographical severity patterns associated with geophysical events 


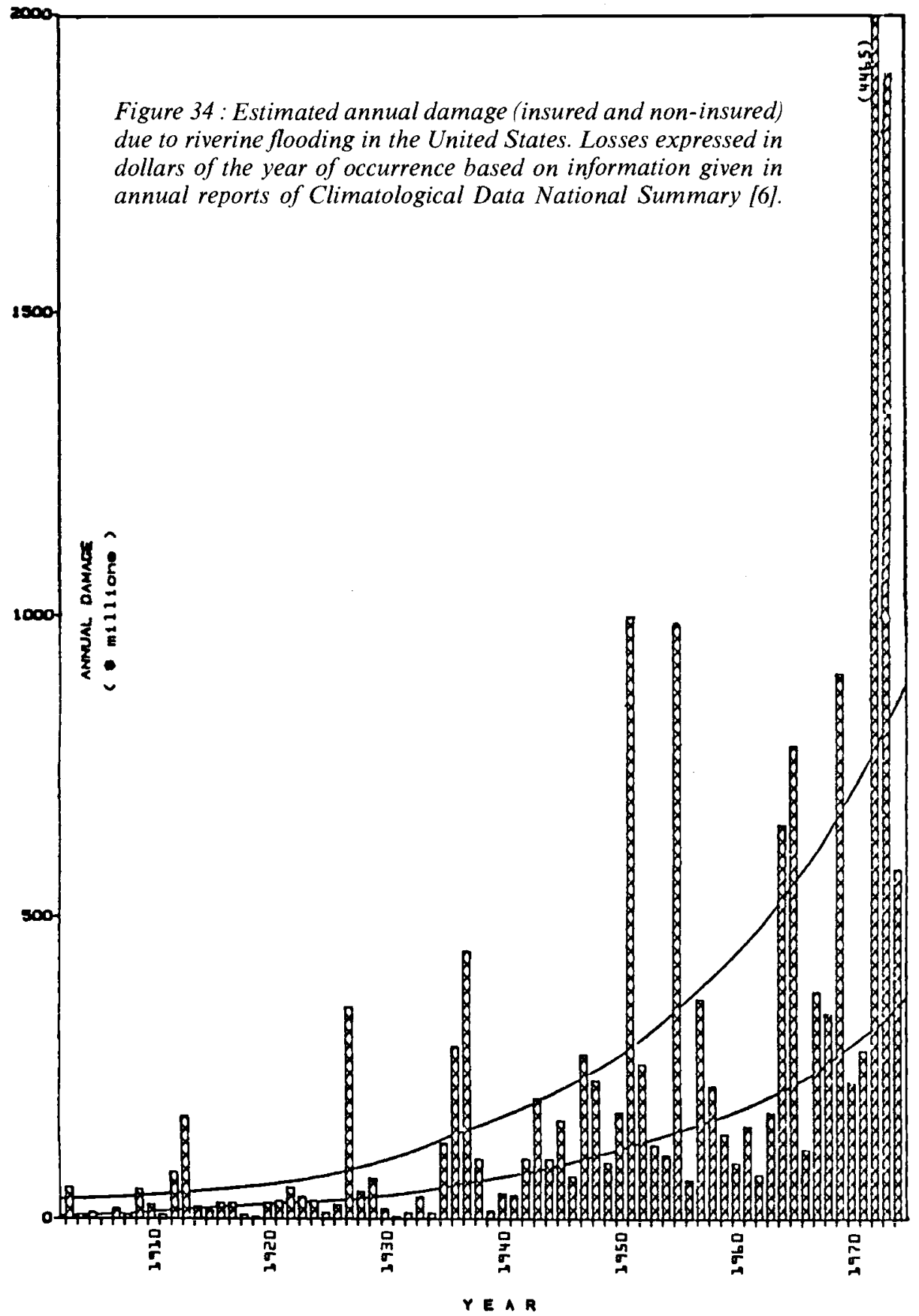


include those of maximum speeds associated with the passage of a hurricane, tornado, or other windstorm ; depth of coastal inundation (and if accompanied by wave wash) caused by a hurricane or winter storm ; depth, speed and debris content of flood waters ; hailstone size (and if driven by a high wind); intensity and duration of earthquake ground motion.

The degree of interaction between the event's severity pattern and the elements-at-risk is determined by the vulnerability of various elements-at-risk to loss when a given level of event severity and duration occurs. A spatial integration of these simulated damages over the area affected by these severity patterns provides a measure of the event's potential for producing a natural disaster. Numerical models generate the geographical severity patterns based upon the physical characteristics of the simulated geophysical event. Effects upon current elements-at-risk and their vulnerabilities can be obtained by the simulated recurrence of past events or hypothetical new ones consistent with the climatology, seismicity or hydrology of the area $[20,26]$. Verification of the computed patterns can be made through comparisons with observed patterns associated with past events.

An analysis of the hurricane wind hazard along a section of the United States coastline has been used as a means of illustrating risk information needs for the operation of an insurance program to cover these hazards and how to satisfy the needs. Other factors to be considered in the development of a new program would be the location and size of the geographical area in which elements-at-risk would be covered and the number, type and interdependence of natural hazards to be covered. Characteristics of the aggregate annual damage experience in the insurance program would depend, among other things, upon these factors. Examples of damage experience by location and size of area have been given :

\begin{tabular}{|c|c|c|c|}
\hline Natural Hazard & $\begin{array}{l}\text { Size of geographic } \\
\text { area included in program }\end{array}$ & $\begin{array}{l}\text { Damage } \\
\text { Unit }\end{array}$ & $\begin{array}{l}\text { Figure } \\
\text { Number }\end{array}$ \\
\hline Hurricane wind (actual) & 5000 < m conol nlain & (1983 dollars) & $3 b$ \\
\hline Hurr & plain & index) & 24 \\
\hline Hurricane wind and flood (actual) & $5000 \mathrm{~km}$ coastal plain & (dollars in year of occurrence) & $4 a$ \\
\hline Wind, hail, earthquake (actual) & entire United States & (1983 dollars) & $2 b$ \\
\hline Riverine flood (actual) & entire United States & (dollars in year of occurrence) & 34 \\
\hline
\end{tabular}

The densely populated coastal strip of southeast Florida, which runs from Miami to Palm Beach, was used as the basis for the application. It has the highest frequency of hurricanes in the United States. A recurrence of hurricanes that affected the area in each of the past 111 years was simulated incorporating available information on each storms' combination of physical intensity and path. The overlapping and interaction of the hurricane's geographical pattern of maximum wind speed with the current array of buildings-at-risk and their susceptibility to damage was made. The aggregate damage producing potential of a recurrence of each hurricane was calculated and tabulated by year of original occurrence of the storm.

An estimate of the average annual damage and catastrophe potential using this " past damage experience" was made using a 10 year length of record. It was compared with the " actual" average annual damages based on recurrence impacts of storms over the entire 111 year period.

These comparisons suggest that the use of short sample periods (such as ten years) in defining past damage experience estimates can produce significant deviations in the 
estimates from " actual" values of average annual damage and catastrophe potential that are based on a long-term interval of years. Results of the southeast Florida analysis emphasize the difference in usefulness of past experience of natural hazards in determining present risk in an insurance program to cover them as compared with that of other insured perils such as dwelling fires or automobile accidents. Natural hazards experience, dominated by infrequent but highly damaging occurrences, is much less useful as a basis for risk estimation. Therefore, it is desirable to incorporate information from other sources to augment the sole use of past experience.

In the southeast Florida analysis, it was shown that climatological information on hurricane frequency, severity and other physical characteristics, such as shown in Figures 20,28 and 29 , could be utilized in supplementing insurance orientated risk assessments of the hurricane wind hazard. Similar types of information from the physical sciences (oceanography, hydrology, seismology, meteorology) are useful in making risk evaluations of other natural hazards $[12,13]$ during the development stage and the subsequent application of an insurance program to cover these hazards.

\section{Acknowledgement}

The considerable assistance of Mrs. Karen Bell in the preparation of this paper is gratefully acknowledged.

\section{Appendix A. Definition of terms [34]}

NATURAL HAZARD meaning the probability of occurrence, within a specific period of time in a given area, of a potentially damaging natural phenomenon.

VULNERABILITY meaning the degree of loss to a given element at risk or set of such elements resulting from the occurrence of a natural phenomenon of a given magnitude and expressed on a scale from 0 (no damage) to 1 (total loss).

ELEMENTS AT RISK meaning the population, buildings and civil engineering works, economic activities, public services, utilities and infrastructure, etc., at risk in a given area.

SPECIFIC RISK meaning the expected degree of loss due to a particular natural phenomenon and as a function of both natural hazard and vulnerability.

RISK meaning the expected number of lives lost, persons injured, damage to property and disruption of economic activity due to a particular natural phenomenon, and consequently the product of specific risk and elements at risk. 


\section{REFERENCES}

1. AYRE, R. S., et al. [1975] : Earthquake and Tsunami Hazards in the United States : A Research Assessment. Monograph NSF-RA-E-75-005. Institute of Behavioral Science, University of Colorado, Boulder, 154 pages.

2. BEST'S AGGREGATES AND AVERAGES [1963-1981] : Annual Tabulations of Insurance Statistics, A. M. Best Company, Inc., Oldwick, New Jersey.

3. BRINKMANN, W. A. [1975] : Hurricane Hazard in the United States: A Research Assessment. Monograph NSF-RA-E-75-007. Institute of Behavioral Science, University of Colorado, Boulder, 100 pages.

4. CRUTCHER, H. L., and QUAYLE, R. G. [1974] : Mariners Worldwide Climatic Guide to Tropical Storms at Sea, Superintendent of Documents, U.S. Government Printing Office, Washington, D.C., 425 pages.

5. DUNN, G. E., and MILLER, B. I. [1964] : Atlantic Hurricanes, Louisiana State University Press, Baton Rouge, Louisiana, 377 pages.

6. ENVIRONMENTAL DATA SERVICE [1950-1981] : Climatological Data, National Summary Annual Issues, U.S. Department of Commerce, National Climatic Center, Asheville, North Carolina.

7. FRANK, N. [1974]: "The Hard Facts about Hurricanes", The Quarterly Magazine of the National Oceanic and Atmospheric Administration, Washington, D.C., July issue, pages 1-6.

8. FRIEDMAN, D. G. [1969]: "Computer Simulation of the Earthquake Hazard", Geologic Hazards and Public Problems Conference Proceedings, Office of Emergency Preparedness, Executive Office of the President, Washington, D.C., U.S. Government Printing Office, pages 153-181.

9. FRIEDMAN, D. G. [1972]: “Insurance and the Natural Hazards", 9th ASTIN Colloquium, International Congress of Actuaries, Randers, Denmark, International Journal for Actuarial Studies in Non-Life Insurance and Risk Theory, Amsterdam, The Netherlands, Vol. VII, Part 1, December, pages 4-58.

10. FRIEDMAN, D. G. [1973] : “ Analysis for Earthquake Insurance ”, Earthquakes and Insurance, The Center for Research on the Prevention of Natural Disasters, DRC-73-02, Earthquake Engineering Research Laboratory, California Institute of Technology, Pasadena, California, pages $1-40$.

11. FRIEDMAN, D. G. [1975] : Computer Simulation in Natural Hazard Assessment. Monograph NSF-RA-E-75-002. Institute of Behavioral Science, University of Colorado, Boulder, 192 pages.

12. FRIEDMAN, D. G. [1976 a] : "Uses of Tornado Technology in an Insurance Operation", Proceedings of the Symposium on Tornadoes: Assessment of Knowledge and Implications for Man, Texas Tech University, Lubbock, Texas, pages 419-427.

13. FRIEDMAN, D. G. [1976 b]: “Hail Suppression Impact upon Property Insurance”, Hail Suppression : Impacts and Issues, Technology Assessment of the Suppression of Hail, ERP 75-09980, Working paper number 11, Illinois State Water Survey, Urbana, Illinois, 69 pages.

14. FRIEDMAN, D. G. [1977]: "Assessment of the Magnitude of the Hurricane Hazard", Conference Papers of the Eleventh Technical Conference on Hurricanes and Tropical Meteorology, American Meteorological Society, Boston, Massachusetts, pages 294-302.

15. FRIEDMAN, D. G. [1979 a] : "What if Hurricane Camille had Hit Houston?", Science and Technology Policy - Building Toward a Hurricane Disaster, Paper prepared for 145th 
National Meeting of the American Association for the Advancement of Science, January, Houston, Texas, 24 pages.

16. FRIEDMAN, D. G. [1979 b]: “A Possible National Simulation Model Using Geographic Coordinates", Natural Hazards Data Resources : Uses and Needs, S. K. Tubbesing, Editor, Program on Technology, Environment and Man, Monograph Number 27, Institute of Behavioral Science, University of Colorado, Boulder, pages 119-147.

17. FRIEDMAN, D.G. [1979 c]: "Economic Impact of Windstorms in the United States", Proceedings of the Fifth International Conference on Wind Engineering, J. E. Cernak, Editor: Colorado State University, Fort Collins, Colorado, Pergamon Press, Section 1-4-1.

18. FRIEDMAN, D. G. [1979 d] : "Computer Simulation Model of the Risks Posed by the San Andreas Fault", Symposium Proceedings of the Human Settlements on the San Andreas Fault, Mexican Federal Secretariet of Human Settlements and Public Works, Department for the Prevention and Attention of Urban Emergencies and the California Seismic Safety Commission, Institute Technologico Regional de Tijuana, Tijuana, Mexico, pages 206-233.

19. FRIEDMAN, D. G. [1980 a] : “Hurricane Impact Assessment ", Joint United States-Australia Workshop : Coping with the Impact of Cyclones and Hurricanes on Domestic Construction, National Science Foundation and the Australian Government's Department of Science, United States-Australia Cooperative Science Program, Townsville, Australia.

20. FRIEDMAN, D. G. [1980 b] : “ Assessment of the Impact of Natural Disasters ”, Paper prepared for International Meeting of the Commission on Geographical Data Sensing and Processing, International Geographical Union, Tokyo, Japan, 17 pages.

21. FRIEDMAN, D. G. [1981]: “Assessing the Hurricane Impact on Human Settlements", Proceedings of the Third International Symposium on Hurricanes and Floods, Their Effects on Human Settlements (in press), Mexican Federal Secretariet of Human Settlements and Public Works, LaPaz, Baja, California, Mexico, 45 pages.

22. FRIEDMAN, D. G. [1982]: "Loss Analysis and Insurance Aspects", Paper prepared for Orientation Program in Engineering Seismology and Earthquake Engineering for Southeast Asian Nations, Agency for International Development, United States Department of State and the United States Geological Survey, Denver, Colorado.

23. FRIEDMAN, D. G., and ROY, T. S. [1966] : "Simulation of Total Flood Loss Experience on Dwellings on Inland and Coastal Flood Plains ", Report prepared as Consultant to the U.S. Department of Housing and Urban Development, Appendix H-5 of the United States Senate Committee on Banking and Currencies, "Insurance and Other Programs for Financial Assistance to Flood Victims ”, 125 pages.

24. FRIEDMAN, D. G., and BOCACCINO, M. [1972] : "Computer Simulation of the Effects of Adjustments to the Inland Flood Hazard", Travelers Insurance Company, Hartford, Connecticut, Unpublished Report prepared for the Institute of Behavioral Sciences, University of Colorado, Boulder, 50 pages.

25. FRIEDMAN, D. G., and MANGANO, J. J. [1983] : "Actuarial Approach to the Estimation of Storm Surge Probabilities on an Open Beach in Lee County, Florida." Issued in supplementary volume of supporting papers for the Report of Committee on Coastal Flooding from Hurricanes, National Research Council, National Academy of Sciences, Washington, D.C., 175 pages.

26. FRIEDMAN, D. G., and MANGANO, J. J. [1983] : " Computer Simulation of the Earthquake Hazard in Montenegro." Report prepared for the Fourth Session of the International Consulting Board, United Nations Development Program, Titograd, Yugoslavia, 89 pages.

27. HEBERT, P. L., and TAYLOR, J. G. [1975] : " Hurricane Experience Levels of Coastal County Populations: Texas to Maine", Special Report, National Weather Service Community Preparedness Staff, Southern Region, National Hurricane Center, Miami, Florida, 153 pages. 
28. HO, F. P, SCHWERDT, R. W., and GOODYEAR, H. V. [1975] : Some Climatological Characteristics of Hurricanes and Tropical Storms, Gulf and East Coasts of the United States, National Oceanic and Atmospheric Administration, Technical Report NWS 15, Washington, D.C., 87 pages.

29. INSURANCE INFORMATION INSTITUTE [1950-1982] : Insurance Facts : Selected Data of General Interest Relating to Property and Liability Insurance, New York.

30. KAPLAN, M. [1972]: "Actuarial Aspects of Flood and Earthquake Insurance", The Proceedings of the Conference of Actuaries in Public Practice, Chicago, Illinois, XXI, pages 474-511.

31. LUDLUM, D. M. [1963] : “Early American Hurricanes, 1492-1870”, The History of American Weather, American Meteorological Society, Boston, Massachusetts, 198 pages.

32. NEUMAN, C. J., CRY, G. W., CASO, E. L., and JARVINEN, B. R. [1978] : “ Tropical Cyclones of the North Atlantic Ocean 1871-1977 ", National Oceanic and Atmospheric Administration, National Climatic Center, Asheville, North Carolina, 170 pages.

33. NATIONAL OCEANIC AND ATMOSPHERIC ADMINISTRATION [1979]: "Meteorological Criteria for Standard Project Hurricane and Probable Maximum Hurricane Windfields, Gulf and East Coasts of the United States ", National Weather Service Technical Report NWS 23, Washington, D.C., 317 pages.

34. OFFICE OF THE UNITED NATIONS DISASTER RELIEF CO-ORDINATOR (UNDRO) [1980]: Natural Disasters and Vulnerability Analysis, Report of Expert Group Meeting, Geneva, Switzerland, 49 pages.

35. STARK, K. P, and WALKER, G. R. [1980] : " Computer Simulation of Tropical Cyclone Impact on a Community", Joint United States-Australia Workshop : Coping with the Impact of Cyclones and Hurricanes on Domestic Construction. Sponsored jointly by the National Science Foundation and the Australian Government's Department of Science, United States-Australia Cooperative Science Program, Townsville, Australia.

36. TANNEHILL, I. R. [1952] : Hurricanes, Their Nature and History, Princeton University Press, Princeton, New Jersey, 308 pages.

37. WHITE, G. F. [1975] : Flood Hazard in the United States : A Research Assessment, Monograph NSF-RA-E-75-006, Institute of Behavioral Science, University of Colorado, Boulder, 141 pages.

38. WHITE, G.F., and HAAS, J.E. [1975]: Assessment of Research on Natural Hazards, Report NSF-RA-E-75-001, Massachusetts Institute of Technology Press, Cambridge, Massachusetts, 487 pages. 